\title{
STUDIES \\ in \\ in
}

AFRICAN LINGUISTICS

\section{JULY 1972 \\ Volume 3. Number 2}


Published by the Depai ument of Linguistics and the African Studies Center

The University of California, Los Angeles

\section{Editorial Board}

\section{Margaret $\mathrm{Ball}$}

Karen Courtenay

Victoria Fromkin

Larry M. Hyman

Charles Kraft

Peter Ladefoged

Alosi Moloi

Thomas Penchoen

J. 0. Skip Robinson

Paul Schachter

Russell G. Schuh

Benji Wald

William E. Welmers

\author{
Associate Editors \\ Charles Bird, Indiana \\ John Eulenberg, Michigan State \\ Jeanette Harries, Wisconsin \\ A. E. Meeussen, Leiden \\ Herbert Stahlke, Illinois \\ Erhardt Voeltz, Indiana \\ Kay Williamson, Ibadan \\ Editorial Assistance \\ Dannie Hoffpauir \\ Alice McGaughey \\ Linda Sparkman
}

Editor

Talmy Givón

Subscription: U.S. and Canada: $\$ 7.00$ per volume (three issues)

$\begin{array}{ll}\text { Overseas: } & \$ 8.00 \text { per volume } \\ \text { Single issue: } & \$ 3.00 \\ \text { Supplement: } & \$ 5.00 \text { (if ordered separately) }\end{array}$

Make checks payable to: African Studies Center

Studies in African Linguistics is published three times a year.

For subscription and editorial information please write:

The Editor, Studies in African Linguistics

c/o Department of Linguistics

University of Caiffornia

Los Angeles, California 90024

Volume 3, Number 2, August 1972

Copyright 1972

by The Regents of The University of California 

The Fourth Annual Conference on African Linguistics will be held in New York City under the sponsorship of Queens College and the Graduate Center of the City University of New York in April, 1973.

Abstracts of papers for presentation at the Conference are to be submitted by January 1, 1973. Send four copies of each abstract to:

Amy Myers

Department of Linguistics

Queens College, C.U.N.Y.

Flushing, New York 11367 

Volume 3, Number 2

August, 1972

TABIE OF CONTENTS

$\underline{\text { Page }}$

Larry M. Hyman, NASALS AND NASALIZATION IN KWA . . . . . . . . . 167

Frank Heny, BANTU LEXICAL CLASSES AND SEMANTIC UNIVERSALS

(WITH SOME REMARKS ON HOW NOT TO WRITE PHONOLOGICAL

RULES) . . . . . . . . . . . . . . . . . . . 207

Alexis Takizala, FOCUS AND RELATIVIZATION: THE CASE

OF KIHUNG'AN . • . . . . . . . . . . . . . . . . . . 259

Talmy Givón, A NOTE ON SUBJECT POSTPOSING . . . . . . . . . . . . . 289 


\section{NASALS AND NASALIZATION IN KWA ${ }^{1}$ \\ Larry M. Hyman \\ Linguistics Program \\ University of Southern California}

O. Introduction

Within the Kwa sub-branch of Niger-Congo a considerable number of languages are found which exhibit a surface contrast between oral and nasalized vowels. Although many linguists have reported such findings (see bibliography), only slight mention is normally made of the following three characteristics of such languages:

i. in many Kwa languages, mid vowels, e.g. [e] and [o] do not occur nasalized

ii. in many Kwa languages, at least one voiced alveolar consonant, e.g. [1], does not occur before nasalized vowels

iii. in many Kwa languages, $[n]$ (and sometimes $[m]$ ) does not occur before mid vowels, e.g. there are often no [ne] and [no] sequences.

It would seem that these three restrictions on nasalized vowels and on nasal consonants are somehow related and any historical account would have to explain their presence in the synchronic phonologies of so many Kwa languages.

There have been surprisingly few attempts at such an explanation. To my knowledge, no one has published any explanation for $i$. at all (I shall provide a possible answer later in this paper). Why should only [thigh] and [+low] vowels be allowed to occur nasalized and not [e] and [o]? And yet, such a system is found over and over in Kwa. Thus, the

II should like to thank Victoria Fromkin, Herbert Stahlke, Theo Vennemann and Kay Williamson for commenting on an earlier version of this paper. Also, I am indebted to the Department of Linguistics and Nigerian Languages and the Institute of African Studies of the University of Ibadan for welcoming me as a Post-Graduate Occasional Student during the academic year 1970-1971. I was supported by a Fulbright-Hays fellowship during that period. 
surface contrasts of Nupe are given in (1), while Vogler [1968] presents the Baoule vowel system seen in (2). In both languages, nasalized mid vowels are absent.

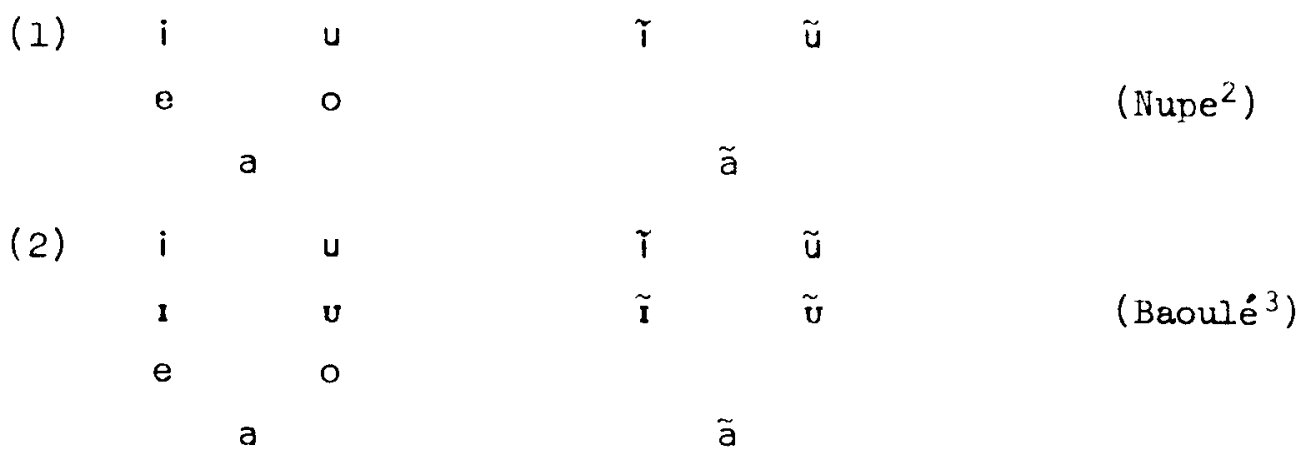

So fundamental is this non-occurrence of [ $\tilde{e}]$ and [ô] that individual languages frequently block otherwise automatic processes of assimilation

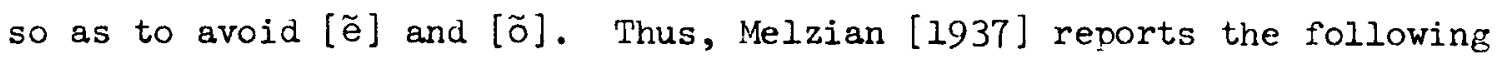
situation in Bini:
"With the exception of $e$ and $\circ$, the vowels also occur nasalized, as the result of assimilation with preceding nasals, and also as separate phonemes. When a nasalized vowel in the context is elided in front of an $e$ or $o$, only a nasalized glide shows its previous existence, the middle and end of the $e$ or $o$ vowel remain unnasalized, at least in slow speech" [p. $\mathrm{x}]$.

Properties $\underline{i}$. and $\underline{i i}$. are related and many linguists (e.g. Thomas and Williamson [1967, p. 10]) have followed Ladefoged's suggestion for Yoruba [1964] in recognizing the one underlying alveolar sonorant $/ 1 /$, which can occur before any underlying vowel, oral or nasalized, but which in combination with a nasalized vowel is converted to [ $n$ ] by a process of regressive assimilation as in the rule in (3):

(3) [+nasal]

2In Hyman [1970a] I offer several arguments for recognizing / $\varepsilon /$ and $/ \mathrm{J} /$, as well as their nasalized counterparts $/ \tilde{\varepsilon} /$ and $/ \tilde{s} /$.

${ }^{3}$ Actually, Vogler writes $/ i /, / e /, / \varepsilon /$ for $[i],[r],[\varepsilon]$ and $/ u /$, $/ \% /, / \mathrm{l} /$ presumably for $[\mathrm{u}],[\mathrm{u}],[\mathrm{o}]$. 
This solution works only because in languages such as Yoruba and Nupe, vowels occurring after [1] are always oral, while vowels occurring after [n] are always phonetically nasalized. Thus, Ladefoged [1964] and others have chosen to represent the complementary distribution of [1] and [n] by means of one underlying segment /// (this position is challenged by Stahlke [forthcoming]). All of the relevant derivations of [1] and [ $n$ ] in Yoruba are seen in (4):

\begin{tabular}{|c|c|c|c|c|c|c|}
\hline (4a) & $/ 1 \mathrm{i} /$ & $-\rightarrow$ & {$[1 \mathrm{i}]$} & & $/ 1 \mathrm{u} /$ & $\rightarrow$ \\
\hline & $/ \mathrm{e} /$ & $\rightarrow$ & [le] & & $/ 10 /$ & $\rightarrow$ \\
\hline & ||$\varepsilon \mid$ & $\rightarrow$ & {$[\mid \varepsilon]$} & & 1101 & $\rightarrow$ \\
\hline & & & $\mid \mathrm{la} /$ & $\rightarrow$ & [la & \\
\hline b) & $/ 1 \pi /$ & $\rightarrow$ & {$[$ [ñ] } & & $/ \mid \tilde{u} /$ & -- \\
\hline & & & / Iã / & $\rightarrow$ & [ nã] & \\
\hline
\end{tabular}

However, by collapsing the observations in $\underline{i}$. and $\underline{i i}$. in such a way, we are right back at the initial problem stated in $\underline{i}_{\text {.: }}$ we have no [ne] and $[n o](=[n \tilde{e}]$ and $[n \tilde{]}])$ because we have no $/ / \tilde{e} /$ and $/ / \tilde{o} /$ (see ii.) and we have no $/ \mid \tilde{e} /$ and $/ \mid \tilde{o} /$ because we have no $[\tilde{e}]$ and [õ] (see $\underline{i}_{\text {.). }}$. So, the whole problem revolves aroung the question: why no [ẽ] and [õ]? And, although we have no answer to this question at this time (see below, however), we can be sure that the correct answer depends upon the answer to a more crucial question -- in fact, the most crucial question: why nasalized vowels?

Several conventions will be followed in this paper. First, nasalization will be marked by a tilde over vowels, e.g. [ã], only when the nasalization represents a phonological property of a given language. For example, in all languages a vowel that is adjacent to a nasal consonant must become at least slightly (perhaps imperceptibly) nasalized ( $c f$. Ohala [1971]) and yet we should not wish to claim that all languages have a phonological rule that nasalizes vowels before and after nasal consonants. Instead, what we have to determine is whether a given language has 'phonologized' this phonetic universal which is due to the timing factors between the movements of the soft palate and the other articulators. 
The term 'phonologized' should not be confused with the term 'phonemicized'. In order for nasalization to become phonologized, it is only necessary that the process exceed the degree that can be said to characterize all languages. At this point nasalization becomes language-specific and must be marked in a broad phonetic transcription. Thus I will transcribe the verb 'to shine' in Nupe as [ná], but as [ná] in the closely related Gwari language. (Actually, /ã/ is realized as [ä] in Nupe, but I shall ignore this detail throughout the discussion.) Although the vowel in 'to shine' in Gwari cannot completely escape the nasalizing effect of the preceding $\mathrm{ln} /$, this fact cannot be attributed to the phonological nature of Gwari, but rather to the phonetic nature of all human speech. A universal phonetic tendency is said to become 'phonologized' when language-specific reference must be made to it, as in a phonological rule. A phonetic property becomes 'phonemicized' when contrastive reference must be made to it, as in underlying phonemic forms. Thus, nasalization is said to be phonologized if a rule is required in the language that nasalizes vowels in the context of nasal consonants. Nasalized vowels are phonemicized when they cannot be predicted by rule, but rather must appear in the lexicon. A number of phonetic processes are best viewed in this light. Chen [1969] reports, for instance, that vowels tend universally to become longer before voiced consonants, but that English has exaggerated this effect beyond what can be attributed to universal phonetics. English has, therefore, phonologized vowel length before voiced consonants, though it has not phonemicized vowel length. For more discussion of this notion of 'phonologization', see Hyman and Schuh [forthcoming].

A second convention that will be followed concerns the identification of proto forms. Proto-Kwa forms are identified by the abbreviation PK, e.g. $P K{ }^{*} G j(k)$ 'hand'. Intermediate historical forms are simply identified by the asterisk, e.g. *aj 'hand' for Proto-Niger-Kaduna. While I will be discussing both synchronic and diachronic properties of Kwa languages, it is hoped that this will cause no confusion. I have divided the paper into three sections. First, I shall discuss the source of nasalized vowels in Kwa. Second, I shall turn to regressive nasal 
assimilation of consonants. And, finally, I shall turn to the synchronic implications of the historical analysis.

\section{The source of nasalized vowels in Kwa}

It is accepted by most phonologists that nasalized vowels derive from earlier states of oral vowels in proximity with nasal consonants (see in particular Ferguson [1966], Foley [1972], Greenberg [1966], Lightner [1970], Schane [1968, 1972], Stahlke [1971a]). Examples of such derivations are numerous in the literature (consult Schane's treatment of French [1968] for a prime example). The most common origin of contrastive nasalized vowels seems to be syllable final sequences of oral vowel followed by nasal consonant $\left(V_{i} i^{\$}\right)$. This source, which Kwa specialists had for years informally relied on, has recently appeared in print (Stahlke [1971a]) and has in fact been the only one considered for Kwa. According to the argument, nasalized vowels derive from vis $\$$ is borrowed from Hooper [1972] and Vennemann [1972] to mark syllable boundaries), as in rule (5),

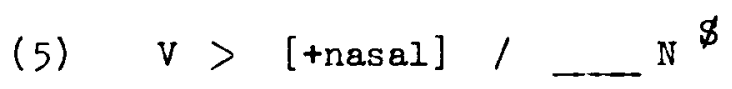

and then the syllable final $\mathbb{N}$ is deleted:

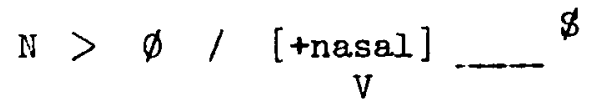

This solution has been so obvious and so appealing that it has met with virtually no opposition as a diachronic explanation of the facts.

In fact, Paul Schachter and Theo Vennemann have independently shown me [personal communications] how such an analysis might even account for

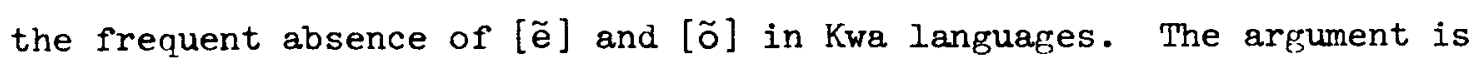
as follows. Suppose that at some point in history all Kwa morphemes were of the structure +CVC+ (cf. the claim made in Hyman [1972b] that Proto-Kwa word structure was *(C) $\dot{\mathrm{V}}-\mathrm{CVCV}$ for nouns and *CVCV for verbs, where the final vowel may have been a suffix in both cases). Let us assume that $C$ can stand for any non-vowel, i.e. for either a true consonant, a glide or a liquid. ${ }^{4}$ Let us aiso say that at this stage

${ }^{4}$ I claim later in this paper that there were no liquids in Proto-Kwa. There quite possibly were no glides either. 
the vowel inventory lacked [e] and [0]. We now say that Proto-Kwa *CVNV first loses the final vowel to yield ${ }^{*} \mathrm{CVN}$, which then develops into $[C \tilde{V}]$. Since $V$ cannot be $[e]$ or $[0]$, we do not obtain ${ }^{*}$ CeN and ${ }^{*}$ CoN nor their derived counterparts $*[C \tilde{e}]$ and $*[C \tilde{]}]$. We complete the picture by saying that the phonemic vowels $/ e /$ and $/ 0 /$ arise from older sequences of vowel followed by glide, i.e. *ay becomes /e/ and *aw becomes $/ 0 /$. Thus, the reason we have no nasalized mid vowels is that at the time vowels become nasalized, there were no mid vowels [e] and [o] in the language. The absence of $[\tilde{e}]$ and $[\tilde{o}]$ is therefore accounted for by the mutual exclusivity of final $/ \mathrm{y} /, / \mathrm{w} /$ and $/ \mathrm{N} /$. Notice how the loss of the final nasal consonants by (6) would be just one instance of a more general consonant deletion process, since we know that Kwa languages have in many cases dropped non-nasal consonants as well. Unfortunately, little if any evidence can be brought forth in favor of proto vowel plus glide sequences.

Considerable evidence for the treatment of nasalized vowels as the historical product of proto $* \mathrm{VN}^{\$}$ (via the sound changes in $(5)$ and $(6)$ ) is however available. While I know of no extensive well-documented study, occasional correspondences with Bantu cannot be missed. In (7) I have compared three Nupe forms with the corresponding proto roots I have reconstructed for Proto-Bamiléké, which I consider to be Bantu: ${ }^{5}$

$\begin{array}{llll}\text { (7) Nupe aà̀ } & : & \text { PBké *'gàm' 'to speak' } \\ \text { Nupe kắ(nã) } & : & \text { PBké *'kán' 'monkey' } \\ \text { Nupe kă } & : & \text { PBké *'kán' 'to fry' }\end{array}$

Here we see that while Nupe has /ã/ in all three words, Proto-Bamiléké possessed three distinct morpheme-final nasal consonants. It seems then that in the derivation of nasalized vowels in Kwa (with reservations about certain dialects of Akan), the distinction between final $/ \mathrm{m} /, \mathrm{n} /$ and $/ \mathrm{h} /$ has been neutralized. Other such examples are readily available.

Evidence like that presented in (7) should be enough to convince any skeptic that the proto language that was the ancestor of Nupe (as representative of Kwa) and Bamiléké (as representative of Benue-Congo), for

${ }^{5}$ For a justification and discussion of these proto forms, see Hyman [1972a]. 
which I ssall use tige ad boc label Benue-Kwa did aot have rasmilized vowels, but instead aldowed morpheme-final nasal consonants. Th the remainder of this paper I shall, however, present problems with this analysis. The view thot has been presented here is that nasalized vowels arise from the historical changes represented in (8):

(a)

PK $*$ CVNV (b)

cVN (c)

$\mathrm{c} \tilde{\mathrm{V}}$

$c \tilde{V}$

In stage (a) Proto-Kwa forms are reconstructed as bisyllabic (these can alternatively be interpreted as having a morpheme boundary as in ${ }^{*} \mathrm{CVN}+\mathrm{V}$ ). In stage (b) the final vowel is lost. In stage (c) vowels are nasalized before syllable final consonants, and in stage (d), the final nasal consonants are lost. The position I shall argue for in this section is that most Kwa languages did not develop nasalized vowels in this way, and that stage (b), where CVN is recognized as an intermediate reconstruction, has no historical validity.

One very common characteristic of languages such as French is that the final nasal consonant that conditions vowel nasalization appears in synchronic morphophonemic alternations. Thus, in French, one says

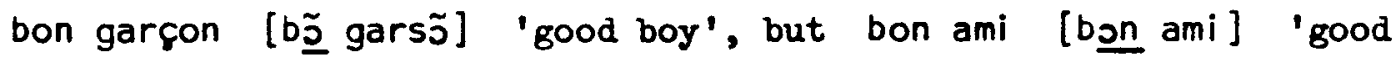
friend'. The proto form of 'good' is "bon and the synchronic reflex is [bj] before a consonant ( $c f$. bonté [bj̃te] 'goodness') or word boundary (i.e. where ${ }^{*} n$ would be in syllable-final position), but [bon] before a vowel (i.e. where $n$ would be in syllable-initial position, e.g. [bo nami]). However, nothing of the kind occurs in any Kwa language to my knowledge. ${ }^{6}$ If we say that ${ }^{*} \mathrm{CVN}$ is the immediate source of $[C \tilde{V}]$ and that ${ }_{N}$ is dropped so as to create a CVCV structure, why then does no Kwa language manifest this [N] in order to break up vowel clusters? Instead, what you find in Kwa languanges where, say, a derivational vowel suffix follows a nasalized rowel is either that represented in (9a) or (9b), assuming there is no elision:

${ }^{6}$ Stahlke [1971a] presents some data from Ewe reduplication which he claims to be evidence for a final nasal. 


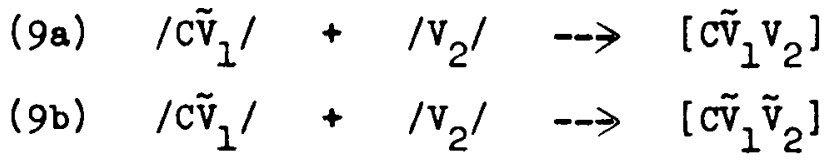

Why does no known Kwa language yield such forms as [CVNV] when a vowel suffix is added? In other words, why are there no alternations of the type we find in French? In the Fe'fe? dialect of Bamiléke (Bantu) a final consonant which has fallen always reappears before a vowel, e.g. " $k a ́ n$ " 'monkey' becomes [jkĕe] in Fepfe?, but compare [jkeen+à] 'my monkey'. Why not in Kwa?

Similarly, why are there apparently no Kwa languages where in some villages one finds [Cr̃] and in others [CVN]? (The Akan dialects covered by Schachter and Fromkin [1968] only marginally provide such an instance, since in the Asante dialect, word-final / $\mathrm{g} /$ becomes [ $\mathrm{T}$ ], thereby creating

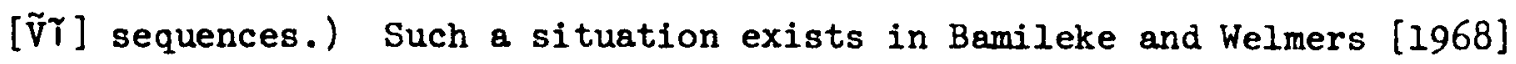
presents similar data from two villages of Jukun (Benue-Congo):

$\begin{array}{lll}\frac{\text { Takum }}{\text { /gbàm/ }} & \frac{\text { Wukari }}{\text { /gbã/ }} & \text { 'be strong' } \\ \text { /tána/ } & \text { /átã்/ } & \text { 'house' } \\ \text { /bana/ } & \text { /ábã/ } & \text { 'stone' }\end{array}$

(The Togoremnant languages, as reported by Heine [1968], may seem to constitute a counter-example, but as we shall see, they add support to the historical analysis I shall propose below.) Finally, if nasalized vowels derive from final nasal consonants in Proto-Kwa, where do the final nasal consonants in Akan dialects arise from? E.g. /ohin/ 'chief' and /apim/ 'a thousand' in Fante (taken from Welmers [1946]). These apparently require a different source.

These facts show that it would be somewhat questionable to suggest /CVN/ as an underlying synchronic analysis of [CṼ] in Kwa (see also my discussion of Stahlke [1971a] below). There are no alternations, no dialect variations and if nasalized vowels derive from $\mathrm{vN}^{\$}$ sequences, the time depth of this derivation would appear to be very great. And yet, if it is so great, then how have so many Kwa languages maintained for such a long time such similar features as, say, the restrictions on 
[e] and [o] in $\underline{i}$. above? (There are, however, exceptions, most notably in Ewe, Togoremnant and Lower-Niger (i.e. Igbo) clusters, though the absence of $[\tilde{\theta}]$ and [ö] characterizes the Akan, Yoruba, Edo and NigerKaduna clusters. There is a similar restriction in Grebo, a Kru language (see below).)

At this point I should like to suggest that Proto-Kwa * CVNV did not develop into CVN, and that rather than losing the second vowel, Kwa languages first lose the first vowel by syncope, creating CNV sequences. Finally, I should like to argue that it was intermediate ${ }^{*} \mathrm{CNV}$ that developed into $[C \tilde{V}]$.

The first argument in favor of *CNV comes from Gwari (also known as Gbari, Gbali and Gbagyi), a language closely related to Nupe. (The two constitute the major representatives of what I term the Niger-Kaduna sub-branch of Kwa, named after the two rivers that delimit Nupe and Gwari country.) Compare the Gwari forms in (11) to the forms we saw in (7) above:

$\begin{array}{lll}\text { (11) Gwari } & \text { [gjà] } & \text { 'to speak' } \\ \text { Gwari } & \text { [òknă] } & \text { 'monkey' } \\ \text { Gwari } & \text { [kna ] } & \text { 'to fry' }\end{array}$

From these forms we observe that Gwari not only permits CN clusters, but also, when the following vowel is /a/, nasalization is not phonologized (i.e. the vowel is not nasalized any more than can't be avoided; cf. Hyman and Magaji [1970]). The corresponding phonological forms are /gula/, /òkNa/ and / kNa/, respectively, where the nasal consonant is made homorganic to the preceding oral consonant by means of a rule of progressive assimilation, as in (12)

(12) $\mathbb{N} \rightarrow[a F] /[\underset{C}{a}]$

One ean say with certainty that Nupe (ef。 the forms in (7)) has developed

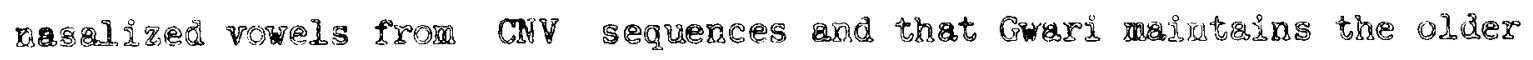

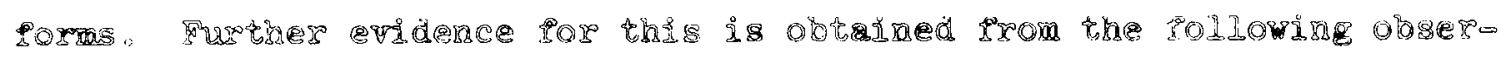

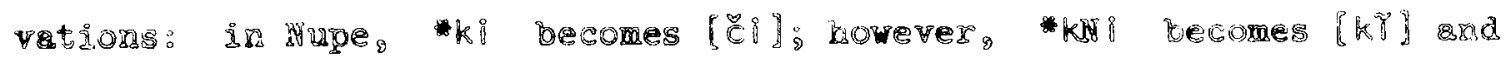
not [Či]. If we analyze Nupe [Čl] as $/ k i /$ and $[k T]$ as $/ k N i /$, thereby 
mirroring the historical development, then we can see why the first $/ k /$ is palatalized, while the second remains [ $k]$. Palatalization of $/ k /$ must precede the creation of [ $T]$ in Nupe. (The situation is a little more complicated than this because *tsi also becomes [či] and this time *tsNi becomes [Či].) ${ }^{7}$ Thus, we have shown that at least in the NigerKaduna sub-branch of Kwa, the immediate source of nasalized vowels was *CNV. Actually, Gwari is right now in the process of developing nasalized vowels itself! For example, *KNu and *gNu are already pronounced [k刀ũ] and [g⿵ũ], where the nasal release is not particularly pronounced. While I analyze both [CNV] and [CṼ] as /CNV/ in Gwari, the phonetic realization will depend in each case on the particular combination of $\mathrm{C}, \mathrm{N}$, and $\mathrm{V}$. For example, $/ \mathrm{sNi} /$ is pronounced [Si].

The question, of course, is whether Niger-Kaduna independently developed CNV out of CṼ or whether other sub-branches of Kwa developed $C \tilde{V}$ out of CNV. The first alternative seems very unlikely, given that Gwari sequences of / CNa/ are always pronounced with an oral vowel. If CNV developed out of CṼ, then not only would the consonant have to become nasally released, but /ã/ would have to be denasalized. Since $N$ is specified only as a homorganic nasal, it seems much more natural to speak of the nasality as having shifted from the consonant to the vowel, i.e. [CNV] becomes [CṼ]. The reverse (with denasalization of $\mathrm{V}$ ) would be very strange indeed.

Notice that CNV derives further support from other Kwa languages. Kay Williamson has informed me [personal commication] that nasal release on consonants (that which I equate with underlying / CN/) occurs in some of the languages of the Niger Delta that she has worked on. Professor Williamson has brought a number of facts to my attention, that can best be explained by recognizing an intermediate historical *CNV stage. Although she will be shortly reporting on these findings, it is interesting to note here how Williamson combines a ${ }^{*} \mathrm{CNV}$ reconstruction with a process of metathesis that occurred in I.jo. Starting with *V-CNV, Williamson notes two possible synchronic reflexes. One is given in (13):

${ }^{7}$ I am equating nasally released consonants with $\mathrm{CN}$ clusters. 
(13)
(a)
(b)
(c)
*V-CNV $>\mathrm{VCN} \tilde{\mathrm{V}}>\mathrm{vC \tilde {V }}$
(if $C$ is not a stop)

The historical derivation in (13) takes piace if the pre-nasal consonant is not a stop. In stage (a), forms are reconstructed with a vowel prefix and a $\mathrm{CNV}$ syllabie. In stage (b), the post-nasal yowel becomes nasalized, and in stage (c), the nasal is lost. The other possible synchronic reflex is seen in (14), and is found only when the consonant is a stop:
(14)
(a)
(b)
(c)
$* \mathrm{~V}-\mathrm{CNV}>\mathrm{VNCV}>\mathrm{V} N \mathrm{NV}$
(if $\mathrm{C}$ is a stop)

Again, forms are reconstructed in stage (a) with a vowel prefix and a CNV syllable. (In both (13) and (14) it is of course possible to go back one step further than Proto-Ijo *V-CNV and propose Proto-Kwa *V-CVNV.) In stage (b) we note that when the consonant is a stop, it metathesizes with the nasal so that *VCNV becomes VNCV. In stage (c), the metathesized nasal nasalizes the preceding vowel. By (14), Proto-Ijọ *àdná 'wrestle' becomes [ầndá] (cf. Williamson [1965]). In addition, Carrell [1970] chooses / CnV/ to represent syllables that are characterized by nasalization throughout in Igbo. (Although her arguments center around the relative 'economy' of recognizing / CnV/ rather than an underlying contrast between oral and nasally released consonants, it is interesting that she did not consider / $\mathrm{CVn} /$ as a possible solution.) If we assume that Proto-Igbo was characterized by CNV sequences, then we are able to explain the presence of aspirated and breathy voiced stops in certain central dialects, e.g. Owerri (cf. Armstrong [1967]): \#å'gNự 'leopard'> á'gnụ́ >á'gnप̣́ > á'ghứ > a'ghụ (optional loss of nasalization on the vowel). If the consonant preceding $/ N /$ is a non-continuant it becomes aspirated in some Igbo dialects. If the consonant is a continuant, it is realized as

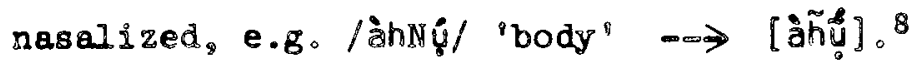

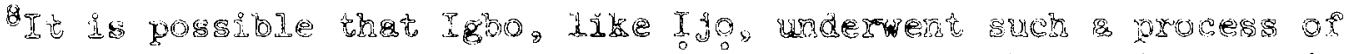
ne

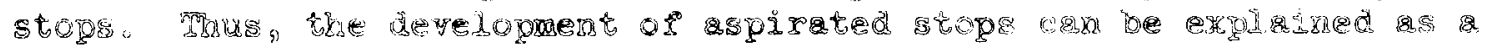

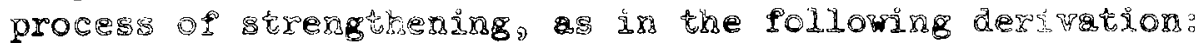


Evidence for intermediate *CNV is also found in Ewe. Here it is necessary to turn to synchronic phonology, where the search for deep underlying phonological forms has generally paralleled the aims of historical reconstruction. Stahlke [1971a] discusses the process of verb reduplication as evidence for recognizing /CVN/ as the underlying representation of $[\mathrm{CV}]$. His attempt is to rid the system of underlying nasalized vowels. He provides the following data:

(15) do 'to borrow' $\rightarrow$ dodo
sẹ 'to be hard' $\rightarrow$ sẹẹ

The general rule is that $C_{1} V_{1}$ reduplicates as $C_{1} V_{1} C_{1} V_{1}$, except that the reduplicated vowel cannot be nasalized, as we see in (15). Stahlke then introduces -- and rejects -- a reduplication rule such as (16):

(16) RED $\rightarrow c_{1} \underset{v_{1}}{[- \text { nasal }]} / \underset{c_{1}}{c_{1}}$

Rule (16) "forces redundancy into the phonology and causes us to lose generalizations" [p. 244]. He then proposes that the underlying form of 'to be hard' be /sen/ and restates the reduplication rule as (17): (17) RED $\rightarrow C_{1} V_{1} / \ldots C_{1} v_{1}$
(a)
(b)
(c)
(d)
(e)
$* \mathrm{~V}_{-} \mathrm{CV}_{1} \mathrm{NV}_{2}>\mathrm{V}-\mathrm{CNV}_{2}>\mathrm{V}-\mathrm{NCV}_{2}>\mathrm{V}-\mathrm{NC}^{\mathrm{h}} \mathrm{v}_{2}>\mathrm{V}-\mathrm{C}^{\mathrm{h}} \mathrm{v}_{2}$

In stage (a), a vowel prefix and a bisyllabic stem is set up for nouns. In stage (b), $V_{\text {I }}$ is syncopated. In stage (c), the nasal is metathesized, if the preceding consonant is a stop. In stage (d), this consonant becomes aspirated (or, presumably, breathy voiced), since the preceding nasal creates a strenthening environment. Finally, this nasal is lost in stage (e). If stage (d) is not postulated, then it is not clear how or why nasally released stops should develop into aspirated and breathy voiced stops. Notice, also, that such a reconstructed intermediate *V-CNV 2 for Williamson's Lower-Niger sub-branch of Kwa accounts for why $\mathrm{CnV}$ often works better than CVn as an orthographic convention for nasalized vowels in these languages (see Williamson [1970]). The CnV convention best recapitulates the historical development, I would claim. 
While the [-nasal] specification of $v_{1}$ in (16) is viewed as a loss of generality, it is questionable whether the alleged generality of (17) is sufficient justification for the abstract synchronic representation /sẹ/. In other words, it is just as plausible that native Ewe speakers have internalized underlying forms such as /sẽ/ and rule (16), and one must confront the complication that has been introduced into the grammar, namely the two synchronic correlates of rules (5) and (6) (given above) which convert/sẹ/ to [sẹ]]. His argument for Yoruba is even weaker. In Yoruba, the vowel in the reduplicated syllable is always [i], as we see in Stahlke's examples in (18):

$\begin{array}{llll}\text { (18) } k u \quad \text { 'to die' } & \rightarrow \text { kiku } \\ k \tilde{u} & \text { 'to } f i l l ' \rightarrow & \text { kikú }\end{array}$

He rejects the reduplication rule in (19):

$$
\text { RED } \rightarrow c_{1}\left[\begin{array}{c}
\text { +high } \\
\text {-back } \\
\text {-nasal } \\
v_{1}
\end{array}\right] /-c_{1} v_{1}
$$

and concludes:

"Just as in Ewe, the reduplicated vowel is non-nasal. For Yoruba also, then, we suggest that in the underlying forms there are no nasalized vowels and that these are derived, as in Ewe, either from a sequence of nasal consonant plus vowel, or by regressive assimilation from a final nasal consonant which is later deleted" [p. 245].

However, the weak argument Stahlke proposes for Ewe is proven faulty when applied to Yoruba. In Yoruba reduplication, how can one say any more than that $C_{1}$ is reduplicated and [ $i$ ] is inserted? The problem is that Stahlke treats the [i] of kiku as a reduplication in some respect of / $/$ / (notice that he writes $v_{1}$ instead of simply $v$ in the structural change of (19)). If we get kikũ (and not *kikũ) because underlyingly we have / kUN/, then why do we get kiku and not kuku? Stahlke recognizes/CVN/ for Yoruba and the revised reduplication rule in (20):

(20) RED $\rightarrow C_{1}\left[\begin{array}{l}\text { thigh } \\ - \text { back } \\ v_{1}\end{array}\right] / \longrightarrow C_{1} v_{1}$ 
(20) looks like a general reduplication rule, because $v_{l}$ is reduplicated in the structural change of the rule. However, there is no reason to claim [i] as a reduplication of $v_{1}$. Instead, the rule should be revised as in (21):

$$
\text { RED } \rightarrow C_{1}\left[\begin{array}{l}
\text { +high } \\
\text {-back } \\
\text {-round } \\
\text {-nasal } \\
\mathrm{V}
\end{array}\right] /-\mathrm{C}_{1} \mathrm{~V}_{1}
$$

This rule states that whatever the features of $v_{1}$, the reduplicated vowel is [i].

While the case for / $\mathrm{CVN} /$ in Yoruba is extremely weak, the argument made for Eve may still appeal to some. However, some additional data which are taken from Ansre [1963] (cf. Westermann [1930: 181]; also Stahlke [1971b]) are presented in (22):

$\begin{array}{lllll}\text { fo } & \text { 'to beat' } & \rightarrow & \text { fofo } & \text { 'beating' } \\ \text { kplo } & \text { 'to lead' } & \rightarrow & \text { kpokplo } & \text { 'leading' } \\ \text { syá } & \text { 'to dry' } & \rightarrow & \text { sásyá } & \text { 'drying' } \\ \text { dzrá } & \text { to sell' } & \rightarrow & \text { dzádzrá } & \text { 'selling' }\end{array}$

(I have taken the liberty of changing Ansre's sia to syá under the impression that $i$ is non-syllabic and non-tone-bearing, this permitting a generalization I shall make below.) What these additional data show is that in reduplication, if there is a sonorant (represented by $R=$ resonant) between $C_{1}$ and $v_{1}$, it is not reduplicated. ${ }^{9}$ Thus, the reduplication rule in (17), taken from Stahlke [1971a], needs to be extended to include these data (cf. Stahlke [1971b]):

(23) RED $\rightarrow C_{1} V_{1} / \longrightarrow C_{1}(R) v_{1}$

But now we see that if the sonorant (or resonant) $R$ is [-nasal], it comes between $C_{1}$ and $v_{1}$ and is not reduplicated, and if the sonorant is [+nasal], in Stahlke's CVN solution, it comes after $V_{1}$ and also is not reduplicated.

${ }^{9}$ Theo Vennemann has informed me that Gothic reduplicates in a similar fashion, e.g. grot becomes gegrot. 
Why not combine $\mathrm{N}$ with the other sonorants and say that Ewe has morphemes of the structure CV and morphemes of the structure CRV, of which CNV is one instance. 10 We could add, then, a rule that converts /CNV/ to first [CNṼ] and then to $[\mathrm{C} \tilde{V}]$, both applying after reduplication. Notice that while I believe to have shown why /CNV/ would be at least as plausible as /CVN/ as a synchronic solution, it may still be that the best solution of all is the one that posits $/ C \tilde{V} /$ and the reduplication rule in (16). The /CNV/ solution provides a neat reduplication rule, but requires additional P-rules to derive phonetic $[\mathrm{CV}]$. Unlike the abstract Yawelmani solution proposed by Kisseberth [1969], these underlying / CNV/ sequences are recognized for the purpose of one rule only, and therefore can be viewed as ad hoc. The /CṼ/ solution, on the other hand, does not require additional P-rules, but the resulting reduplication rule (which says: don't reduplicate post-consonantal non-nasal sonorants and don't reduplicate the nasality of nasalized vowels) is less general, though possibly still correct. What I do claim, however, is that CNV represents a true diachronic fact in the history of Ewe.

Perhaps we can extend our conclusion that Ewe once had CNV to include other Kwa languages, since remnants of such sequences are found elsewhere in reduplication. In Nupe, for instance, /Cĩ/ and /Cũ/ reduplicate as [CíCi] and [CũCũ], while /Cã/ reduplicates as [CíCã], i.e. with an oral vowel, as in $(24)$ :

$$
\begin{aligned}
& t i \text { 'to plait' } \rightarrow+i+i \\
& \text { tũ 'to send' } \rightarrow \text { tũtũ } \\
& \text { tã 'to rub on' } \rightarrow+i+a
\end{aligned}
$$

At some intermediate stage, forms such as [ $+\underline{i}+\tilde{T}]$ and [tútũ] must have been prevalent. A later assimilation was introduced, but was restricted

10 The one problem with this analysis is that there are morphemes such as [gb|ẽ] 'to be spoiled', which reduplicates as [gbegblẽ]. This morpheme would presumably have to be recognized underlyingly as /gb/Ne/ if /CNV/ is to represent [ $\mathrm{C} \tilde{\mathrm{V}}]$ synchronically. This is hardly an improvement over the /CVN/ analysis of Stahlke, who would set up /gbleN/. Thus, it is not quite true to say that $/ / /, / r /$ and $/ y /$ share the same 'slot' with /N/, though we still can say that sonorants come between the initial consonant and the vowel. 
to environments where reduplication created successive syllables with like high vowels. Schachter and Fromkin [1968] present basically the same findings for Akan:

$$
\begin{array}{llll}
\text { si 'to hang on' } \rightarrow & \text { sis i } \\
\text { su 'to cry' } & \rightarrow \text { sũsũ } \\
\text { sã 'to tie up' } \rightarrow & \text { sisã }
\end{array}
$$

Conceivably there was a time when both Nupe and Akan had CNV and the reduplicated form was then CVCNV (later modified, of course, to CVCṼ). One inexplicable fact is that Gwari Kuta (the main Grari dialect and the one described in Hyman and Magaji [1970]) completely reduplicates the verb, as we see in the forms in (26):

$$
\begin{aligned}
& \text { (26) gà 'to give' } \rightarrow \text { gàgà } \\
& \text { gaà 'to speak' } \rightarrow \text { gnàgnà }
\end{aligned}
$$

This situation is exceptional even in Niger-Kaduna alone, where we expect a high vowel in the reduplicated syllable (cf. the corresponding Nupe forms yiyà and gigâ). In addition, if Gwari Kuta were like Ewe, then we would expect *gàgnà instead of gnàgnà. It might look as though Gwari Kuta is the most conservative language of them, maintaining complete reduplication in all cases, but it is possible that Gwari reintroduced complete reduplication. 11 (No Niger-Kaduna language has CLV sequences.) Idoma, on the other hand, does not have nasalized vowels or CN clusters,

1 There is reason to believe that Eve, which completely reduplicates the stem vowel, once had only high vowels in the reduplicated syllable. Thus, compare the following remnants taken from Westermann [1930: 90]: dzudzo 'to rest', from $d z s$ 'to wait'; gbugbs 'to return', from gbs 'to return' etc. It is also interesting to note that Schachter and Fromkin report the following reduplicated forms [1968: 167], where the final nasal consonant is reduplicated:

$$
\begin{aligned}
& \text { [sẽm?] 'strip' } \rightarrow \text { simsãm? } \rightarrow \text { [sinsãm?] } \\
& \text { [pãn?] 'leave a space' } \rightarrow \text { pinpãn? } \rightarrow \text { [pımpãn'] }
\end{aligned}
$$

A corrective rule is required to nasalize the reduplicated high vowel. Thus, Akan CVN reduplicates as CVNCVN and not as CVCVN as in Ewe. 
but does have CLV sequences. Reduplication in Idoma (see Abraham [1967]) is accomplished by prefixing o- (mid tone) to the verb and then reduplicating the whole thing (placing low tone on the initial 0-). Vowel elision then occurs: the first instance of $v_{1}$ drops before the second (mid tone) o-:

$$
\text { ma 'to remain silent' } \begin{aligned}
& \rightarrow 0+m a \\
& \rightarrow \dot{c}+m a+o+m a \\
& \rightarrow \text { òmoma }
\end{aligned}
$$

The interesting thing about Idoma is that / / (which is syllabic, carrying tone) is also elided before the mid tone o-:

$$
\begin{aligned}
& \text { bì̀ 'to remember' } \rightarrow 0+b i a ̀ \\
& \rightarrow \text { ò + bì̀ +o + bì̀ } \\
& \rightarrow \text { òbobìà }
\end{aligned}
$$

Thus we have another language where a post-consonantal sonorant is not reduplicated. Returning to Akan, Bill Greenberg has brought to my attention that there are certain CVLV verbs that function as if they were monosyllabic (while there are others that function as bisyllabics). Thus, Christaller [1933] includes the following two verbs with their corresponding reduplicated forms in his dictionary:

$$
\begin{array}{ll}
\text { siri 'to be careful about' } & \rightarrow \text { susorl } \\
\text { siri 'to rise' } & \rightarrow \text { sorisor }
\end{array}
$$

The first functions as monosyllabic with high vowel reduplication; thus, Schachter and Fromkin recognize this word as sor and insert the vowel 1 The second behaves as a polysyllabic verb, which normally reduplicates completely as in the example. The first form suggests a possible explanation for why sonorants are not reduplicated in Ewe: if the $\supset$ of susori were to fall, we would be left with susri (and the root would presumably be sri). Now we must take another look at Eve. Perhaps CLV sequences derive from an older CVLV sequence, where the first vowel was syncopated. Synchronic evidence in another Kwa language, Grebo, in the Kru sub-branch, is reported by Innes [1966]. The forms in the left hand column of (30) represent the pronunciation in slow speech, while the forms in the right hand column represent the pronunciation in rapid speech: 


\begin{tabular}{|c|c|c|}
\hline (30) péde் & $p l \dot{e}$ & 'bald patch' \\
\hline bỏdó & blo & 'chalk' \\
\hline kidè & $k l \dot{e}$ & 'chest' \\
\hline geda & gla & 'divide' \\
\hline kpoda & kpla & 'sew' \\
\hline gbudó & $g b \mid \dot{0}$ & 'room' \\
\hline fodo & flo & 'emptiness' \\
\hline
\end{tabular}

If Ewe /kplo/ 'to lead' (see (22)) were historically *kpVlo (or perhaps *kpVdo; see below), then we can understand how the reduplicated form [kpokplo] came into being. But how does this explain the lack of nasalization on [sẹsẹ]]? Evidence has been provided for a proto form *sNẹ. Might this have come from an older *sVNe, as hypothesized earlier? One example is found in Gwari Kuta:

(31) Proto-Bantu *tanu : Gwari ìtnǔ 'five'

Innes presents in addition to the data in (30) the following data in (32):

$\begin{array}{lll}\text { pone } & p l \tilde{e} & \text { 'rat' } \\ \text { kene } & k l \tilde{e} & \text { 'wickerwork basket' } \\ \text { kpona } & \text { kplã } & \text { 'snore' } \\ \text { fona } & f l a ̃ & \text { 'wood-boring insect' }\end{array}$

(In Grebo the so-called 'muffled' vowels $/ \dot{e} /$ and $/ \dot{o} /$ do not occur nasalized.) We might be tempted to conclude from (32) that nasalized vowels arise from the process of vowel syncope followed by the denasalization of $/ \mathrm{n} /$ to $[1]$, as in (33):

$$
\text { *pone }>\text { ponẽ }>\text { pnẽ }>\text { [p|ẽ] }
$$

However, Innes reports that oral voiced stops do not occur before nasalized vowels in Grebo (cf. discussion below). Thus it is possible to consider the underlying forms of those words in (32) to be as in (34):

(34) /podẽ/ 'rat'

/kedẽ/ 'wickerwork basket'

/kpodã/ 'snore'

/fodã/ 'wood-boring insect' 
Having recognized these forms, we now see the relationship between these and the forms given in ( 30$)$. Roughly speaking, $/ d /$ is pronounced [d] intervocalically before an oral vowel, [n] intervocalically before a nasalized vowel and [1] after a consonant. (My limited knowledge of Grebo has not permitted me to make any conclusions about the apparent contrast between [d] and [ 1 ] in initial position.) If we assume that the underlying forms in (34) are also the historical forms, then Grebo appears to add little to our understanding of the origin of nasalized vowels. At this point, let us then consider the many kwa languages that have restrictions on consonants that precede nasalized vowels.

2. Regressive nasal assimilation of consonants

In a number of Kwa languages non-strident voiced consonants become nasal before nasalized vowels. ${ }^{12}$ In some languages (e.g. Grebo, some Akan dialects) the picture is complete: no voiced oral consonants appear before nasalized vowels in surface forms. Thus, Schachter and Fromkin [1968] report the following derivations for their dialects of Akan:

$\begin{array}{llll}/ \text { ã } / & \rightarrow & {[\text { mã] }} & \text { 'give' } \\ / \text { dã } & \rightarrow & {[\text { nã] }} & \text { 'and' } \\ / \text { yã } / & \rightarrow & {[\tilde{y} a \tilde{]}]} & \text { 'receive' } \\ / \text { wãd } / & \rightarrow & {[\tilde{w} \tilde{n} \tilde{\mathbf{I}}]} & \text { 'scrape' } \\ / \text { hũ } / & \rightarrow & {[\tilde{h} \tilde{u}]} & \text { 'fear' }\end{array}$

The forms for 'receive' and 'scrape' have the possible free variants [nã] and [ iwãnĩ , respectively.

In other languages, however, there is some variation, most notably with respect to the voiced labial and alveolar consonants. Thus, while all relevant Kwa languages appear to nasalize both glides and liquids occurring before nasalized vowels, some Kwa languages, such as Nupe, have a contrast between $/ b /$ and $/ \mathrm{m} /$ before nasalized vowels, as well as a contrast between $/ d /$ and $/ n /$ :

${ }^{12}$ I specify these consonants are non-strident in order to include languages such as Nupe where $[d z \tilde{V}],[v \tilde{V}]$, etc. are found. 


$\begin{array}{lll}\text { [ba] 'to cut' } & \text { [da] 'to get wet' } \\ \text { [bã] 'to break' } & \text { [dã] 'to be in' } \\ \text { [mã] 'to give birth' } & \text { [nã] 'to shine' }\end{array}$

While the processes in (35) explain why Schachter and Fromkin set up only underlying initial $/ \mathrm{b} /$ and $/ \mathrm{d} /$ (and not $/ \mathrm{m} /$ and $/ \mathrm{n} /$ ), it is not possible to do the same for Nupe, as we can see from the contrasting forms in (36). However, it is possible to recognize underlying /I $\tilde{V} /$ for phonetic [ñ̃], since the same distribution is found in Nupe as in Yoruba (cf. (3) and (4) above). Thus, 'to shine' could be represented as underlyingly $/ 1 \dot{a} /$, which is then converted to [nắ] by means of a rule of regressive assimilation such as the one given in (3) above. Since no final consonants occur in Nupe, we can thus claim that Nupe has no underlying $/ \mathrm{n} /$. But what about the contrast between $/ b /$ and $/ \mathrm{m} /$ ? Where is the voiced oral consonant that would be in complementary distribution with [m]? It can't be [w], for instance, because /wã/ 'to catch' is realized either as [w̃a] or [jwã]. In fact, there is no corresponding oral consonant... and yet there had to be one, historically, because we do not find sequences of *me and *mo in inupe. In other words, there seems to be a constraint on vowels that appear after $/ \mathrm{m} /$, namely only [ĩ], [ũ] and [ã]. We could say that underlying sequences of $/ \mathrm{mi} /, / \mathrm{mu} /$ and $/ \mathrm{ma} /$ become phonetic [mT], [mũ] and [mã] by means of a rule of progressive assimilation as in (37): (37) $\quad v \rightarrow[$ nasal $] / \mathrm{m}$

But this would hardly explain why there are no sequences of $/ \mathrm{me} /$ and $/ \mathrm{mo} /$. Instead, we must insist that the correct underlying representations of the occurring sequences are $/ \mathrm{mT} /, / \mathrm{mu} /$, and $/ \mathrm{ma} /$. But then, the nasality of $/ \mathrm{m} /$ would seem to be redundant. For, historically, it was. In fact, we needn't go far to find the answer to this diachronic puzzle.

In closely related Gwari there are two volced oral labial stops: $/ 0 /$

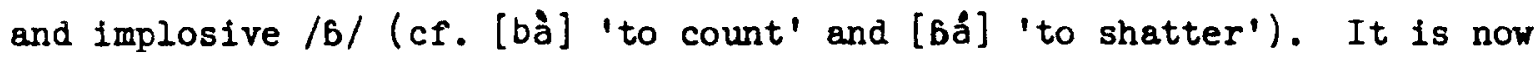

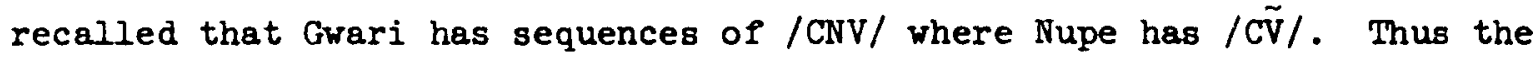
forms in (41) from Gwari should be compared with the Nupe forms in the second row of (36), repeated below: 
(38)

$$
\begin{aligned}
& \text { Gwari [bmà] 'to break' [dná] 'to be in' } \\
& \text { cf. Nupe [bã] 'to break' }
\end{aligned}
$$

It happens that /ô/ and / / do not occur in [CNV] sequences in Gwari, at least in surface forms. Underlyingly, however, it is possible to recognize / $\mathrm{fN} /$ and $/ \mathrm{IN} /$ on a par with $/ \mathrm{bN} /$ and $/ \mathrm{dN} /$, the former sequences being realized phonetically as $[m]$ and $[n]$, respectively:

$$
\begin{array}{rllllll}
\text { Gwari /GNa/ } & \rightarrow & \text { bma } & \rightarrow & \text { [ma] } & \text { 'to give birth' } \\
\text { Gwari /INá/ } & \rightarrow & \text { Iná } & \rightarrow & \text { [ná] } & \text { 'how much' } \\
\text { cf. Gwari /bNà/ } & \rightarrow & & & \text { [bmà] } & \text { 'to break' } \\
\text { Gwari /dNá/ } & \rightarrow & & & \text { [dná] } & \text { 'to be in' }
\end{array}
$$

Thus, we would have to claim that Proto-Kwa had an implosive / $6 /$.

This claim seems to me to be beyond question. 13 Some Proto-Kwa reconstructions with *6 are: *60 'hand',14 *61 'child' and *6á 'they' (cognate with Proto-Bantu class two prefix ba, which possibly also reconstructs as "6a, the way it appears in Basaa). The verb 'to come' must also reconstruct with an initial *b, though the identity of the proto vowel is uncertain. Reflexes of these proto forms are seen in

\begin{tabular}{|c|c|c|c|c|c|}
\hline & Edo & Yoruba & Gwari & Nupe & Akan \\
\hline 'hand' & ùbó & owว & o6wá & egwa & obasa \\
\hline 'child' & ble? & bi (vb.) & ebi & egi & obá \\
\hline 'they' & بбау. & wã́ & Bá & $\mathbf{a}$ & wo \\
\hline 'come' & & wá/bj & Bé & bé & bà \\
\hline
\end{tabular}
various Kwa languages in (40). The Edo (Degema) forms are taken from Thomas and Williamson [1967], the Akan forms from Christaller [1933]. The one Ebrié form is taken from Dumestre [1970]. Blanks mean that I am unaware of the word in that language.

Additional cognates can be obtained for 'hand' (= 'arm' in Akan), 'child' (= 'to bear a child' in Yoruba) and 'to come' from Armstrong [1964]. The

13 While I was in Ibadan, Ben Elugbe mentioned to me that Kay Williamson had reconstructed implosive consonants for Kwa as well.

${ }^{14}$ These Proto-Kwa forms most likely should be reconstructed with a morpheme-final consonant, e.g. *bok 'arm' (cf. Efik ubok, Proto-Bantu *boko). 
presence of an implosive / $6 /$ in the form for 'hand' in Edo, Gwari and Ebrié (= Akan), three different sub-branches of Kwa, would seem to suggest that other Kwa languages not having /6/ have lost that sound (Yoruba, for instance, has changed *6 into /w/ in three of the forms in (40)). Additional forms supplied by Armstrong from West Atlantic (e.g. Fula Gi'i 'child') and Benue-Congo (e.g. Ufia kj-6j 'hand') strongly suggest that *6 should be reconstructed for all of Niger-Congo. Thus, returning to our discussion of nasals in Kwa, we are on solid ground when we analyze Gwari [mV] as historical *6N. In fact, we can go one step further.

Dumestre [1970] reports that in Ebrié, an Akan dialect spoken in Ivory Coast, there is not only $/ 6 /$, but $/ d /$ as well. Furthermore, he states: "...nous considérons que l'ébrié ne possède aucune consonne nasale phonologique, et que $[m],[n]$ et $[n]$ sont les allophones respectifs de $/ 6 /, / d /$ et $/ y /$ [before nasalized vowels]" [p. 25]. Let us now propose the following voiced oral stops in Proto-Kwa:

$\begin{array}{llll}\text { (4I) } & b & d & g \\ \text { b } & d & \end{array}$

Some Proto-Kwa roots with *d are: *di 'to eat', *de 'to look at', * C'e 'blood' (cf. Proto-Bantu *dia 'to eat', Proto-Bamiléké *dég 'to look at', and the common Bamiléké root / $\mathrm{d} \hat{\mathrm{e}} \mathrm{m} / \mathrm{blood}$ '). The form for 'to eat' is /di/ in Edo and / $d i /$ in the Gnawu dialect of Gwari. The form for 'blood' is [ $\dot{\varepsilon} j \dot{\xi}]$ in Yoruba. Now let us say that in many languages Proto-Kwa * $6 \mathrm{~N}$ is realized as [m] and * $\mathrm{ON}$ is realized as [n]. In Ebrié, where * $\mathrm{CNV}$ has become [CṼ], we find that ${ }^{*} \mathrm{bNV}$ is realized as $[m \tilde{V}]$ and *dNV is realized as [nṼ]. In Ebrié it is possible to get $/ b /$ and /d/ followed by nasalized vowels, just as it was in the proto language. However, while the proto language had constraints on nasals following the two implosive consonants, Kwa languages that lack these sounds have realigned these constraints. Dialects of Akan treated by Schachter and Fromkin, for instance, once having merged ${ }^{*} b$ and ${ }^{b} b$, and ${ }^{*} d$ and *d, now do not permit nasalized vowels after any voiced oral consonant, as schematized in (42): 
(42) $/ 6 \mathrm{~V} / \quad \rightarrow[\mathrm{BV}]$

$$
\begin{aligned}
& / \mathrm{bV} / \rightarrow[\mathrm{bV}]>[\mathrm{bV}] \\
& \mid \mathrm{B} \tilde{\mathrm{V}} / \rightarrow[\mathrm{m} \tilde{\mathrm{V}}] \\
& / \mathrm{b} \tilde{\mathrm{V}} / \rightarrow[\mathrm{b} \tilde{\mathrm{V}}]>[\mathrm{m} \tilde{\mathrm{V}}]
\end{aligned}
$$

(The phonemic forms $/ 6 \tilde{V} /$ and $/ b \tilde{V} /$ derive of course from $* 6 N V$ and ${ }^{*} b N V$, and ultimately from Proto-Kwa *bVNV and *bVNV, respectively, according to the argument advanced above.) In these dialects of Akan, [b] and [m] are now in complementary distribution after ${ }^{*} B$ and $*_{b}$ have merged: [b] is found before oral vowels and [m] before nasalized vowels. In Nupe, the situation is different, as we see schematized in (43):

$$
\text { (43) } \begin{aligned}
/ \mathrm{bV} / & \rightarrow[\mathrm{bV}] \\
/ \mathrm{bV} / & \rightarrow[\mathrm{bV}] \\
/ \mathrm{b} \tilde{\mathrm{V}} / & \rightarrow[\mathrm{m} \tilde{\mathrm{V}}] \\
/ \mathrm{b} \tilde{\mathrm{V}} / & \rightarrow[\mathrm{bV}]
\end{aligned}
$$

The difference between Akan and Nupe, then, is that Nupe has merged ${ }^{*} 6$ and only before oral vowels, keeping their respective reflexes [m] and [b] distinct before nasalized vowels. Thus, what was formerly analyzed as / $6 \mathrm{~V} /$ in Nupe, must now be analyzed as $/ \mathrm{m} \tilde{\mathrm{V}} /$, as argued above.

As for Proto-Kwa *d and ${ }^{d}$, Schachter and Fromkin's dialects of Akan merged them in a parallel fashion to ${ }^{*} b$ and ${ }^{*} b$, as we see in (44):

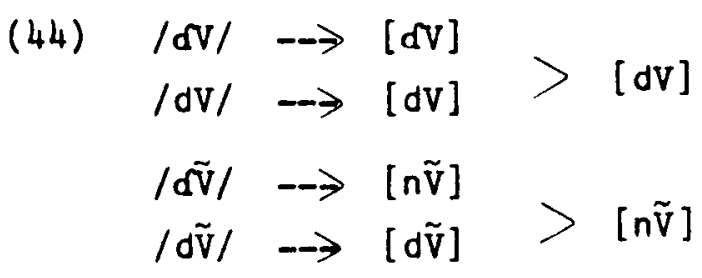

(Recall that $/ d \tilde{V} /$ and $/ d \tilde{V} /$ derive from *dNV and *dNV, respectively and ultimately from Proto-Kwa *dVNV *dVNV.) However, in Nupe it is [1] (and not [d]) that is in complementary distribution with [n], as we stated above. (In Akan, /d/ is also realized as [ $r$ ] intervocalically before oral vowels.) In fact, Nupe is representative of a number of Kwa languages that changed $*_{d}$ into [1]. In (40) we saw that Yoruba ${ }^{*} G$ becomes [w]; Yoruba * becomes [1]. Since sonorants cannot be implosive (cf. 
Greenberg [1970]), [+implosive] segments will always be redundantly [-sonorant]. What has happened in Yoruba (and partially in Nupe) is that the redundant feature specifications have been reversed: [+implosive, -sonorant] segments have become [-implosive, tsonorant]. Because of these feature neutralizations, one frequently finds implosives developing into sonorants, as reported in a number of cases by Greenberg [1970]. We have already said- that Ebrié (Akan) and Edo have $/ d /$. The one Niger-Kaduna language that has instances of $[d]$ occurring on the surface is Gnawu Gwari, where [ $\alpha^{i}$ ] means 'to eat'. However, there is considerable evidence that the whole sub-branch once had / $/$ /. In Gwari Kuta, /g/ is realized as [j] before front vowels. However, there is a palatal stop [j] whose synchronic source is analyzed in (45):

(45) $\begin{aligned} \mid 1 i / & \rightarrow\left[j^{y} i\right] \\ \mid 1 e / & \rightarrow\left[j^{y} e\right] \\ \mid 1 a / & \rightarrow[1 a] \\ \mid 1 u / & \rightarrow[1 u] \\ \mid 10 / & \rightarrow[10]\end{aligned}$

In Gwari there are processes of labialization and palatalization that apply to particular sets of consonants before labial and palatal vowels, respectively. Thus, /ofé/ 'dawn' is obligatorily pronounced [of ${ }^{\gamma} \hat{b}$ ], where the palatal off-glide is particularly pronounced. This process of palatalization partially explains the first two forms in (45), but why should we get $\left[j^{y_{i}}\right]$ and $\left[j^{y_{e}}\right]$ instead of $\left[1_{i} y_{i}\right.$ and $\left[1^{y_{e}}\right]$ ? In other words, why are these forms [-cont]? We can explain why palatal stops are found in these positions, if we accept the hypothesis that Proto-Niger-Kaduna (and Proto-Kwa in fact) had ${ }^{*} d$, which much later became both $\left[j^{y}\right]$ and [1] in Gwari. Thus, the historical derivations of three appropriate morphemes are given in (46):
*di 'to eat'
* de 'blood'
$\rightarrow d^{y_{i}} \rightarrow\left[j^{y_{i}}\right]$
* de 'to look at' $\rightarrow d^{y_{e}} \rightarrow\left[j^{y_{e}}\right]$
$\rightarrow d^{y} z \rightarrow j^{y} \varepsilon$
$\rightarrow\left[j^{Y} \mathbf{a}\right]$ 
(The last step in the derivation of 'blood' represents a rule that merges ${ }^{*} \varepsilon$ and *o with *a, a rule that is discussed with reference to Nupe in Hyman [1970a].) Thus, while $*_{d}$ becomes $\left[j^{y}\right]$ before front vowels, in other environments it becomes [1], e.g. "dá 'to take' $\rightarrow$ [lá]. Thus we conclude that Proto-Kwa had both ${ }_{b}$ and $*_{d}$ and that these consonants, when followed by $/ N /$ were pronounced $[m]$ and $[n]$, respectively.

Now that we have established ${ }^{*} b$ and ${ }^{*} d$ for Proto-Kwa, we can present one of the strongest arguments in favor of ${ }^{*} \mathrm{CNV}$ as an intermediate source of $C \tilde{V}$. We have said that it is impossible to produce an implosive sonorant. In addition, an implosive $/ \mathrm{m} /$ or $/ \mathrm{n} /$ is apparently a phonetic impossibility because what is involved in the production of an implosive is the rarefaction of the air pressure inside the mouth by a downward movement of the whole glottis (Mona Lindau [personal communication]). This rarefaction or lowering of the air pressure would be impossible if the nasal passage were coupled to the oral passage. Furthermore, a nasally released implosive would be phonetically impossible because since the air pressure is lower within the mouth, it is not possible for air to be released through the nose. Instead, air rushes into the mouth after the implosive has been released. This phonetic impossibility explains why no Kwa language has been observed with phonetic sequences such as $[6 \tilde{V}]$ and $[d \tilde{V}]$, which are possible, phonetically. Since we are assuming that Proto-Kwa *CVNV becomes *CNV by syncopation of the first vowel, if $C$ is an implosive and if $\mathrm{CN}$ is normally to be realized as a nasally released consonant, then sequences of GNV and aNV which arise from ProtoKwa * *VNV and *dVNV must automatically be modified, for they are unpronounceable -- or at least extremely 'inefficient' (Peter Ladefoged [personal communication]). We might propose the appropriate derivations in (47):

$$
\begin{aligned}
& { }_{\mathrm{GVNV}}>\mathrm{GNV}>\mathrm{GmV}>\mathrm{mmV}>[\mathrm{m} \tilde{\mathrm{V}}] \\
& { }_{\mathrm{G} \mathrm{oVNV}}>\mathrm{aNV}>\mathrm{dnV}>\mathrm{nnV}>[\mathrm{n \tilde {V }}]
\end{aligned}
$$

Since [bmV] and [dnV] are phonetic impossibilities, we have an explanation as to why [G] and [ $[\delta$ ] do not occur before nasalized vowels in Ebrié, but only before oral vowels. Namely, nasalize $\alpha$ vowels derive historically 
from preceding nasally released consonants. If we say that Proto-Kwa *CVNV becomes *CVN, then we have no explanation as to why *6VN and *dVN should become $[m \tilde{V}]$ and $[n \tilde{V}]$, respectively, since $[G \tilde{V}]$ and $[d \tilde{V}]$ are phonetically possible. Of course, in Akan, Grebo and elsewhere, what was initially a modification of phonetically impossible combinations has been extended, since [b] and [d] are also not found before nasalized vowels (see (42) and (44)).

Thus, to summarize, I assume that most -- if not all -- Kwa languages developed nasalized vowels as in the derivation in (48):
(48)
(a)
(b) (c)
(d)

$\mathrm{PK} \quad{ }^{*} \mathrm{CVNV}>\mathrm{CNV}>\mathrm{CN} \tilde{\mathrm{V}}>\mathrm{C} \tilde{\mathrm{V}}$

In Proto-Kwa in stage (a), bisyllabic stems are set up where the second syllable begins with a nasal consonant. In stage (b) the vowel of the first syllable has been syncopated, leaving an intermediate CNV stage. In stage (c), the remaining vowel has become nasalized, and in stage (d) the nasal (i.e. nasal release) has been lost. While this derivation may seem somewhat less natural than the one given earlier in (8), there are unmistakable instances of vowel syncope of the type posited here in many Kwa languages. First, there are the numerous instances of alternation between CVLV and CLV, as illustrated in (49) from Gã (cf. Truteneau [1971]):

(49) [kala] : [k!a] 'to nail'

A number of cases are also reported by Heine [1968] in his study of Togoremnant languages:

(50) PTR *bòlè $>$ Likpe blè 'to hit'
PTR *kálà $>$ Likpe klà 'to count'

On the other hand, some Togoremnant languages appear to have lost the final syllable:

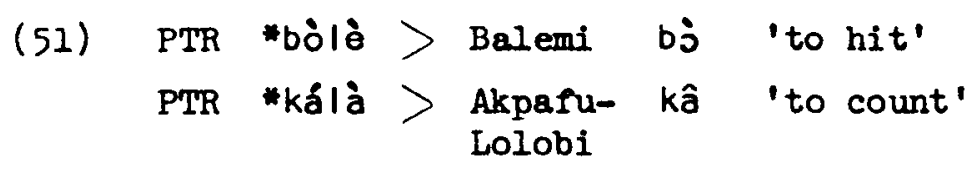


however, refrain from setting up underlying nasalized vowels in Gwari. Instead, underlying / CNV/ is realized either as [CNV], [CNṼ] or [C̃̃], depending on the nature of the consonant and the vowel. Recall that this post-consonantal nasal is an archiphoneme, e.g. /òkNa/ 'monkey' is realized as [òkgă] and /ōsNi/ 'breath' is realized as [ōsí].

A more difficult question is how to represent voiced consonants that are always nasal before nasalized vowels. For instance, it is recalled that $[m]$ and $[n]$ are in complementary distribution with [b] and $[d]$, respectively, in Ebrié: the former are found before nasalized vowels, the latter before oral vowels. If we represent $[\mathrm{mV}]$ and $[n \tilde{\mathrm{V}}]$ as $/ 6 \tilde{\mathrm{V}} /$ and $/ d \tilde{\mathrm{V}} /$, respectively, then Ebrié will have no underlying nasal consonants, as suggested by Dumestre [1970]. In Akuapem, Asante and Fante there would also be no $/ \mathrm{m} /$ and $/ \mathrm{n} /$, since $[\mathrm{m}]$ and $[\mathrm{n}]$ are, at least in initial position, in complementary distribution with [b] and [d]. Thus, in these Akan dialects, $[m \tilde{V}]$ and $[n \tilde{V}]$ can be represented as $/ b \tilde{V} /$ and $/ d \tilde{V} /$, respectively, as proposed by Schachter and Fromkin [1968]. Note, however, that Victoria Fromkin has informed me [personal communication] that in the revised version of A Phonology of Akan, she will probably set up underlying nasal consonants only in syllable final position. These dialects are exceptional in Kwa in that they permit final nasal consonants, a problem that cannot be explained by any existing hypothesis. ${ }^{16}$ In Gwari there would

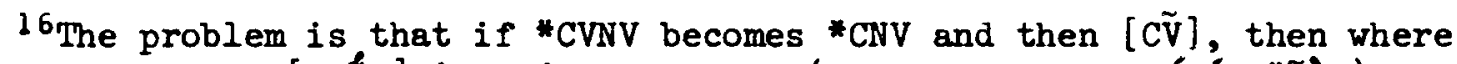
does a word̃ like [Enấm] 'meat' come from? (c.f. Proto-Bamiléké *ñàm). There are several possible explanations, but I don't have evidence for any of them. First, it is possible that at the time ${ }^{*} \mathrm{CVNV}$ became ${ }^{*} \mathrm{CNV}$, these words were of the structure ${ }^{*} \mathrm{CVN}$, i.e. they lacked a final vowel and therefore couldn't syncopate. Second, it is possible that *CVNV became * CNV only if the two vowels were identical (cf. Truteneau [1971] for $G \tilde{a})$, and that these morphemes had non-identical final vowels. Third, it is possible that syncope could occur only if the first vowel was of a certain nature (e.g. Kay Williamson has suggested to me that this vowel was always a high vowel). Those instances of * CVNV which did not become * CNV later became CVN (and still later perhaps [CV] outside of Akan). Fourth, the syncopation process could have been determined in part by the nature of the first or second consonant. For example, Grebo pVnV and $k V n V$ have the respective alternants $p i \tilde{V}$ and $k I \tilde{V}$ in rapid speech, but $+V n V$ cannot be pronounced $*+i \tilde{V}$ (Gordon Innes [personal communication]). Thus, those cases of ${ }^{*} \mathrm{CVNV}$ which did not become ${ }^{*} \mathrm{CNV}$ because of the nature of the consonant later became CVN. 
vowel *a becomes nasalized before a nasal consonant and in stage (d) that nasal consonant drops. We now have the forms from Nyangbo-Tafi. In stage (e) the nasalized vowel denasalizes and we have the form from Avatime. Finally, in stage $(f)$ the $[g]$ spirantizes to $[\gamma]$ and we have the form from Kposo. Thus, in (53) and (54) we observe that we must recognize intermediate ${ }^{*} \mathrm{CNV}$ and ${ }^{*} \mathrm{CVN}$ for different Togo-Remnant languages. This reveals first that nasalized vowels can possibly derive from two different processes in Kwa languages. But this also suggests that nasalized vowels may have a more recent origin in Togo-Remnant than elsewhere in Kwa, since motivated proto forms with nasal consonants can be reconstructed. As a final illustration of vowel syncope, notice the forms in (55) from the Kente dialect of Kpàn (Jukunoid), reported by Shimizu [1970]:

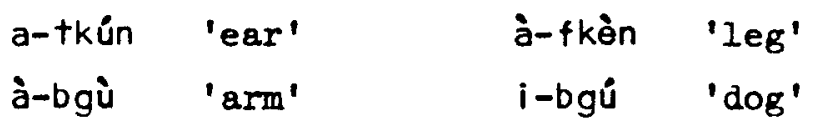

Since these syllable initial consonant clusters are of a highly marked nature, we tend to want to reconstruct a proto vowel between them. In fact, the forms in the left hand column correspond directly to the ProtoBantu reconstructions *ku-tul 5 'ear' and *boko 'arm'.

\section{Synchronic and diachronic implications}

In the first section of this paper I presented evidence for a * CNV stage in the development of nasalized vowels in Kwa. In the second section I established the diachronic processes operative on ${ }_{6 N}$ and ${ }_{0} d N$. Let us now briefly consider the synchronic representation of nasals and nasalization in Kwa. It should be clear from the earlier sections that Yoruba, Nupe, Akan and possibly Ewe are best viewed as having an underlying contrast between nasalized and oral vowels. While I am not ignoring the arguments made for /CVN/ in Eve by Stahlke [1971a,b], I hardly find them sufficient justification for positing abstract forms that do not conform to the morpheme structure conditions of the language. One might,

$15 \mathrm{ku}$ - is the noun class marker of class 15 in Bantu. Since many NigerCongo languages exhibit noun class suffixes, it is possible to hypothesize a form such as tu-ku 'ear' to explain the reversed order of $[t]$ and $[k]$ in $(55)$. 
Vennemann [1972b]. This, then, raises the second objection that might be raised against the solutions suggested in the previous paragraph. Namely, by recognizing forms such as Nupe /I $\tilde{V} /$ which is realized as $[n \tilde{v}]$, individual morphemes will contain underlying segments that are never heard on the surface, since there are no alternations between [1] and $[n]$ in Nupe. (There is a limited alternation between [1] and [ $n$ ] in Yoruba, which is discussed by Stahlke [forthcoming].) How can a Nupe internalize underlying forms with /I V / if he never hears [1] followed by a nasalized vowel? Kiparsky would allow such a representation if the rule converting $/ / /$ to $[n]$ were a 'low-level phonetic rule'. Vennemann would disallow $/ I \tilde{V} /$ because of the lack of alternation. (He argues, for instance, that the unaspirated $[p]$ in spin is a third phonological unit distinct from the aspirated [ $p^{h}$ ] in $p i n$ and the roiced [b] in bin, since the [p] in spin never alternates with $\left[p^{h}\right]$ or $\left.[b].\right)$ Thus, Vennemann's position can be restated in the following way: no underlying segment can be set up in a morpheme that is unpronounceable in that position, unless there is a surface realization of that morpheme where the underlying segment is heard phonetically. Thus, Nupe will have to have $/ n \tilde{v} /$ in Vennemann's system. If we return to Ebrié we see that Vennemann would recognize [ $\mathrm{m} \tilde{\mathrm{V}}$ ] and $[n \tilde{V}]$ as $/ m \tilde{V} /$ and $/ n \tilde{V} /$, respectively, and not as $/ b \tilde{V} /$ and $/ d \tilde{V} /$, since there are no alternations. What this does in effect is create 'phonemes in complementary distribution 18 : $/ 6 /$ and $/ d /$ would occur only before oral vowels and $/ \mathrm{m} /$ and $/ \mathrm{n} /$ only before nasalized vowels. Stahlke [forthcoming] reaches a similar solution for Yoruba, where /1/ is recognized before oral vowels and $/ n /$ before nasalized vowels (with a minor rule that changes $/ n /$ in certain morphemes to [1]). Presumably, these cases of complementary distribution will have to be signaled in the lexicon by morpheme structure conditions (which Vennemann calls 'rules'). This, then, leads into the third objection to the more abstract solutions. Namely, since the rules that change oral consonants to nasal consonants

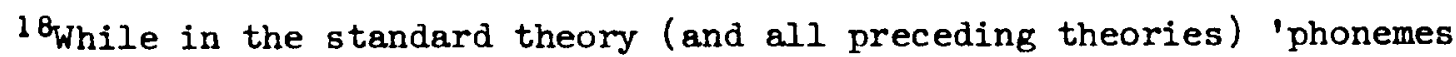
in complementary distribution' would be disallowed, Vennemann's theory of natural generative grammar "forces such an analysis" [personal communication]. 
also be no $/ \mathrm{m} /$ or $/ \mathrm{n} /$, but rather a homorganic $/ \mathrm{N} /$ which would follow initial consonants. 17 In this analysis, the phonetic occurrences of [m] and $[n]$ would be derived from underlying $/ 6 N /$ and $/ 1 N /$, respectively. In closely related Nupe, however, we have underlying $/ \mathrm{m} /$, because of contrasts such [bã] 'to break' and [mã] 'to give birth'. Finally, neither Nupe nor Yoruba would be said to have $/ n /$, since phonetic [ñ̃] would be viewed as the realization of $/ I \tilde{V} /$.

While all of these analyses would have been accepted with no principled objections in classical phonemics and in the standard version of generative phonology (as exemplified by Chomsky and Halle [1968]), some phonologists have voiced certain reservations they have as to these solutions. One reservation centers around the pronounceability of underlying forms. This argument has both a weak and a strong form. In the weak form, it is argued that underlying forms must be pronounceable at least in some human language. Chomsky and Halle [1968] have, for example, been criticized ( $c$. Kiparsky [1968]) for setting up an 'epsilon glide', the pronunciation of which is uncertain. Thus, as has been brought to my attention by Victoria Fromkin [personal communication], one might object to an analysis that represents Gwari [mV] as /6NV/ on the basis that implosives cannot be nasally released ( $\mathrm{c} f$. the discussion in section 2). While /6NV/ neatly represents a structural fact about Gwari, it is hard to imagine any native speaker intermalizing an unpronounceable underlying form. This underlying form would therefore be ruled out by a weak condition on pronounceability, which most phonologists would probably now acknowledge. A Strong Pronounceability Condition would state that no underlying form can be set up in a language that is not pronounceable by speakers of that language. As just stated, probably no phonologist would accept the strong form of the condition. However, the Strong Pronounceability Condition in conjunction with the Alternation Condition (Kiparsky [1968]) accurately represents the view of phonology presented by

${ }^{17}$ This same archiphoneme /N/ is present as a prefix of certain nouns,

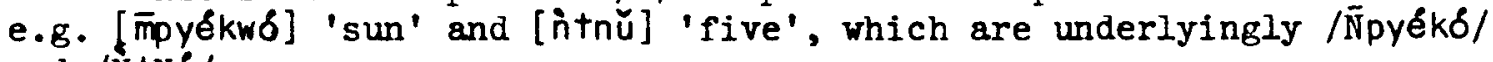
and $\mid \hat{N}+\hat{N} \dot{u} /$. 
morpheme structure condition that states that / / occurs before oral vowels and $/ n /$ before nasalized vowels. The situation is even more clear in Ebrié. Since [ $[B]$ and $[\sigma]$ do not occur before nasalized vowels, it should not be surprising to find foreign-sounding [ $6 i]$ and [ $d T$ ] being modified as [mĩ] and [nĩ], respectively. However, we should never expect an Ebrié speaker to adapt [mi] and [ $\mathrm{ni}$ ] as [fi] and [fi]. Rather, these too would be adapted, I would claim, as [mĩ] and [nĩ]. We might try to salvage the concrete solutions by incorporating notions of 'natural' vs. 'unnatural' assimilation processes (cf. Schachter [1969]). However, at the moment there appears to be at least as much reason to believe that [1] and [ $n$ ] are one underlying segment in Yoruba, as there is to believe otherwise. ${ }^{19}$

While it is therefore possible to describe some Kwa languages as lacking underlying nasal consonants, the remaining problem is a diachronic one: did Proto-Kwa then have no $/ \mathrm{m} /$ and $/ \mathrm{n} /$ ? Or, if Fromkin's proposed revisions are correct, did Proto-Kwa have $/ \mathrm{m} /$ and $/ \mathrm{n} /$ only in morpheme final position? We are no doubt tempted to say that Proto-Kwa did in fact have $/ \mathrm{m} /$ and $/ \mathrm{n} /$ and that these merged with ${ }^{*} \mathrm{bN}$ and $* d N$, respectively. ([mã] and [nã] would then have to represent a three-way merger in Akuapem, Asante and Fante between the intermediate reconstructions *GNa, *bNa and *ma, on the one hand, and *dNa, *dNa and *na on the other.) I know of no evidence for this merger, though I should like to mention that I am struck by the anomalous nature of Eve, which permits nasalization in a much wider context than other Kwa languages (e.g. all vowels can occur nasalized and nasalized vowels occur after all consonants: [als] 'hand' vs. [alõ] 'sleep'; cf. Westermann [1954]). It would be very

19 Notice that the same problem of where to capture complementary distribution characterizes other assimilatory processes. Thus, in a language which has [či] where we would expect [ki], and no alternations, we have to decide whether to have a rule converting / $k /$ to [č] before $/ \mathrm{i} /$, or whether to represent the two as phonemes in complementary distribution in the lexicon. Once again, the directionality argument favors the abstract solution. While one might expect a foreign [ki] to come into the language as [či], one would be less inclined to expect a foreign [ču] to come into the language as [ku]. Instead, one expects [ču] to come into the language as [či] (cf. Hyman [1970b]). This criterion merits further exploration. 
before nasalized vowels cannot be shown to follow any other phonological rule, why not incorporate the complementary distributions into the lexicon? In other words, since these rules that convert $/ B /$ to $[\mathrm{m}], / \delta /$ to $[n]$, etc., can always be the first rule in the phonological component, what evidence is there that these do in fact exist as rules? (This does not apply to the nasalization of $[r],[y]$ and $[w]$ in Yoruba, since this rule must follow other phonological rules in the language; cf. Stahlke [forthcoming].) We can pass a ruling by which nasal consonants are always forced into the lexicon, but this decision would have strong theoretical implications, which cannot be dismissed. The crucial difence between the two approaches is one of directionality. In Nupe, either we say that $[n]$ is derived from $/ 1 /$, or that $/ 1 /$ and $/ n /$ are phonemes in complementary distribution (i.e. with no directionality). It seems to me that if the principles I proposed (Hyman [1970b]) to explain foreign sound adaptation are correct, then the two solutions make very different predictions. While I was in Nigeria I frequently asked Yoruba speakers (who have [1] and [n] in complementary distribution) to repeat the nonsense word [elí], which they invariably repeated as [ení]. In the abstract solution we can claim that the rule that converts /// to [ $n$ ] before nasalized vowels is responsible for the [n] in the repeated form. No Yoruba ever repeated [ếî] or [edî], which are also possible. The concrete solution explains the [n] in the repeated form by means of the morpheme structure condition that identifies, so to speak, /// with $/ \mathrm{n} /$. However, while both solutions can explain the Yoruba speaker's inability to repeat [1] before a nasalized vowel, only the abstract solution can explain the reverse case. Namely, when Yoruba speakers are asked to repeat forms with [ni], they repeat these forms with [ni] and not with [1i]. The directionality of the rule converting / / to [ $n$ ] before nasalized vowels is again responsible for the change in the repeated form. The Yoruba speakers hear the derived segment [n] and assume that [n] was derived in an approprate environment, i.e. before a nasalized vowel. Thus, they make the [i] of [ni] nasalized, so that the rule can apply (cf. Hyman [1970b]). In the concrete solution there is no explicit reason why Yorubas should perceive [ni] as [ni] rather than as [li]. Both are predicted by the 
nasalized vowels either. A number of investigators have suggested privately to me that the absence of [e] and [o] might be due to a merger

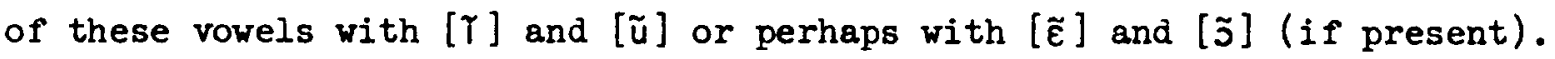
While nasalized vowels have a tendency to merge, the picture presented in (56) provides a structural explanation which is specific to Kwa. Such an explanation is, I think, what is required. Of course, we still have to explain why some Kwa languages have the full repertory of nasalized vowels. 4. Conclusion

I should like to conclude this paper with the obvious remark that a proper understanding of nasalization in Kwa may not only add to our understanding of nasalization in individual Kwa languages and of nasalization as a general linguistic phenomenon, but also may some day prove to be a valid criterion for determining what is and what is not Kwa. We are far from that day, however, since some Kwa languages (e.g. Idoma, Ikom) do not have nasalized vowels (perhaps at one time they did), and since some non-Kwa languages exhibit certain traits in common with those languages we have been considering (e.g. Bariba, a Gur language, where nasalized $/ \tilde{T} /, / \tilde{\varepsilon} /, / \tilde{a} /, / \tilde{u} /$ and $/ \tilde{z} /$ are found in contrast with their non-nasalized counterparts, but only oral $/ e /$ and $/ 0 /$ are found; see Welmers [1952], also Welmers [1950a,b] for comparable data from two Senufo languages of the Gur group). But, then, it may simply be that our present classifications are wrong. On the other hand, it may turn out that high and low vowel nasalization is an areal feature. While I have presented evidence for an intermediate *CNV stage in Kwa, I think it may still be possible that a part of Kwa developed nasalized vowels from an intermediate *CVN stage. I should at least like to leave open this possibility . 
strange if the proto language did not permit $/ \mathrm{m} /$ and $/ \mathrm{n} /$ in initial position, since we know, for instance, that $/ \mathrm{m} /$ and $/ \mathrm{n} /$ are necessary for Proto-Bantu.

Still the greatest unsolved problem is: why do so many Kwa languages disallow [ẽ] and [õ]? The fact that we often do not find [mẽ] and [nẽ], [mõ] and [nõ] also supports our decision to regard these as derived segments. (Cf. Yen [1968], where a similar situation is described in some Chinese dialects, but where the presence of all nasalized vowels after nasal consonants leads to a different type of solution.) While Igbo dialects that have nasalized vowels permit all vowels to be nasalized, Welmers and Welmers [1968] report only two words that have [ne], n' né/ìné 'mother' and únèrè 'banana', while there are no instances of words with [no]. At this point, let me present a very speculative account for the

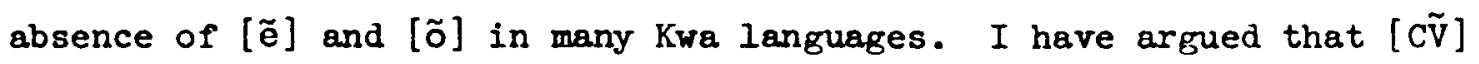
derives from Proto-Kwa *CVNV with an intermediate *CNV stage. It has occurred to me that the second rowel probably was historically a suffix -either a noun class suffix or a verb suffix. Given the likelihood that this was the case, if we postulate that suffixes were limited to the three vowels *-i, * $u$ and $*_{-a}$, then we have an answer, as shown in $(56)$ : (56)

\begin{tabular}{|c|c|c|c|}
\hline (a) & (b) & & (c) \\
\hline $\mathrm{CVN}-i$ & $\mathrm{CNi}$ & $>$ & CNi \\
\hline $\mathrm{cus}$ & CNIU & & CNŨ \\
\hline & $\mathrm{CNa}$ & & CNã \\
\hline
\end{tabular}

In stage (a), Proto-Kwa * CVN - roots are posited which always carry a suffix, either $-i,-u$, or $-a$. In stage (b) the first vowel is syncopated, leaving intermediate ${ }^{*} \mathrm{CN} i,{ }^{*} \mathrm{CNu}$ and ${ }^{*} \mathrm{CNa}$. In stage (c) the preceding nasal (or nasal release) nasalizes the vowel, and in stage (d) the nasal is lost. Thus, the reason why we do not find [Cẽ] and [Cõ] in many Kwa languages is that there were no words in Proto-Kwa of the structure ${ }^{*} \mathrm{CVN}-\mathrm{C}$ and ${ }^{*} \mathrm{CVN}-\mathrm{O}$. I offer no evidence for this explanation other than the observation that some Benue-Congo languages restrict suffixes to those three vowels (e.g. Jukunoid; cf. Shimizu [1971]). Notice that there is no mention of $[\tilde{\varepsilon}]$ or $[\tilde{\partial}]$. Many Kwa languages do not have these 
Hyman, Larry M. 1970a. "How concrete is phonology?". Language 46.1: 58-76.

Hyman, Larry M. 1970b. "The role of borrowing in the justification of phonological grammars". Studies in African Linguistics 1.1: 1-48.

Hyman, Larry M. 1972a. A Phonological Study of $\mathrm{Fe}^{7} \mathrm{fe}^{7}$-Bamiléké. University of California, Los Angeles, doctoral dissertation. Studies in African Linguistics, Supplement 4.

Hyman, Larry M. 1972b. "The great Igbo tone shift". To appear in the Proceedings of the Third Annual African Linguistics Conference, April 7-8, 1972, Bloomington, Indiana. Edited by Erhard Voeltz.

Hyman, Larry M. and Daniel J. Magaji. 1970. Essentials of Gwari Grammar. Ibadan: University of Ibadan Press. Occasional Publication No. 27 of the Institute of African Studies.

Hyman, Larry M. and Russell G. Schuh. Forthcoming. "Prolegomena to a theory of natural tone". Studies in African Linguistics.

Innes, Gordon. 1966. An Introduction to Grebo. London: School of Oriental and African Studies, University of London.

Kiparsky, Paul. 1968. "How abstract is phonology?". Unpublished paper. Kisseberth, Charles W. 1969. "On the abstractness of phonology: the evidence from Yawelmani". Papers in Linguistics 2: 248-282.

Ladefoged, Peter. 1964. A Phonetic Study of West African Languages. Cambridge: Cambridge University Press.

Lightner, Theodore M. 1970. "Why and how does vowel nasalization take place?". Papers in Linguistics 2.2: 179-226.

Melzian, Hans. 1937. A Concise Dictonary of the Bini Language of Southern Nigeria. London: Kegan Paul, Trench, Trubner and Co., Ltd.

Ohala, John J. 1971. "Monitoring soft palate movements in speech". Project on Linguistic Analysis No. 13, Phonology Laboratory, Department of Linguistics, University of California, Berkeley.

Schachter, Paul. 1969. "Natural assimilation rules in Akan". IJAL 35.4: 342-355.

Schachter, Paul and Victoria Fromkin. 1968. A Phonology of Akan: Akuapem, Asante and Fante. Working Papers in Phonetics, No. 9, University of California, Los Angeles.

Schane, Sanford. 1968. French Phonology and Morphology. Cambridge, Mass.: M.I.T. Press.

Schane, Sanford. 1972. "Natural rules in phonology", in Linguistic Change and Generative Theory, pp. 199-229. Edited by Robert P. Stockwell and Ronald K. S. Macaulay. Bloomington, Indiana:

Indiana University Press. 


\section{REFERENCES}

Abraham, Major R. C. 1967. The Idoma Language. London: University of London Press.

Ansre, G. 1963. "Reduplication in Ewe". Journal of African Languages 2.2: $128-132$.

Armstrong, Robert G. 1964. The Study of West African Languages. Ibadan: Ibadan University Press.

Armstrong, Robert G. 1967. A Comparative Wordlist of Five Igbo Dialects. Ibadan: Institute of African Studies, University of Ibadan. Occasional Publication No. 5.

Carrel1, Patricia L. 1970. A Transformational Grammar of Igbo. Cambridge: Cambridge University Press.

Chen, Matthew. 1969. "Vowel length variation as a function of the voicing of the consonant environment". Project on Linguistic Analysis No. 9, Phonology Laboratory, Department of Linguistics, University of California, Berkeley.

Chomsky, Noam and Morris Halle. 1968. The Sound Pattern of English. New York: Harper and Row.

Christaller, Rev. J. G. 1933. Dictionary of the Asante and Fante Language. Basel: Basel Evangelical Missionary Society.

Dumestre, G. 1970. Atlas Linguistique de Côte d'Ivoire. Abidjan: Institut de Linguistique Appliquée XI, Université d'Abidjan.

Ferguson, Charles A. 1963. "Assumptions about nasals: A sample study in phonological universals", in Universals of Language, second edition, pp. 53-60. Edited by Joseph H. Greenberg. Cambridge, Mass.: M.I.T. Press.

Foley, James. 1972. "Nasalization as universal phonological process". Paper delivered at the Second Annual California Linguistics Conference, May 6-7, 1972, University of California, Los Angeles.

Fromkin, Victoria. Forthcoming. Revision of Schachter and Fromkin, A Phonology of Akan.

Greenberg, Joseph H. 1966. "Synchronic and diachronic universals in phonology". Language 42.2: 508-517.

Greenberg, Joseph H. 1970. "Some generalizations concerning glottalic consonants, especially implosives". IJAL 36.2: 123-145.

Heine, Bernd. 1968. Die Verbreitung und Gliederung der Togorestsprachen. Berlin: Dietrich Reimer Verlag.

Hooper, Joan. 1972. "The syllable in generative phonology". Language 48. 
Westermann, Diedrich. 1954. Wörterbuch der Ewe-Sprache. Berlin: Akademie-Verlag.

Williamson, Kay. 1965. A Grammar of the Kolokuma Dialect of Ijs. Cambridge: Cambridge University Press.

Williamson, Kay. 1970. "Reading and writing Ikwerre". Rivers Readers Project. Institute of African Studies. University of Ibadan, Ibadan, Nigeria.

Yen, Sian L. 1968. "Two measures of economy in phonological description". Foundations of Language 4.1: 58-69. 
Stahlke, Herbert. 1971a. "On the status of nasalized vowels in Kwa", in Papers in African Linguistics, pp. 239-247. Edited by Chin-Wu Kim and Herbert Stahlke. Edmonton: Linguistic Research, Inc.

Stahlke, Herbert. 1971b. Topics in Ewe Phonology. Unpublished doctoral dissertation, University of California, Los Angeles.

Stahlke, Herbert. Forthcoming. "The $n / l$ alternation: a minor rule in Yoruba phonology", to appear in Papers in Linguistics in Honor o Henri and Rene Kahane. Edited by Braj B. Kachru et al.

Shimizu, Kiyoshi. 1970. "Morphotonology of the Kente Dialect of Kpan, the same language as the "extinct' Eregba". Paper read at 9th West African Languages Congress, Freetown, March 19-24, 1970.

Shimizu, Kiyoshi. 1971. Comparative Jukunoid. Doctoral Dissertation, University of Ibadan.

Thomas, Elaine and Kay Williamson. 1967. Wordlists of Delta Edo: Epie, Engenni, Degema. Ibadan: University of Ibadan Press. Occasional Publication No. 8 of the Institute of African Studies.

Truteneau, H. M. J. 1971. "Synchronic/diachronic variation of the type $/ \mathrm{CV}_{1} \mid \mathrm{V}_{I} / \sim / \mathrm{CIV} /$ in the Gä language". Paper read at the VIIth International Congress of Phonetic Sciences, Montreal, August 1971.

Vennemann. Theo. 1972a. "On the theory of syllabic phonology". Linguistische Berichte 18: 1-18.

Vennemann, Theo. 1972b. "Phonological uniqueness in natural generative grammar". Glossa 6.1.

Vogler, P. 1968. "Esquisse d'une phonologie du Baoulé", in Annales de I'Université d'Abidjan, Linguistique, Série H, Tome I, Fascicule I.

Welmers, William E. 1946. A Descriptive Grammar of Fanti. Supplement to Language, Vol. 22, No. 3 .

Welmers, William E. 1950a. "Notes on two languages in the Senufo group, I. Senadi". Language 26.1: 126-146.

Welmers, William E. 1950b. "Notes on two languages in the Senufo group, II. Sup'ide". Language 26.4: 494-531.

Welmers, Willaim E. 1952. "Notes on the structure of Bariba". Language 28.1: 82-103.

Welmers, William E. 1968. Jukun of Wukari and Jukun of Takum. Ibadan: Ibadan University Press. Occasional Publication No. 16 of the Institute of African Studies.

Welmers, William E. and Beatrice F. Welmers, 1968. Igbo, A Learner's Dictionary. Los Angeles: African Studies Center, University of California, Los Angeles.

Westermann, Diedrich. 1930. A Study of the Eve Language. London: Oxford University Press. 


\section{BANTU LEXICAL CLASSES AND SEMANTIC UNIVERSALS}

(With some remarks on how not to write phonological rules)

Frank Heny

Department of Linguistics

University of Massachusetts, Amherst

\section{Introduction}

This paper has three related yet partially independent aims. In the first place I want to argue for a particular analysis of Shona adjectives, showing that at a rather deep syntactic level they are closely related to nouns. Secondly, I want to show that this analysis tends to vindicate the hypothesis of a syntactically and semantically defined level quite close to Chomsky's [1965] deep structure. Thirdly, I hope that the paper may serve as a kind of prolegomenon to a theory of lexical classes -- an important yet almost totally neglected aspect of the theory of natural language. In developing the argument for the analysis of adjectives, which is the central part of the paper, I shall deal primarily with some problems in the concord system. It will be necessary to demonstrate that a phonological solution is inappropriate although apparently possible within current theory. Some general restrictions are proposed on the use of morphological features or syntactic brackets in phonological rules, and it is argued briefly that the lexicon must probably include some of the rules which are now treated as phonological -- i.e. some of the P-rules.

In many Bantu languages, including Shona, there is a small, closed class of lexical items which have generally been called adjectives. There appear to be less than forty in Shona (Fortune [1955: 152-156]i. Most can be glossed by English adjectives, with which they also share a good number of syntactic characteristics. As in English, adjectives in Shona can be used either predicatively (e.g. 'The sky is blue') or

IThis is a greatly expanded and modified version of a paper first read at the summer 1968 meeting of the Linguistic Society of America. I should like to thank Barbara Partee for extensive discussion of the earliest versions, and Earl Stevick for helpful comments. Talmy Givón, Erhard Voeltz, Tom llanwell, Tom Peterson, and Richard Demers have made helpful comments on an intermediate version. None of them agree with everything I say here. 


\section{BANTU LEXICAL CLASSES AND SEMANTIC UNIVERSALS}

(With some remarks on how not to write phonological rules)

Frank Heny

Department of Linguistics

University of Massachusetts, Amherst

\section{Introduction}

This paper has three related yet partially independent aims. In the first place I want to argue for a particular analysis of Shona adjectives, showing that at a rather deep syntactic level they are closely related to nouns. Secondly, I want to show that this analysis tends to vindicate the hypothesis of a syntactically and semantically defined level quite close to Chomsky's [1965] deep structure. Thirdly, I hope that the paper may serve as a kind of prolegomenon to a theory of lexical classes -- an important yet almost totally neglected aspect of the theory of natural language. In developing the argument for the analysis of adjectives, which is the central part of the paper, I shall deal primarily with some problems in the concord system. It will be necessary to demonstrate that a phonological solution is inappropriate although apparently possible within current theory. Some general restrictions are proposed on the use of morphological features or syntactic brackets in phonological rules, and it is argued briefly that the lexicon must probably include some of the rules which are now treated as phonological - i.e. some of the P-rules.

In many Bantu languages, including Shona, there is a small, closed class of lexical items which have generally been called adjectives. There appear to be less than forty in Shona (Fortune [1955: 152-156]). Most can be glossed by English adjectives, with which they also share a good number of syntactic characteristics. As in English, adjectives in Shona can be used either predicatively (e.g. 'The sky is blue') or

IThis is a greatly expanded and modified version of a paper first read at the summer 1968 meeting of the Linguistic Society of America. I should like to thank Barbara Partee for extensive discussion of the earliest versions, and Earl Stevick for helpful comments. Talmy Givón, Erhara Voeltz, Tom Manwell, Tom Peterson, and Richard Demers have made helpful comments on an intermediate version. None of them agree with everything I say here. 
attributively (e.g. 'the blue sky ...'). In either environment, the Shona adjective consists of a stem and a prefix, the latter determined by one of the nouns in its sentence.

If the adjective is attributive, the prefix is identical to that of its head noun, as in:

(1) munhu mukuru akaenda

man big went

'The big man went.'

The prefix of an adjective used predicatively differs only in tone from its attributive form, the copula being deleted, leaving behind a high tone on the adjective prefix. In this case, however, the adjective agrees with the subject:

(2) munhu múkuru

The agreement of an adjective with its noun is nart of an extensive concordial system found throughout the Bantu languages. I shall assume that the reader is familiar with this system of class concord, and will simnly draw attention to certain relevant aspects.

It is important, first, to note that the genders have some kind of semantic (as well as syntactic) significance. For full details the reader is referred to Fortune [1955]; the following summarizes the main semantic categories that are represented in the common, basic genders; noun stems naming classes of people tend to take class 1 and 2 prefixes, and so on.

$$
\begin{array}{ll}
\text { Class } 1 / 2 & \text { : people } \\
\text { Class } 3 / 4 & : \text { atmospheric phenomena, plants, long things } \\
\text { Class } 5 / 6 & : \text { masses or pairs }(6) \text {, things inspiring fear } \\
\text { Class } 7 / 8 & : \text { inanimate objects, worthless things } \\
\text { Class } 9 / 10: \text { animals, many everyday objects } \\
\text { Class } 11 / 10 \\
\left.\begin{array}{l}
11 / 6
\end{array}\right\}: \text { Iong thin things, times of day } \\
\text { Class } 14: \text { abstractions, substances }
\end{array}
$$


It would be a mistake to emphasize too strongly the semantic significance of the class system since there are numerous examples which resist the most determined efforts to interpret the classificatory system as strictly semantic -- it often seems to be purely arbitrary. On the other hand it would be pointless to deny that there is some kind of semantic basis to the class system. We shall later make some use of this.

The second important set of facts to note is the precise form of each class prefix before a noun or an adjective:

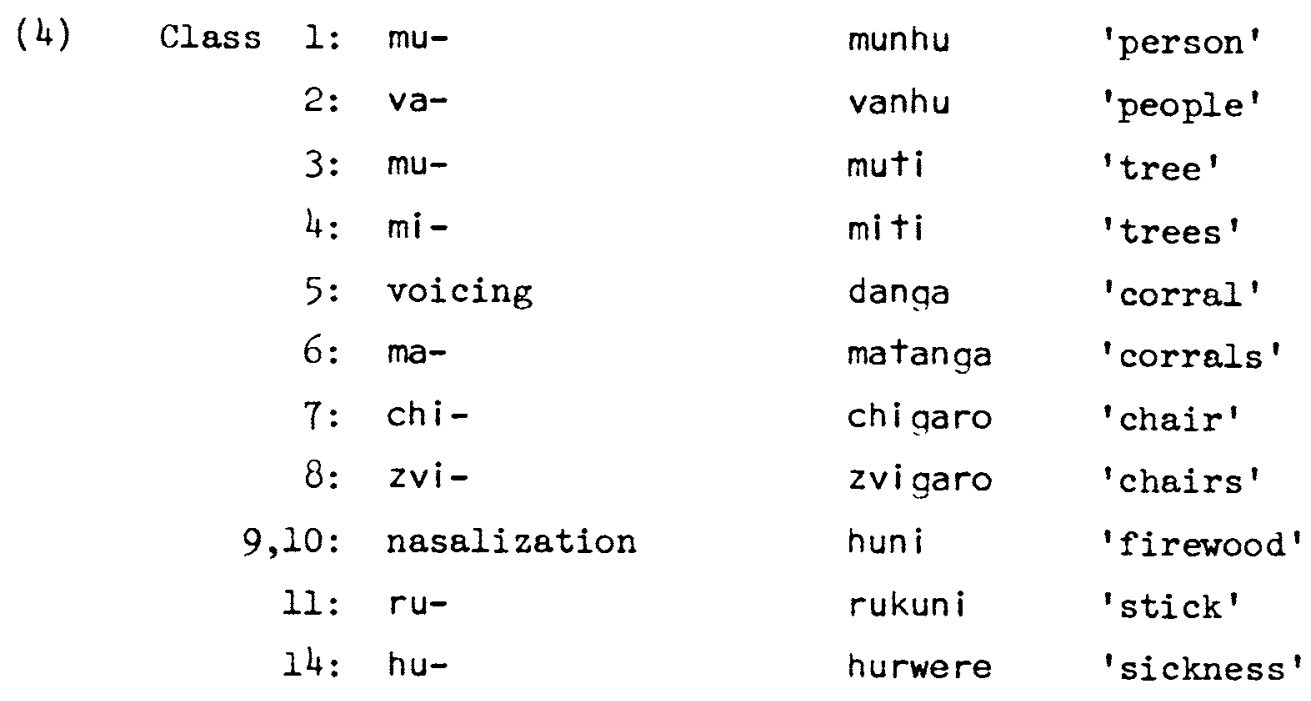

It will be noticed that the class 5 prefix is given as "voicing" while that for $9 / 10$ is said to be "nasalization". These "prefixes" have no segmental realization at all, but affect certain consonants in steminitial position. All the other prefixes consist of a single CV syllable. We shall concentrate on the non-segmental prefixes since they are crucial to the present argument. Notice that if the noun is in class 5, 9 or 10, the precise effect of the prefix may not be the same for that noun and an adjective in agreement with it since they need not possess identical steminitial consonants; nevertheless, their prefixes may be considered identical -- either "voicing" ("nasalization") or whatever causes the phonological change to occur. Some attributive adjectives in agreement with head nouns will show these facts in more detail: 
attributively (e.g. 'the blue sky ...'). In either environment, the Shona adjective consists of a stem and a prefix, the latter determined by one of the nouns in its sentence.

If the adjective is attributive, the prefix is identical to that of its head noun, as in:

(1) munhu mukuru akaenda

man big went

'The bif man went.'

The prefix of an adjective used predicatively differs only in tone from its attributive form, the copula being deleted, leaving behind a high tone on the adjective prefix. In this case, however, the adjective agrees with the subject:

(2) munhu múkuru

'The man (is) big.'

The agreement of an adjective with its noun is part of an extensive concordial system found throughout the Bantu languages. I shall assume that the reader is familiar with this system of class concord, and will simply draw attention to certain relevant aspects.

It is important, first, to note that the genders have some kind of semantic (as well as syntactic) significance. For full details the reader is referred to Fortune [1955]; the following surmarizes the main semantic categories that are represented in the common, basic genders; noun stems naming classes of people tend to take class 1 and 2 prefixes, and so on.

(3)

$$
\begin{array}{ll}
\text { Class } 1 / 2 & \text { : people } \\
\text { Class } 3 / 4 & : \text { atmospheric phenomena, plants, long things } \\
\text { Class } 5 / 6 & : \text { masses or pairs }(6) \text {, things inspiring fear } \\
\text { Class } 7 / 8 & : \text { inanimate objects, worthless things } \\
\text { Class } 9 / 10: \text { animals, many everyday objects } \\
\left.\begin{array}{l}
\text { Class } 11 / 10 \\
11 / 6
\end{array}\right\}: \text { Iong thin things, times of day } \\
\text { Class } 14: \text { abstractions, substances }
\end{array}
$$


Thus we can distinguish two very similar but distinct sets of prefixes. Begging the question somewhat, let us call these the noun series and the agreement series:

(8)

$\begin{array}{cllc}\text { Class } 1 & \text { Noun } & \text { Agreement } \\ 2 & \text { mu- } & i- \\ 3 & \text { va- } & \text { va- } \\ 4 & \text { mu- } & u- \\ 5 & \text { mi- } & i- \\ 6 & \text { voicing } & \text { ri- } \\ 7 & \text { ma- } & \text { a- } \\ 8 & \text { chi- } & \text { chi- } \\ 9 & \text { zvi- } & \text { zvi- } \\ 10 & \text { nasalization } & i- \\ 11 & \text { nasalization } & \text { dzi- } \\ 14 & \text { ru- } & \text { ru- } \\ & \text { hu- } & \text { hu- }\end{array}$

A fully satisfactory account of this data will explain:

(a) The considerable similarity between the series.

(b) The fact that there are nevertheless two series.

(c) The association of one series with just nouns and adjectives in Shona.

(d) The phonological details of the observed differences.

Probably the most obvious way of trying to handle the data is by means of phonological rules or low level adjustment rules just prior to the phonology. These rules would either apply just to nouns and adjectives or to all other relevant environments, modifying appropriately the basic segmental form of those prefixes which differ in the two series. Such an account would set up a single series of prefix formatives, treating the differences as trivial and either as an integral part of the sound system of the language or as a set of minor unexplained deviants. In either case it is very hard to imagine that we could explain in any serious way why nouns and adjectives act alike (and unlike the rest) with respect to the rules that differentiate the two series. For if the rules are 


$\begin{array}{llll}\text { (5) munhu } & \text { mukuru } & \text { 'a big person' } & \mathrm{Cl} .1 \\ \text { person } & \text { big } & \text { 'a longs snake' } & \mathrm{Cl} .9 \\ \text { *nyoka } & \text { ndefu } & & \\ \text { snake } & \text { long } & \text { 'a good corral' } & \mathrm{Cl} .5 \\ \text { * Danga } & \text { huya } & & \\ \text { corral } & \text { good } & & \end{array}$

Note: * prefix realized only by consonant changes if any

It is not only adjectives that show agreement with nouns. Every constituent of the noun phrase does, while the verb acquires a prefix in agreement with its subject noun. The following sentence serves to illustrate the effect that concordial agreement has in the language:

$$
\begin{aligned}
& \text { vanhu vakuru vaviri vàkaenda vákafa } \\
& \text { people big two went died } \\
& \text { '(The) two big people who went died.' }
\end{aligned}
$$

In this example, using a class 2 noun, all the prefixes have essentially the same segmental form. That is not always the case. If instead of a class 2 noun we use one in class 5 , it is immediately obvious that the phonological shape of the concordial prefix is strikingly different according to its environment:

$$
\begin{aligned}
& \text { banga guru rino rinocheka rine ngura } \\
& \text { knife big that cuts has rust } \\
& \text { 'That big knife which cuts is rusty.' }
\end{aligned}
$$

In the plural, preceded by a class 6 prefix, the stem of ' $k n i f e$ ' is -panga, while the stem of 'big' is otherwise -kuru, thus, the class 5 prefix is realized as the voicing of the initial consonant of the noun and adjective. Notice that even if the consonant following $r i-$ could be voiced it would undergo no changes following that overt, segmentally realized form of the prefix. In a similar way, the prefix for classes 9 and 10 is realized solely by a series of stem-initial changes before nouns and adjectives, but elsewhere the class 9 prefix is basically i- , the class 10 one basically dzi- . Finally, the prefixes of classes 1, 3, 4 , and 6 lose their initial (bilabial) nasal when they do not precede either a noun or an adjective. 
used one set of concordial prefixes, and one very general rule to spread these from the noun to demonstratives, relatives, adjectives, verbs and so on, assuming that there would be phonological rules to take care of the differences. He saw no particular significance in the two series and did not try to account for them directly. Givón [1969] for Bemba noted some of the problems inherent in Gregerson's mules; nevertheless he, too, chose to regard the differences between the noun prefix and agreement prefix as trivial, and he handled them in the phonology. ${ }^{2}$

Let us see more precisely what this would involve for Shona. First, I shall deal with the nasal of the prefixes of classes $1,3,4$ and 6 . The prefixes which appear as $m u, m i$ and $m a$ before nouns and adjectives are realized elsewhere as $u, i$ and $a$ respectively. At this stage there is little to choose between a rule of insertion and one of deletion. Loss of a nasal, rather than insertion, is probably commoner, in some sense less expensive, so let us assume that there is a rule:

$$
[+ \text { nasal }] \rightarrow \infty / \text { env. }
$$

What environment? There seem to be no relevant phonological features. The crucial fact is that a nasal is deleted (according to our present

${ }^{2}$ Givón's account did not, strictly speaking, involve ordinary phonological rules. He introduced a device, which he called "spelling out" rules, to convert various syntactic features directly into phonoIogical features. He did not provide any clear motivation for adopting this formalism; as far as I can see he uses it in such a way that it is no more capable of explaining Shona facts than a standard phonological account, though it has the distinct advantage of placing the phonological rules applying to the concord system in (or in close association with) the lexicon. We shall later propose doing the same; but the rules will be far less powerful than his. Givón has claimed [personal communication] that his account of the similarity between noun and adjective prefixes in Shona (as opposed to e.g. Bemba) relies on the historical facts. But history cannot explain the fact that these two series are the same in Shona. I am trying to provide such an explanation in this paper. 
phonological, we should expect any explanation of the difference to involve, crucially, some general phonological factor which sets aside the nouns and adjectives. There does not appear to be any such factor. Low level rules prior to the phonology are rather unlikely in principle to explain a difference of this sort since they seem to be essentially no more than a way of describing a lack of fit between the output of the syntax and the input to the phonology. There is, of course, no difficulty in describing the Shona facts, and either of these methods would be acceptable, were it not for the fact that a more explanatory account seems to be available.

Under this very different, and, according to the arguments presented here, more explanatory account of Shona concord, we postulate two closely related but at all stages distinct sets of prefixes: one for nouns and adjectives and another for the rest. Then we attempt to argue that the noun-adjective prefix is present in deep structure, while the other is not. Certain semantic and syntactic facts about Shona nouns and adjectives either predict or gibe very well with the existence of two distinct series of prefixes, giving this account considerable explanatory value and suggesting the need to modify current linguistic theory to select it rather than any other.

My account suffers from the considerable disadvantage that whereas a phonological solution appears to work using established theoretical mechanisms, there is at present no way or representing two series of distinct yet phonologically very similar formatives or of capturing the generalizations that hold between the noun and agreement series if they are basically distinct. However, insofar as the analysis is successful, this must be taken to demonstrate the need for adding suitable apparatus to the theory.

\section{The phonological solution}

Previous generative treatments of Bantu concord (at least those of which I am aware) have chosen a phonological account of the relationships between the two series. Gregerson [1967], dealing with Swahili, simply 
series, using only, or mainly, phonological rules. First of all, our nasal deletion rule will automatically delete the nasal $/ \mathrm{n} /$ before forms other than nouns and adjectives, leaving/i/ and /dzii/. A rule conmonly found in Bantu languages,

Vowel Shortening:

$$
v_{i} \rightarrow \varnothing / v_{i}-
$$

(applying only within morphemes), would reduce /dzii/ to /dzi/. Thus the correct form of the agreement prefix can be generated.

The nasal of $\mathrm{ni}$ - would not be deleted before nouns and adjectives, of course, (just as the nasal of $m u, m i$ and $m a$ is not deleted there), and it would therefore be available to induce the so-called "nasalization" of certain initial consonants in those forms. The principle changes are:

$$
\begin{aligned}
& {\left[\begin{array}{l}
p \\
t \\
k
\end{array}\right] \rightarrow\left[\begin{array}{l}
m h \\
n h \\
h
\end{array}\right]} \\
& {\left[\begin{array}{lll}
b & b, & v \\
d & r
\end{array}\right] \rightarrow\left[\begin{array}{l}
m b \\
n d
\end{array}\right]} \\
& {\left[\begin{array}{l}
f \\
s
\end{array}\right] \rightarrow\left[\begin{array}{l}
p f \\
t s
\end{array}\right]}
\end{aligned}
$$

Where /mh/ and / $\mathrm{nh} /$ are a kind of murmured nasal and $/ \mathrm{h} /$ is essentially a murmured onset to the following vowel.

To subsume all these under the title "nasalization" is at least superficially misleading. Nevertheless they may all have a common origin, and it is, in fact, quite feasible to add a few rules to generate the correct forms through processes triggered by the nasal of $\mathrm{ni}$-.

However, it is worth trying to establish first that there are indeed synchronic rules of some kind operating in the language to derive these forms. This is not immediately obvious since a noun stem in $9 / 10$ never appears in any form exhibiting the underlying $/ t /, / p /, / r /$ or whatever of the above table but only in the "nasalized" form determined by the output of these putative rules. However, there are adjective stems that clearly exhibit the alternations. The stem -kuru 'big' generally occurs with an initial /k/: munhu mukuru 'big person'. But in agreement with classes 9 or 10 it appears as huru: 
account) whenever it would be initial in a prefix before any form except a noun or an adjective. There are several possible ways of representing this; it does not seem to be very important which we choose. If we use labeled brackets, the negative environment will be a little complicated to state, so let us simply assume that the syntactic class features are spread from a stem onto its prefixes -- but not vice versa. We could formulate the rule thus: ${ }^{3}$

(10) Nasal Deletion:

$[+$ nasal $] \rightarrow \infty /\left[\begin{array}{l}-\overline{\text { Noun }} \\ - \text { Adjective } \\ + \text { Prefix }\end{array}\right]$

This rule, or something essentially like it, will account for the differences between the two series for classes $1,3,4,6$.

Now let's try and deal with the prefixes of classes 9 and 10 . These two classes are linked in a singular/plural gender -- though there are noun stems which take the class 10 prefix in the plural yet have some other singular prefix. There is generally no difference in the noun prefix for classes 9 and 10: the same nasalization process occurs initially in both. Thus nhou means either 'elephant' or 'elephants'. However the agreement prefix for class 9 is i-, for class 10, dzi-. Historically we can be fairly sure that there were two prefixes: $n i-$ and dzini- respectively. If we assume that the underlying forms of these prefixes remain roughly just that (i.e. /ni/ and /dzini/) we may be able to account both for the neutralization of the prefixes before nouns (and adjectives) and for the difference in form of the noun and agreement

${ }^{3}$ The phonological rules which we set up at this stage will later be rejected. Hence we shall not spend much time trying to justify them in detail. The use of lexical features in this particular rule is a very natural extension of the original proposal for the use of morphological features contained in Chomsky and Halle [1968: 374] to the revised lexicon proposed in Chomsky [1969]. It is, however, probably too powerful in principle -- see later in text. 
This rule changes $\mathrm{ni}+$ stem to $\mathrm{n}+$ stem, hence setting up an environment which is phonologically unique in the language, with $/ n /$ preceding all sorts of consonants that it does not otherwise precede. The consonant is mentioned so that this rule fails to operate before a vowel and forms like nyama 'meat' and nyoka 'snake' can be automatically derived, by a well-motivated rule not spelled out here, from ni-ama and ni-oka respectively.

The first set of changes that we shall deal with are those found with the voiceless stops: $/ n p / \rightarrow / m h /, / n t / \rightarrow / n h /, / n k / \rightarrow / h /$. The $/ \mathrm{h} /$ signifies a murmured or slack voice quality, adhering either in the nasal or (in the case of $/ k / \rightarrow / h /$ ) in the onset of the following vowel. This is a very interesting set of relationships. Were the rules that are involved really part of the synchronic grammar, we should have to examine it in more detail. But for the purpose of this exposition it is necessary only to show that a reasonably satisfactory phonological account can be given of the facts. There is some merit in interpreting this aspect of "nasalization" as an assimilation of the nasal to a subsequent consonant in terms of place of articulation, followed by a change of the following voiceless consonant to a murmured glide. Late rules not given here will delete $/ \mathrm{h} /$ before $/ \mathrm{h} /$ and interpret a nasal followed by $/ \mathrm{h} /$ as a murmured nasal. The basic rules are:

(16) Rule 3. Nasal assimilation:

$$
\begin{aligned}
& {[+ \text { nasal }] \rightarrow[\propto \text { place }] /-\left[\begin{array}{l}
\mathrm{C} \\
\alpha \text { place }
\end{array}\right]} \\
& \text { (where [place] is a convenient cover symbol) }
\end{aligned}
$$

(17) Rule 4. Murmur:

$$
[\text { [ voice ] } \rightarrow h /[+ \text { nasal }][\overline{- \text { cont }}]
$$

At this point, let us deal with the affricates [ $p f]$ and [ $t s]$ :

(18) Rule 5. Stop intrusion:

$$
\emptyset \rightarrow\left[\begin{array}{l}
- \text { cont } \\
- \text { voice } \\
\alpha_{i}
\end{array}\right] /[+ \text { nasal }]-\left[\begin{array}{l}
+ \text { cont } \\
- \text { voice } \\
\alpha F_{i}
\end{array}\right]
$$




$$
\begin{aligned}
\text { Class } 9: & \text { nyoka huru iri pano } \\
& \text { snake big is here } \\
& \text { 'The big snake is here.' } \\
\text { Class 10: } & \text { nyoka huru dziri pano } \\
& \text { snakes big are here } \\
& \text { 'The big snakes are here.' }
\end{aligned}
$$

Moreover, there are some noun stems which occur with a segmental prefix of class 11 in the singular but with class 10 prefix in the plural, and appropriate changes occur, as in rurimi 'tongue', ndimi 'tongues'. There are abundant examples like these, showing clearly that some sort of synchronic relationship is involved.

In reaching for a unified account of the changes that were outlined above, let us suppose that the /i/ of $\mathrm{ni}$ - is deleted, that the nasal then assimilates a following voiceless stop to itself in nasality, that $/ \mathrm{v} /$ and / $/$ / become stops, that an intrusive voiceless stop appears between a nasal and a following voiceless fricative, and that there is a late rule of nasal deletion which, unlike the rule we have already postulated applies to nouns and adjectives. A set of rules capturing these processes will generate more or less the right output, with one or two important exceptions to be dealt with directly. I give the rules very roughly below, along with the rules discussed earlier.

(14) Rule 1. Nasal deletion:

$$
[+ \text { nasal }] \rightarrow \infty /\left[\begin{array}{l}
-\overline{\text { noun }} \\
- \text { adj } \\
+ \text { prefix }
\end{array}\right]
$$

This rule deletes the nasals of $/ \mathrm{mu} /, / \mathrm{mi} /, / \mathrm{ma} /$ and $/(d z i) n i /$ except before nouns and adjectives.

(15) Rule 2. i-deletion:

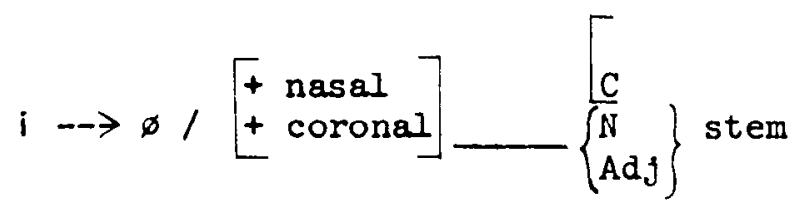


the form of prenasalization in stops (and some voiced fricatives, which we have ignored) this nasal never reaches the surface even when the first deletion rule left it alone.

Finally, it is necessary to shorten long vowels produced by the deletion of the nasal in the class 10 prefix dzini $\rightarrow$ *dzil:

(22) Rule 9. Vowel shortening:

$$
v_{i} \rightarrow \varnothing / v_{i}-
$$

Let us summarize our progress toward a phonological account of the difference between the noun and agreement series. None of our rules will apply to prefixes of classes $2,7,8,11$ and 14. That is correct. In these classes there is no difference between the two series. In classes $1,3,4$ and 6 , only rule (1) will apply, accounting for the loss of the nasal in the agreement series. So we have only to account for the complicated differences that occur in classes 5, 9 and 10.

In class 9, the first nasal deletion rule will apply as before in the environments where the agreement series is found, leaving behind (correctly) the prefix /i-/. No other rules then apply. But before nouns and adjectives, rule (2) will apply if the stem starts with a consonant, bringing the nasal next to stem-initial consonants. Rules (3) - (9) can then apply, only where appropriate, giving derivations like the following, and producing more or less the right output:

$(23 a)$

$\begin{array}{ccl}n i+\text { rimi } & \text { (tongues) } \\ & & \text { i-deletion } \\ & d & \text { stopping } \\ & \text { nd } & \text { prenasalization } \\ \varnothing & & \text { nasal deletion } \\ & \text { ndimi } & \end{array}$

(23b) $\mathrm{ni}+$ ama

(meat)

$\frac{\text { ny }}{\text { ny ama }}$ glide formation (not given) 
The intention is to introduce $/ p /$ and $/ t /$ between a nasal and $/ f /$ and $/ \mathrm{s} /$ respectively, examples of a process which is very widespread in the languages of the world. Allowing for certain frankly ad hoc aspects of the rule, it will correctly generate the observed affricates -provided we interpret them (at some stage) as clusters, and later as affricates.

(19) Rule 6. Stopping:

$$
\left\{\begin{array}{l}
v \\
r
\end{array}\right\} \rightarrow[- \text { cont }] / n-
$$

This, if we assume some kind of linking rules, will change / $/$ to $/ b /$ and $/ r /$ to $/ d /$ after the nasal. It might be possible to combine it with the previous rule but precisely how is not clear.

Several different accounts could be given of the relationship between the elements of what is written as a nasal + stop cluster like /nd/. For several reasons, which need not concern us here, it is very reasonable to interpret such a "cluster" as a single, prenasalized stop. For simplicity, let us therefore assume that a voiced stop imediately following a nasal acquires a feature [ + prenasal $].^{4}$

(20) Rule 7. Prenasalization:

$$
[\text { - cont ] } \rightarrow[+ \text { prenasal }] /[+ \text { nasal }]-
$$

We can now delete any nasal preceding a true consonant. Nasals drop before the afficates, before these prenasalized stops and before steminitial consonants like $/ \check{c} /, / \breve{s} /$ which are totally unaffected by our rules. A fair approximation to the rule would be the following.

(21) Rule 8. Nasal deletion 2: $[+$ nasal $] \rightarrow \infty /-[+$ consonantal $]$

Notice that this second rule of nasal deletion is required to delete the $/ \mathrm{n} /$ of the putative prefix / $\mathrm{ni} /$ after it has been used to induce the necessary stem-initial changes. Except in combination with $/ \mathrm{h} /$ or in

\footnotetext{
"It may be inconsistant with the treatment of the affricates as clusters in rule (5) to deal with the prenasalized stops as units. But we need not take these rules too seriously.
} 
although nouns and adjectives exhibit only the voicing of the stem-initial consonant if that consonant is $p, t, k, \check{c}, t s^{w}$, or $p f$. If we can somehow get rid of the $r i$ - after using it to induce voicing, and if all the above are stops, the rule seems basically quite simple if we ignore the strange fact that plain ts has to be excluded from the rule (cf. tsimba/matsimba 'footprint (s)').

(24) [ - cont $] \rightarrow[+$ voice $] / \mathrm{ri}-$

This rule must apply only before noun and adjective stems.

But recall rule (2), which deleted $/ / /$ after $/ \mathrm{n} /$, before nouns and adjectives. We could very easily generalize that mule roughly as follows: (25) Rule 2a. Vowel deletion:

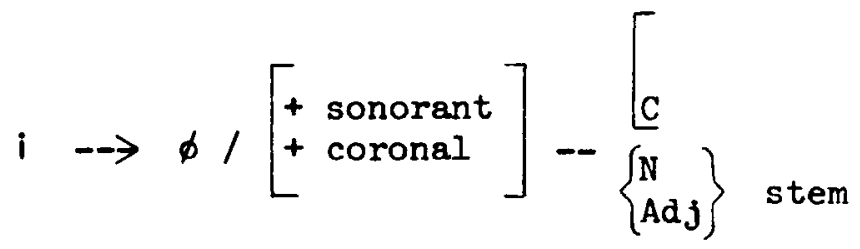

This will take $\mathrm{niC}-$ and $\mathrm{riC}-$ to $\mathrm{nC}-$ and $\mathrm{rC}$ - respectively, both otherwise absent from the language. We can now reformulate the class 5 voicing rule as one of assimilation:

(26) Rule 10. Voicing assimilation:

$$
[- \text { cont }] \rightarrow[+ \text { voice }] /\left[\begin{array}{l}
+ \text { voice } \\
- \text { nasal }
\end{array}\right]-
$$

Now we need to delete / $/$ / immediately before a consonant. Again, we can extend a rule that was needed elsewhere; the rule Nasal deletion can be ordered after (10) and restated as:

(27) Rule 11. Cluster simplification:

$$
\left[\begin{array}{l}
+ \text { sonorant } \\
+ \text { anterior }
\end{array}\right] \rightarrow \phi /-C
$$

With this rule we have completed in rough outline a more or less standard phonological account of the relationship between the noun and agreement series. We showed first that synchronic rules of some sort must apply to generate the stem-initial consonants of class 9 and 10 , and 


$\begin{array}{ll}\text { (23c) } n i+\text { pami } & \text { (broad; adj.) } \\ \varnothing & i \text {-deletion } \\ m & \text { nasal assimilation } \\ \frac{h}{\text { mhami }} & \text { murmur }\end{array}$

In class 10, in the agreement environments rules (1) and (9) will remove the $/ \mathrm{n} /$ in $/ \mathrm{dzini} /$ and will then shorten the long $/ 1 \mathrm{i} /$. Before nouns and adjectives on the other hand rule (2) will apply, removing the second /i/ of /dzini/ thus placing/n/ next to stem-initial consonants. All subsequent rules will apply as for class 9.

The postulated $d z i-$ will remain before the stem, yielding forms like *dzinyoka, *dzihuku. It is interesting to note that while such plurals are generally unacceptable, there are two stems that do form their plurals in that way. In class 9 there is the singular imba 'house'; in class 10, dzimba 'houses'. There is a class 11 noun rumbo 'song', ana a corresponding class 10 plural, dzimbo 'songs'.5 Our rules correctly generate these forms. But we must suppose that there is a further rule deleting that part of the prefix before all other noun and adjective stems. The existence of such a general deletion rule is suspicious -- but the two exceptional items, along with the satisfactory operation of the rest of our rules may be thought to provide some justification for generating the full form and later removing part of it. We can simply assume that there is a rule of dzi-deletion.

We still have to deal with class 5 . In the agreement series, the prefix is ri-. Let us assume that this is the general form of the prefix

SFortune [1955: 90] also notes a rather special use of the full class 10 prefix $d z i+$ nasalization with class 9 nouns in "secondary function", as in e.g. dzimhandara ('girls' -- disparaging them). For a general discussion of this usage see Fortune. I have not been able to get much agreement among informants on this particular secondary usage. Note that the examples in the text have stem-initial vowels. The nasal(ized) consonants probably do not arise by rule but are basic stem consonants. The nasal prefix (if any) then has no effect at all on the stem -imbo. 
quite spurious. The fact that none are independently motivated as presentday Shona rules means that they have scarcely any explanatory power.

A second objection is that rule (2) as a synchronic rule is really little more than a trick. It makes no mention at all of the concord classes in which it applies, but appears to be a perfectly ordinary rule of phonology relevant to certain very general, structurally defined contexts. Yet, only stems with class 5, 9 or 10 prefixes can possibly meet the description of its domain, while the fact that it results in two different series of sound changes in the initial consonants of such forms is represented as a chance result. That seems quite wrong. Unless we have other good evidence to the contrary, we should accept the superficial evidence provided directly by the language: the two distinct series of sound changes (or whatever they are) in present-day shona depend not upon the presence of initial $/ \mathrm{n} /$ or $/ \mathrm{r} /$ in the prefix, but on the class features of 5 or 9/10. We shall shortly return to this point, but first let us consider some other objections to the rules.

A third, minor, problem concerns rules (1) and (8) (= (11)), two rules deleting nasals. The first removes all prefix nasals when they don't occur before a noun or an adjective; the second has the effect of removing the nasal of class $9 / 10$ before a noun or adjective. In other words, it removes a nasal left just long enough to condition the assimilations etc. that realize the $9 / 10$ prefix before nouns and adjectives, and then it, too, disappears. It has recently been argued (e.g. by Brame [1970]) that identical or similar rules must sometimes apply at a number of points in a grammar; but the presence of two rules related in this manner in a set of such narrow relevance and little motivation must be regarded as suspicious. The rules cannot, of course, be combined, since the difference between the non-noun prefixes $i-/ d z i-$ and the corresponding process of nasalization before nouns is "explained" by the ordering. The possibility of generalizing (8) to (11) does not, of course, increase significantly the credibility of having a second rule that deletes the previously protected nasal -- and the generalization is not strongly motivated. 
there is abundant evidence for this, as well as for the synchronic nature of the voicing rule of class 5. We then sketched a set of rules which would generate virtually all the forms of both series. These rules are on the whole quite unexceptionable. They seem to be, at first sight, no more than a rather dull set of not very tightly structured and relatively unmotivated phonological rules. Every one of them could probably be found more or less as it stands or in more complex form in some existing generative grammar. In fact there is no question but that several of them do occur as synchronic phonological rules in languages closely related to Shona. The processes of nasalization and voicing are obviously very natural phonological processes involving assimilation to $/ \mathrm{n} /$ and $/ \mathrm{r} /$ respectively. So what is wrong with our account?

There is no doubt in my mind that it is a totally misguided treatment of the relationship between the two series of concords even though it superficially mirrors what is probably a partially correct account of what happened historically. I should like to show that it is wrong, that it should probably be excluded in principle, and that there is in any case in this instance a far better account available of the synchronic facts, which has at least some explanatory value.

First, some objections to the rules sketched above. Perhaps the most obvious is that none of them operate synchronically in Shona beyond the particular phenomena we are trying to explain. Because of the effect of rule (2) (which is in itself a perfectly harmless kind of rule), most of the other rules can be formulated in quite general terms. Rule (2) creates phonological sequences which don't otherwise occur in the language, so very little environment has to be given in subsequent rules in order to make them apply to just the right form. Yet there is absolutely no evidence that those rules apply elsewhere in the synchronic grammar of Shona (whatever the case in related languages like $X h o s a^{6}$ ) and their apparent generality is

${ }^{6}$ I should like to thank Erhard Voeltz for Xhosa examples which (had I needed it) would have convinced me that a generalized form of this rule is a synchronic $P-r u l e$ in that language. The reader must forgive me for assuming that while there are many universal aspects of language structure, the existence of specific P-rules in a grammar must be argued afresh for each language. 
on the complete separation of "levels". 7 Numerous examples could be cited of rules which have to make use of non-phonological information. The English stress rules are an obvious example (Chomsky and Halle [1968]). Kuroda [1967] suggests a number for Yawelmani; so does Kisseberth [1970]. Such rules seem to be at least as well motivated as many rules which refer only to phonological features.

So there is, at present, no way of excluding from the phonology a rule like ( 1 ) which has absolutely no phonological content. It is of course very easy, and probably quite correct, to modify present theory so as to prohibit $P$-rules that produce a deletion or feature change in an environment defined solely in non-phonological terms. Let us assume that a principle to that effect is incorporated into the theory. What are its effects?

We shall have to find some other, general way of accounting for the relationship between the noun and agreement prefixes in $1,3,4,6$ and for the postulated underlying forms for 5,9 and 10.

First, however, let us consider the relevance of the proposal to a rule like (2a):

(28) Rule 2a. Vowel-deletion:

$$
i \rightarrow \phi /\left[\begin{array}{l}
+ \text { sonorant } \\
+ \text { coronal }
\end{array}\right]-\left\{\begin{array}{l}
\mathrm{C} \\
\text { Adj }
\end{array}\right\} \text { stem }
$$

This rule would escape our prohibition as it stands. The rule makes reference to some obviously phonological information. Yet, as we observed earlier, Vowel-deletion seems to be little more than a trick which makes use of the fact that only in the prefixes of classes 5,9 and 10 does $/ \mathrm{i} /$ appear in the stated, largely phonological environment. In other words, we could substitute for (2a) a rule of roughly the following form -assuming (as I believe we must) that concordial class features are easily

\footnotetext{
${ }^{7}$ For example by Chomsky [1964].
} 
A fourth objection depends crucially upon some observations made by Hale [1970]. I shall not repeat Hale's evidence. Suffice it to say that he has argued that there is a general constraint on underlying structures which prevents them from violating the "canonical form" of the morphemes of a language. It is hard to make this idea precise, partly because the notion of "canonical form" is not really well-defined, so any objection resting on these claims cannot be allowed too much weight. Nevertheless it is worth pointing out that Hale's constraint would exclude the postulated form for the basic class 10 prefix / dzini/ since no current Shona noun class or concord prefix is disyllabic at the surface. Most have a mono-syllabic form, while even apart from classes 5,9 and 10 there is a small class of nouns (( $1 a)$ : mainly kinship terms) which have no segmental prefix. To set up an underlying prefix/dzini/ would therefore violate Hale's suggested constraint, although either a zero prefix or a monosyllabic one would not.

The most significant of these internal objections is probably the second, and I want to develop a little further the point that by using these rules we have represented as phonological a process which is in fact primarily morphological in nature. Take the deletion of the nasal in classes 1, 3, 4, 6 and (by hypothesis) 9 and 10. Rule (1) deletes nasals occurring in a prefix before anything but a noun or adjective. No phonological features at all are mentioned in the environment of the rule. The only purely phonological mules that it interacts with in any way are those which follow in the set given above -- and they simply fill in the details of the class $9 / 10$ prefix as realized before nouns and adjectives. There is, in other words, no independent empirical reason for claiming that the difference between, say, mu and $u$ has anything to do with the sound pattern of Shona.

of course we need to be able to mention aspects of the syntax, morphological features and so on as part of the environment of phonological rules: some must be restricted to nouns, others to verbs and so on. Pre-generative phonologists have been rightly criticized for arbitrarily excluding grammatical information from phonological rules by insisting, 


\section{The two-prefix solution}

Up to now we have been assuming that there is a single prefix available for each noun class, which starts out before appropriate noun stems and is presumably spread to other items in the noun phrase, such as demonstratives, possessives, and perhaps adjectives and relative clauses, and to the verb with which a subject noun agrees. We have, in other words, assumed that a sentence like vanhu vose vanofa, 'all people die', starts out in deep structure as something like:

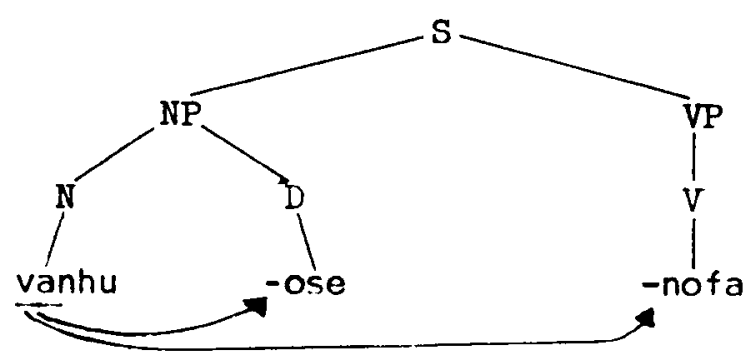

The morpheme (or formative) va- is simply spread as shown. Or, to follow Givón's [1969] more sophisticated proposal, the noun munhu/vanhu 'person'/ 'people' has a set of appropriate features associated with it in the lexicon and in deep structure and these are spread onto other items. Late lexical rules insert the appropriate prefix (va- in this case) before elements bearing the relevant features. For our present purposes the two proposals need not be distinguished since both involve the assumption that only one basic phonological form is involved for each class prefix.

This is a very natural assumption. It has formed the basis of much of generative phonology. Unless we permit pairs like 'decide' and 'decision' to incorporate a single phonologically invariant morpheme, there is no basis for many of the rules of Sound Pattern of English. Generative phonology is characterized, in fact, by a reluctance to posit distinct allomorphs which are at all related in sound. Clearly there are no sound rules in English which will relate 'go' and 'went', so those must be regarded as suppletive allomorphs. But not 'sit' - 'sat', any more than 'receive' 'reception', or 'satisfy' - 'satisfaction' -- pairs which are all to be accounted for by regular sound rules [SPE, p. 201]. 
available to the phonology: 8

(29) Rule 2a'. Vowel-deletion:

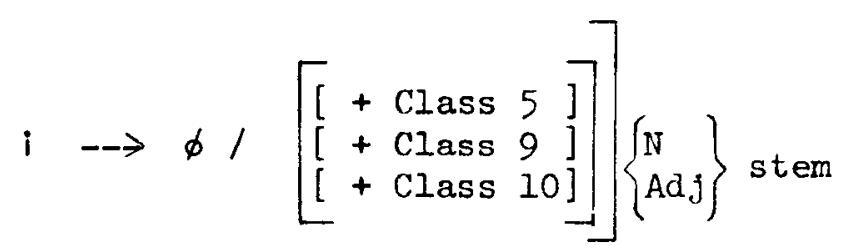

The precise form of the rule is unimportant. What matters is that it makes use of no phonological features yet achieves precisely the same effect as rule (2a). Perhaps we should extend the original principle:

\section{The anti-cheating law:}

No P-rule may be included in the phonological component

which makes exclusive use of a non-phonological environment or is equivalent in effect to such a rule.

To include such a general principle in linguistic theory incorporates, I suppose, the clain that a language learner will prefer to make use of syntactic/morphological information rather than phonological, if possible.

Such a claim seems quite plausible, though I don't want to pursue it until later. 9 For whether or not there is a general principle of grammar which will exclude rules like $(1)$ and $(2 a)$, we have seen that those particular rules are highly suspect and lack independent motivation. I shall now show that there is an alternative account of the phenomena which looks more promising.

${ }^{8}$ It would, of course, be possible to avoid all the separate "phonological" rules discussed earlier, to set up zero prefixes (or delete the entire prefixes) before nouns and adjectives in classes 5, 9 and 10, and to use class features to initiate directly the stem-initial changes of voicing and nasalization. This would avoid the specific objections made earlier to the proposed set of phonological rules. Nevertheless such a solution would remain totally unexplanatory. Fortunately it is excluded in principle by the prohibition just suggested.

It will be possible to discuss this principle more meaningfully once an alternative framework is sketched for the Shona data, and we shall return to consider it in some detail at the end of the paper. 
meaning of the whole word is affected by the prefix (as we can see from contrasting words like 'appear', 'attach' and 'deceive') yet somewhat idiosyncratically and not in such a way that the prefixed morpheme can be assigned a clear independent meaning.

However there is a way of using noun prefixes which focuses unambiguously on their semantic content and shows clearly that they differ in this respect from the concordial series.

As in most Bantu languages, noun prefixes can be used in "secondary function" (Fortune [1955: 54]). In this usage a prefix which is not normally associated with some stem is used before it, either alone or in addition to a normal prefix. Clear semantic change results. For example, the word mwana (i.e. mu-ana) means 'child'; a prefix used only in secondary function is ka- meaning 'small', and a small child may be either kamwana or kana. Lacking the "human" prefix mu-, the latter is rather more general in meaning. Fortune glosses it 'small offspring' [p. 58]. All class prefixes may be used in this way. The class 7 chihas as one of its meanings in secondary function the notion 'short, stumpy'. So the class 3 word muti 'tree' may take the class 7 prefix in secondary function, yielding chimuti 'short stumpy tree'. It is often not necessary to include the basic, customary prefix in order to retain the meaning of the original word. Sometimes, in fact, it is necessary to discard it. For example, the word musikana 'girl' may be modified by secondary use of the class 5 prefix (which before an /s/ is unrealized) yielding sikana 'big girl'. A good deal is known about the environments in which the original prefix is lost, the meaning relations, and so on, but the area is still in need of a good deal of study.

How to represent these relations in a theory of linguistic structure is not yet clear. It may seem that the prefixes should be segmentalized out transformationally, using features of the noun stem after the manner suggested by Postal [1966] for the English determiners and pronouns. Givón [1969] in effect chooses such a system, entering all prefixes from the lexicon at a very late stage and representing them only in the form of semantic and syntactic features on nouns in the underlying structure. 
Now it must be perfectly obvious that the class 2 noun prefix vaand the class 2 prefix used in concord with it (i.e. va-) are very closely related; even more so perhaps, than the basic stem in a pair like the English 'receive' - 'reception', where there may be no simple relationship in meaning between the two words. And the prefixes of the noun and agreement series are phonologically identical for most classes. So it would certainly be right, other things being equal, to derive the aberrant forms from the other series by phonological rules, positing a single basic set of prefixes.

However, it is worth noting that if there are really two distinct yet related series of prefixes this will not be the first case in generative phonology where an obvious, "phonological" solution seems to be wrong. Hale [1971] has shown that there are good reasons for setting up a whole series of allomorphs for the Maori passive, and has extended his argument to other cases. Stampe 10 has argued against a "phonological" solution for the English strong verbs.

Now notice that the noun prefix is not necessarily "the same morpheme" as the concordial prefix related to it. Indeed there are some rather good reasons for thinking that they may be distinct -- quite apart from the fact that they are not always phonologically identical. For one thing, the noun prefix bears at least some elements of meaning. As a classificatory device each prefix might be regarded as the realization of certain aspects of the inherent meaning of its noun. (See (3) above). For example, the word mukadzi, in class 1, means 'woman'. There is also a class 9 noun hadzi meaning 'female animal'. The only difference in form is the class difference, and the difference in class "meaning" between $I$ and 9 amounts in effect to the observed semantic difference between these two words. With most nouns, the semantic relevance of the characteristic prefix is less clear: it generally seems to contribute to the meaning of the whole construct much as the English prefixes 'dis-', 'de-' and 're-' do in 'disappear', 'detach', and 'receive'. To varying degrees the

10 According to Jim Heringer [personal communication]. 
to cover the normal case, as when the noun muti selects a class 3 demonstrative, in muti uyu, we shall have to assume that even a basic noun prefix is entered before any concoraial prefix is entered.

Then mu- will be the left-most noun prefix -- since it will be the only one -- and will be available to spread the prefixes onto the other items.

I claimed above that the simplest account of this process would be a notational variant of the version I have just given. Thus, while it would be possible to reformulate this account using, a hierarchical arrangement of features within the noun, to do so would be no different from what we have suggested.

Thus, pace Givón [1969] -- but following Gregerson [1967] -- we need to have a rule spreading concord from a noun prefix, roughly thus:

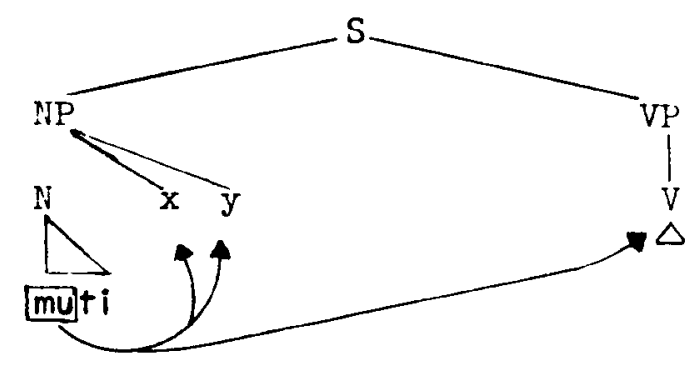

Instead of:

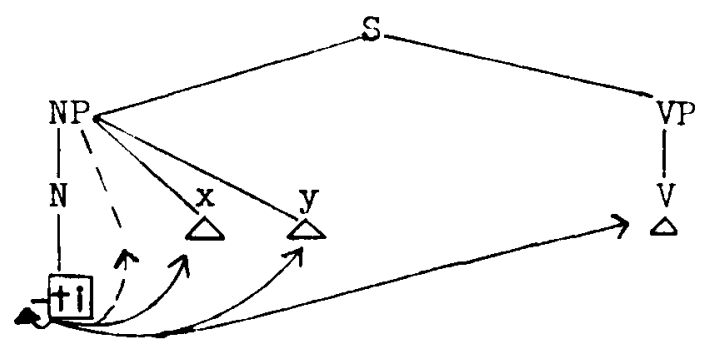

We could, of course, assume that in a normal case like muti the noun prefix mu- was attached to the noun by the same transformational process that attached the concord prefix $u$ - to other constituents of the noun phrase and to the verbs as in muti uyu uzofa 'This tree will die'. However, even if we did that, we should still have to introduce a special 
That may be correct, though Givón's system is not adequately structured to account naturally for the differences between e.g. kamwana and kana and at the same time to explain the existence of only sikana, on the one hand and only chimuti (not *chiti) on the other.

One significant fact which must be handled by any account of the prefixes is this: when a prefix is added to an existing prefix then it is only the ieft-most one that controls concord.l l so we get chimuti ichi 'this short tree', not *chimuti uyu. Hence, if the noun prefixes are to be segmentalized on the basis of features of the noun stem, there are three consequences: (1) the normal "class" features associated with that stem must first segmentalize to mu-, and (2) the added semantic (and perhaps syntactic) force apparently carried by the secondary prefix must be assigned to the noun, and (3) these added features must segmentalize, and they alone are permitted to induce concordial agreement. It is therefore necessary to ensure, for example, that while both chi- and -mucan appear (in that order) on $-+i$, any other elements in concord with chimuti will have the prefix chi-. The most important point is the fact that chi-, a meaning-bearing element entirely un-related to the stem -ti (or whatever corresponds to chi- at the appropriate stage in a derivation) controls the concord.

The most economical account of these facts will, as far as I can see, be a notational variant of a theory in which the left-most prefix of a string of noun prefixes determines the form of all the non-noun prefixes in concordial dependence on that noun. ${ }^{12}$ If we generalize such an account

1 When one of the locative prefixes pa-, mu, ku- appears, either that prefix or the left-most noun prefix controls concord: pamusha apa or pamusha uyu. There is a meaning difference. The locative prefix appears to be analyzable as either inside or outside the noun phrase with which it is associated. This may well be comparable to the behavior of prepositions in English which may optionally be treated for certain purposes (e.g. question fronting) as part of their object noun phrases.

12 Givón [personal communication] has pointed out that he considers a system of ordered features, which includes some features on the noun stem, to be just such a notational variant. Probably it is. But I see no reason at present for adding the power of ordering to a system of features which is already grossly over-powerful. I see every reason for trying to avoid having to use features if at all possible. 
arguments for adopting it come from its explanatory value when applied to our original problem -- the two series of prefixes.

A moment's reflection will serve to throw considerable doubt on the relevance of our present strategy to an explanation of those facts. For we have suggested only that noun prefixes should be entered directly from the lexicon with the stems. The rest will be handled by a transformational rule -- including the prefixes on adjectives. Yet it is the prefixes on nouns and adjectives that are identical, and they differ from the others. I shall now try to show that far from defeating our proposal, this may actually increase the explanatory value of that hypothesis.

We must consider the details of the system of concord spreading. Both Gregerson [1967] and Givon [1969] have formulated rules. Gregerson proposed the following very general rule:

$$
\begin{aligned}
& A^{*} P-N-X=\Rightarrow A^{*} P-N-A-X \\
& A \text { is the left-most prefix } \\
& P \text { is the noun prefix } \\
& X \text { is a variable, possibly null } \\
& N \text { is a noun stem }
\end{aligned}
$$

This may be represented, still roughly but in less esoteric notation as:

$$
\begin{array}{ccccc}
X & -P & -(P *) & -N-Y \\
1 & 2 & 3 & 4 & 5 \\
1 & 2 & 3 & 4+2 & 5
\end{array} \Rightarrow \Rightarrow
$$

What Gregerson intended his rule to do was to copy the left-most noun prefix once, immediately to the right of the head noun. So from *vanhu - no, the rule would derive vanhu vano 'these people'.

of course a very general rule like Gregerson's is highly desirable. If it really worked, we should be much inclined to accept it even if that meant treating the irregularities in the form of the concord prefixes in a very ad hoc fashion. But it is grossly over-simplified. None of the boxed prefixes below can be generated since they don't fall immediately to the right of the head noun and since only one concordial prefix can be obtained from each head. 
rule into the grammar to enter the -mu- prefix found in chimuti, this time without affecting any of the concordial prefixes. Obviously the most general procedure is to separate the entering of the noun prefix(es) from the process whereby features, prefixes or whatever are spread onto or entered before demonstratives, relative pronouns, verbs and so on.

In fact there is no good reason for supposing that a noun like muti comes out of the lexicon in any other form than precisely that. $1 \mathrm{I}$ If such lexical items are entered into syntactic trees at a level somewhat resembling Chomsky's [1965] deep structure; then just as English words like 'dismay', 'disappointment' and so on enter deep structure as units, so does muti. No matter how the affixal material is stored in the lexicon (and we can safely leave that question quite open) the English words are syntactic units. Likewise Shona words like muti and munhu. In due course I shall show how it is necessary to assume a level much like deep structure in order to capture several imnortant relations which are otherwise lost - - in particular to explain the identity of the noun and adjective series of prefixes, but so far we have only provided one slight argument for separating the noun prefixes from the rest -- by implication regarding, the noun prefixes in all instances as, in some sense, meaning bearing, morphemes present in deep structure, while treating the related concordial prefixes as empty formatives introduced by transformation. Such an analysis is intuitively satisfying -- but not yet well supported. The really strong

13 Something obviously needs to be said at this point about the fact that the plural of muti 'tree' is miti. At the very least, the stem $-t i$ cannot appear in the lexicon associated irrevocably with just one prefix. There must be some way of capturing the fact that each stem is normally associated with two or more prefixes. If number is a syntactic category in Shona, then the plural prefixes (at least) may have to be associated with the stems after confunction reduction. (See Givon [1969] but also Roberts and Wolontis [1972]). Nevertheless, the relationship between a stem and its prefixes appears to be a lexical fact. Both the singular and the plural prefix appropriate to a stem are lexically associated with it either individually or by redundancy rules or in both ways. If there is a second access to the lexicon after conjunction reduction (etc.), this probably needs to do no more than make use of the information already given there concerning the normal association of pairs of sinfular/ plural prefixes. 
by any rule other than the first case of the above, since I know of no serious arguments to the contrary. Likewise, there is no syntactic reason for distinguishing Givon's class of numerals ("two", "three" etc.) from the adjectives.

If we make these adjustments, it is possible to generalize Givon's rule and reformulate it within our framework so that it assigns concordial features (or a prefix -- whichever turns out to be the correct version) to: (a) every other constituent in the noun phrase of the head noun; and (b) to the initial element in a VP following a head noun.

I shall not bother to formulate the new concord rule precisely. It must operate as shown below:

(38a) NP agreement:

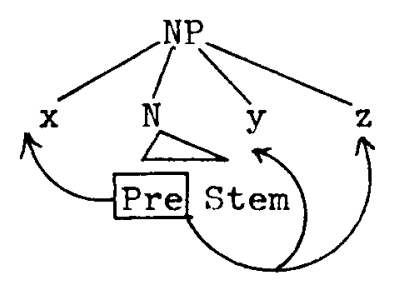

(38b) Verb agreement:

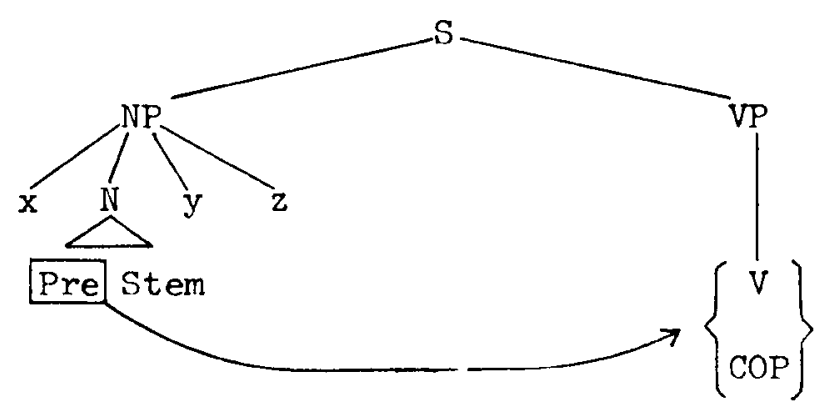

Other things being equal it would be nice to be able to formulate the concordial agreement rules in this way. We should not need to specify the whole set of concordable elements, and could apnarently provide a much simpler structural description for the rule. Furthermore it may well turn out that universal constraints can be put on agreement transformations permitting them to recognize only such grammatical relations as "headmodifier", "subject-verb", "object-verb". Our new rule(s) would be able 

(35a) $\mathrm{N}-\mathrm{X}$ Not generated Gloss $\mathrm{miti}$ yangu ijyi yose 'all those trees of mine' trees mine those all
(35b) miti iyi Jchazowira pasi 'Those trees will fall down' they-will- ...

Givón [1969] gave a more adequate rule. His is in the form of a schema. In this discussion I shall simplify his treatment whenever this will not affect the argument. First he defines the categories of lexical item which can take concord, letting $X$ be such a category:

(36) $X \rightarrow$ (DEM, QUANT, VERB, COP, ADJ, NUM, ORD)

Then he spreads concordial features ${ }^{4}$ (which I shall simply represent as [Class ${ }_{i}$ ] onto all such items in the relevant positions:

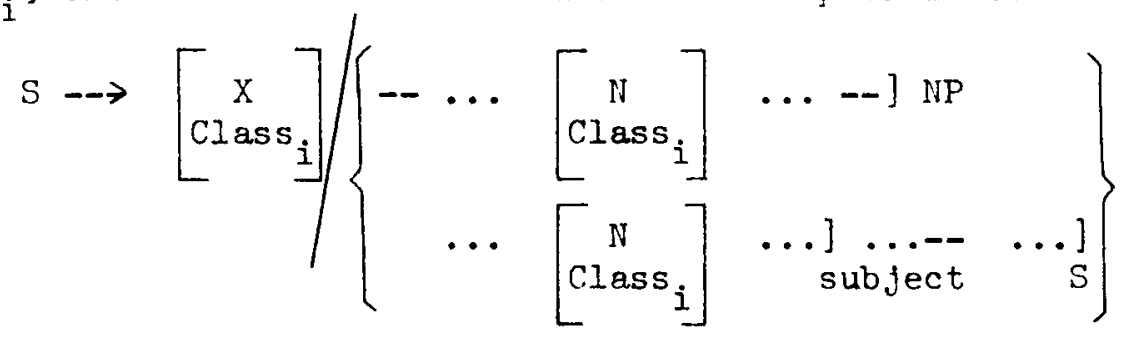

The first case of the schema spreads concord onto demonstratives and quantifiers. All the other categories are assumed by Givón to be somewhere in the predicate at the time that this spreading rule operates so will acquire appropriate features from the operation of the second sub-part. At least in outline, then, the mule achema seems to work. We might find fault with the details, but there seems no doubt that concord must be spread (a) onto certain constituents of NP, and (b) onto certain constituents of VP, and Givon's rule reflects this.

I shall assume without further discussion that Shona ordinals (and possessives -- not mentioned in this connection by Givon) are generated within the noun phrase -- or at any rate need not be assigned concord

14 Givón [1969] ends up spreading various pronominal and referential features, in addition to his concord rules. He does not make his motive for doing so clear enough to be persuasive. 
rather than

(4I)

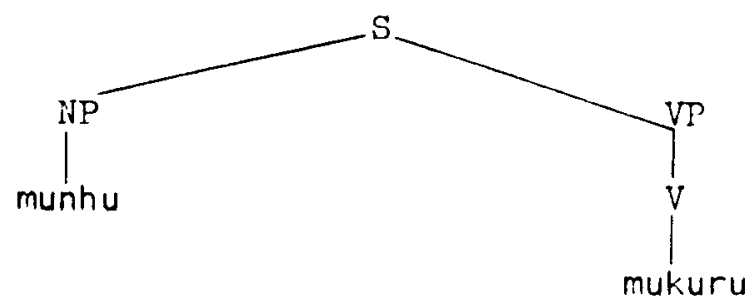

For in all but the positive indicative and relative forms with third person subjects the copula -ri (or some more obvious form of that verb than the high tone indicated in the above examples) has to appear. Thus there are forms like:

(42a) ha a ri mùdiki

neg he be small

'He is not small.'

(42b) a nna ari mùdiki

He past he be small

'He was small.'

Low tones are indicated on the adjective to show that in such constructions we do not find the high tone that occurs when -ri is deleted.

Even if we obtained the adjectival concord for munhu múdiki by using the verbal rule we should need another for all other tenses and for negative sentences, e.g.

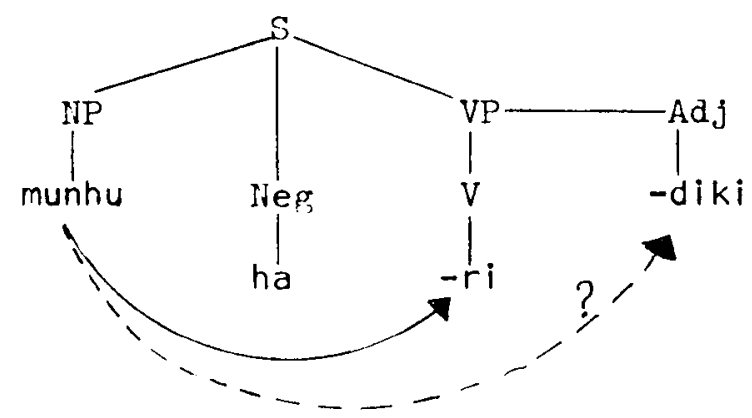

We could, of course, follow Ross's analysis yet further, postulating a noun phrase dominating a sentence out in the predicate after the copula: 
to reflect such constraints while the old one would not. We have not, of course, provided direct evidence for modifying Givón's rule in this way, but have simply suggested that it would be good to try and introduce such a simplification.

There is some apparent counter-evidence. For notice that we have apparently failed, in our new account of the syntax of concord, to assign agreement to predicate adjectives. That this is so may not be obvious. For we find sentences like the following:

(39) munhu múkuru

person big

'The person (is) big.'

No overt copula occurs. In fact it cannot do so: *munhu ari mukuru. Thus it might seem that a predicate adjective works just like a verb in Shona, acquiring concord by the second sub-part of our tentative rule. Gregerson [1967] analyzed adjectives as verbs in Swahili, citing in support Ross's [1969] analysis of Fnglish adjectives; and he used this analysis to avoid a special concord rule for predicate adjectives in Swahili, subsuming, them under his one, very general (and incorrect) schema. See also Voeltz [1.970: 150$] .15$

But there is pretty clear evidence that munhu mukuru ('The person is bif') has a deleted copula. The structure is:

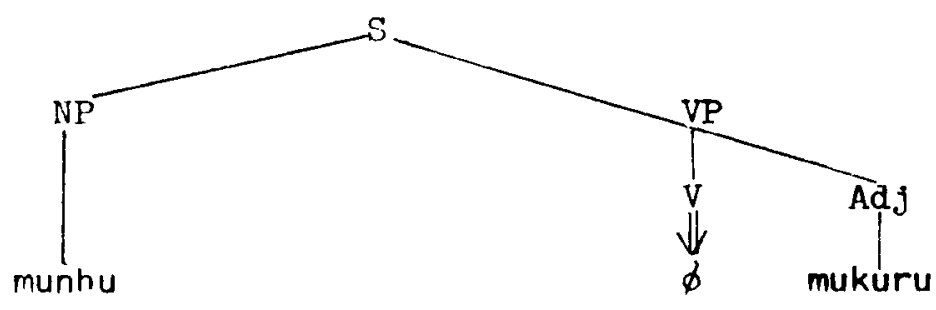

15 Voeltz [personal communication] has indicated that he intended only to imply that the "adjectives" in Xhosa which take secondary (i.e. nonnoun) prefixes are derived from verbs. This was not clear. In any case I rather doubt whether even that class of words, which does not occur in Shona and is not discussed further in my paper, comes from verbs. The concord comes from a relative clause; the words are basjcally nouns used as predicatives, just like the more generally found class of Bantu adjectives. 
Hence we should expect an underlying structure modeled on Ross to be something like

(47)

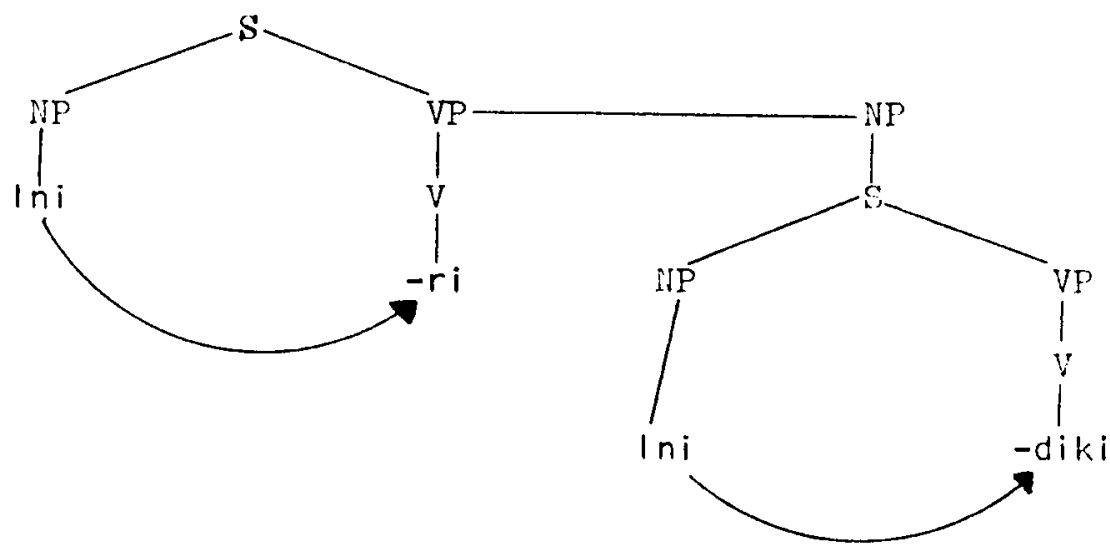

which would generate only the undesirable form snown earlier.

The existence of sentences like ndiri múdiki beside ndira ndona..., while not crucial, must be seen to play a major role in my areument. ${ }^{\text {is }}$ For such examples show very clearly that no matter how the rule of adjective concord is stated it cannot be precisely the same as any other rule spreadinf, agreement. For the adjective rule, alone, must spread class I instead of first and second person agreement. Hence it becomes more profitable to look

${ }^{18}$ Shona is not alone in displaying this phenomenon. It is, in fact, common. 'Thus Sotho possesses forms like Ke mobe 'I am bad (evil)', where the stem -be is an adjective and the syllable -mo- is the noun prefix (INOT the concordial prefix) of class 1 . In contrast, a verbal construction like Ketlile 'I have come' exhibits only the first person concord. Likewise in Xhosa there are adjectival constructions like sibahle 'We are beautiful' which must incorporate the noun prefix, -ba- of class 2 in this instance, and thus contrast with verbal forms like sihamba 'We fo'. Notice that in both Sotho and Xhosa, the overt form of the conula has disappeared, even with first and second person pronouns. Givon [nersonal commuication] has pointed out that in Bemba the relative clause concord for first and second persons in class $1 / 2 \mathrm{e} . g$. né-ì-bomba 'I who work'. He considers this to reduce the force of my argument. However, it must be remembered throughout this naper that my argument forms a coherent whole for Shona, not necessarily for other, even closely related languages. I would not be surprised to find a radically different analvsis to apnly to this small class of words in other Bantu languages. See footnote 33. 
(44)

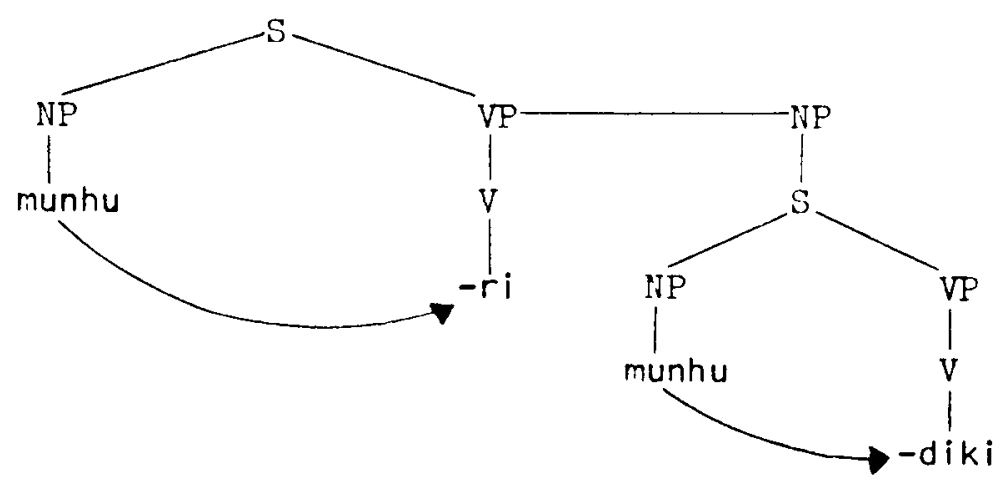

Cyclical operation of the concord rule would obtain the right agreement in this sentence prior to the operation of EQUI to delete the subject of the lower sentence.

That would be wrong for two reasons. In the first place it would force us to yield up all hope of explaining the fact that nouns and adjectives possess prefixes which are alike and differ significantly from the verbal prefix. Any account of concord which can explain that fact is (other things being equal) better than one that can't.16 The second objection is more tangible and, perhaps, more immediately persuasive. It involves predicate adjectives with first and second person subjects, such as:

(45) ndi ri mudiki

I be small

'I am small.'

Observe that in such forms the adjective has a class 1 prefix. A form like *ndiri ndidiki is totally unacceptable, although there is clearly a first person concordial prefix available and used elsewhere, as in ${ }^{17}$ :

Ini $\underset{\text { only }}{\text { ndoga }}$ hdiri mudiki

${ }^{16}$ We could posit a special kind of EQUI which would leave behind (and move onto the adjective) a copy of the noun prefix. If independently motivated, that would explain the similarity between nouns and adjectives. Unfortunately, I find no other evidence for such a rule.

17 The form ini shown under the subject NP is the "absolute pronoun" for the lst person. When it appears it generally has somewhat emphatic force. Nevertheless I shall assume that the underlying form of ndinoenda is *ini -noenda. Then ndi- the subject concord is inserted by transformation and ini is deleted. 
(49)

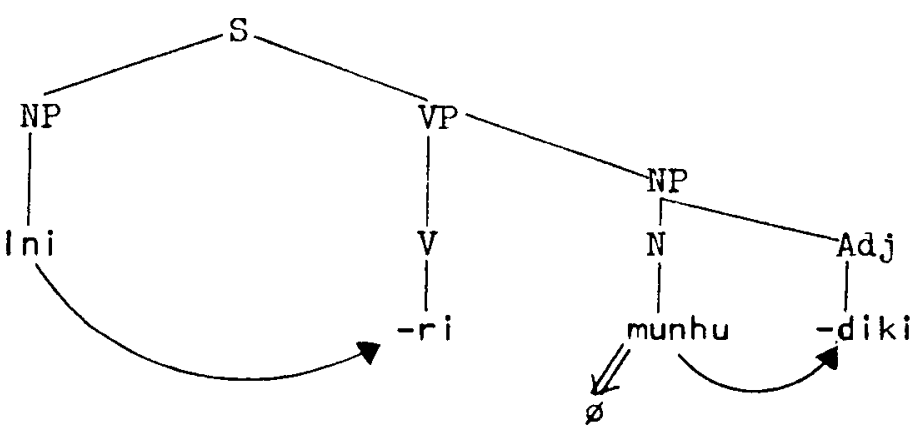

This treatment comes very close to accounting for all the facts. But it is not quite good enough. In the first place, although deletion of an identical head noun in the predicate is a reasonable hypothesis, the required extension is very ad hoc. Moreover, the choice of head, munhu, is entirely arbitrary.

A more serious objection concerns the change in meaning which results from the hypothetical deletion. In English, there is one meaning of 'that elephant is small' which is not synonymous with 'that elephant is a small one'. The reading in question is probably false. Fleas, mice and perhaps even dogs are small in that sense but not elephants. In a comparable fashion 'that singer is good' may be non-synonymous with 'that singer is a good singer'; the former but not the latter may be interpreted as a reference to the singer's moral rectitude. Such facts are well known. They have been used by Vendler [1967] to argue for an adverbial source for one sense of the adjective in 'good singer'; they can equally well argue against deriving all predicate adjectives from within a noun phrase, for it is at least clear that we should not be able to represent the meaning of 'that elephant is small' by deriving it from 'that elephant is a small elephant'.

Shona speakers (predictably) make the same distinction. Informants have reported in particular that ndiri múdiki 'I am small' and ndiri múnhu mudiki 'I am a small person', differ in the expected fashion and hence to derive the former from the latter would fail to give any account of the difference in meaning between them.

Moreover, if we derived all adjectives as modifiers in a noun phrase this would (just as surely as a derivation from verbs) totally fail to 
elsewhere for an account of adjective agreement and to leave the concord spreading rule in the very general form set out above: (a) NP agreement and (b) Verb agreement.

There is a way of accounting for the agreement of predicate adjectives which will handle forms like ndiri múdiki perfectly well. We could derive all adjectives from the attributive form. Thus we should obtain the sentence munhu múkuru ('The person is big') from an underlying form:

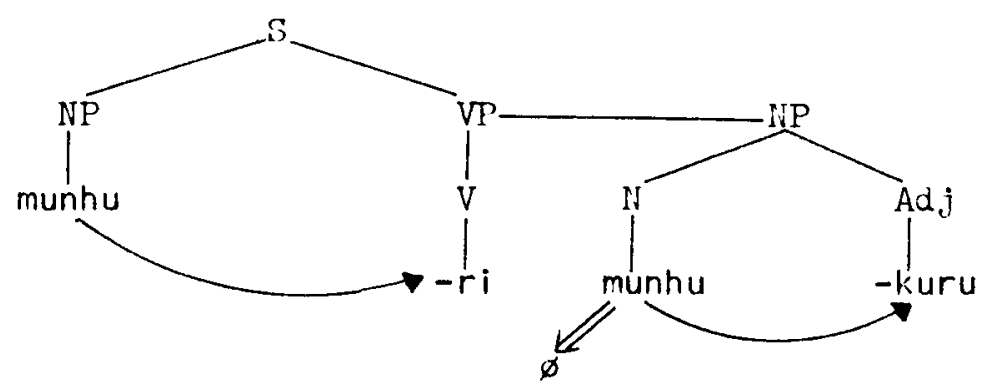

The NP agreement rule would, of course, operate within the predicate noun phrase, producing *munhu ari munhu mukuru $\rightarrow-\rightarrow$ munhu múnhu mukuru. 19 Optionally, the head of the predicate noun phrase would be deleted 20 (in addition to the copula) and a simple rule moving the high tone acquired by múnhu onto múkuru would yield the correct forms. How since we already have separate rules for NP and Verb agreement, we should need to posit a deleted head noun, say munhu in the predicate of the underlying structure of ndiri múkuru, and to permit the rule deleting the identical head noun in the predicate of the previous case to cover the head noun when there is a first or second person subject:

19 This is, of course, a perfectly well-formed sentence -- it means, roughly, 'The person is a big person'.

20 There appears to be a rule in the grammar which deletes the head noun in phrases containing a modifier e.g. Mukuru akaenda 'The big, (person) has gone'. This rule must be rather similar to the one that might be proposed to derive the English sentence 'That book is John's' from 'That (book) is John's book'. 


\section{(v)(a) His recovery is unlikely \\ (b) *His shirt is unlikely}

In Chomsky [1965] such selectional restrictions are taken to be a part of the syntax. McCawley [1968] argued, largely on the basis of sentences like *'My buxom neighbor is virile' that selection was really accomplished in the semantics. Whichever is correct, it seems clear that there is a mechanism which (1) involves at least some semantic rather than purely syntactic machinery, and (2) operates no later than the point of lexical insertion, to characterize sentences like (50)(i.b) - ( v.b) as anomalous. The degree to which those sentences are felt to be syntactically anomalous varies. A speaker might hesitate to call (50)(i.b) ungrammatical yet be willing to admit that (50)(iii.b) is syntactically bad. Without trying to deal in more detail with the problem of sub-categorization, and merely noting these facts, we may pass on to the problem at hand.

Can the concord of predicate adjectives in Shona be handled by the mechanism for capturing selectional restrictions? I think it can. But the theory of selection needs to be broadened. Precisely the same kinds of anomaly result in Shona in sentences comparable to (50)(i) - (v). I shall not bother to illustrate that, since it is predictable on peneral frounds. However, ordinarily there is no constraint on the concordial class of the subject and nredicate noun. We find sentences like:

(51) munhu uyu ínanga

man this doctor

(class 1) (class 9)

'This man is a doctor.'

Hence, if we wish to account for the ungrammaticality of:

(52) *munhu uyu iguru man this big

(class 1) (class 5)

'Ihis man is big.'

by using the selectional apparatus of the frammar, we cannot do so merely by using the existing machinery which apnlies to ordinary nouns. 
explain the special relationshin between noun and adjective prefixes -- we should expect the adjective prefix to be the same as the one on demonstratives, quantifiers and so on. 21

We have now shown that all the obvious alternative derivations fail to explain the fact that nouns and adjectives take the same series of prefixes, and that all those sources introduce additional problems. At the same time we have demonstrated that the adjective concord rule must be quite distinct from the others and should assign the features of a noun class to a nredicate adjective - even when the subject is not third person. We are now in a position to set un a specific counter-proposal which will not be subject to the cbjections raised so far. Above all, it will permit a (partial) explanation of the two series of prefixes. It is proposed that noun-adjective agreement in Shona is obtained not by a transformational rule at all, but by the oneration of selectional restrictions onerating at the point of lexical entry. Shona adjectives are a special kind of noun which appears only in the predicate of a copula and which has to agree in class with the subject of the sentence.

To justify this nroposal, consider first the fact that there are selectional restrictions between a subject and nouns or adjectives after the conula in English:
(i) (a) John is a teacher
(b) *John is a fire
(ii)(a) The gun is a weapon
(b) *The Eun is abstractions
(iii)(a) For John to go now is a pity
(b) *For John to go now is a flower
(iv)(a) Mary is prepnant
(b) *John is pregnant

21 ihe special relationshin between the noun prefix and the nrefix on predicate adjectives might still be accounted for: the prefix of the deleted noun could simply be left behind when the noun was deleted. But I know of no motivation for such a maneouvre. In any case, since attributive adjectives would be basic, and could not come from reduced relatives, such an account could not in nrinciple be extended to cover adjectives within noun phrases. 
and only humans can generally be expected to speak or be addressed and hence to be represented as first or second person. 24

Secondly, the proposal accounts very naturally for the fact that the attributive adjective (as in munhu mùdiki ('a small person')) have, in Shona, precisely the same form as their predicative counterparts save only for the low tone on the prefix. We need only to suppose that all adjectives are ultimately derived from the predicatives, as implied in (2) above. The high tone on a predicative adjective is transferred from the high tone on the subject concord of the copula when that copula is last:

(53) munhu $\frac{a ́ r i}{\not{\not}}$ mùdiki

munhu múdiki

In Shona the only overt mark of relativization involving the subject of an embedded sentence is lowering of the high tone on the subject concord. We find contrasts like the following:

(54a) munhu ánofamba

'The man travels.'

(54b) munhu ànofamba ...

'The man who travels'

In the process of relativization the high tone normally acquired by the predicative form is therefore lost. 25 (It is likely that in fact the

${ }^{24}$ Note that in stories involving animals having the power of speech etc., those animals generally act as class 1.a nouns (see Fortune [1955]) and select class $1 / 2$ concord. Voeltz [personal communication] has advanced a very interesting objection to the present proposal which, I believe, should be accounted for in a similar manner to this. He points out that under my proposal, gender resolution under conjunction reduction (see Voeltz [1971]) would be selectional for adjectives, but transformational for verbs. It is obviously unsatisfactory to propose two distinct methods of resolution which happen to have the same effect: I expect to find that a single semantic mechanism will handle the problem but cannot at present provide details. See, however, Roberts and Wolontis [1972].

${ }^{25}$ Fortune [1955:329] makes the rather confusing claim that "the positive relative (of the copula, $-r i$ )...is not used in the third person with a (noun or adjective) complement, this not being used in the indicative." We have interpreted munhu múkuru 'The person is big' as having a deleted 
Yet recall that the noun class system is at least in part semantic. We need to find some special aspect of the semantics of the class prefixes which would block the insertion of an adjective unless it fell into the same class as its subject noun. If we found that, we could seek to analyze adjectives as:

(1) a special class of nouns which occur in all classes, and are

(2) restricted to insertion in predicate position after the copula, 22 and are

(3) nermitted to enter a syntactic structure only if their class prefix did not clash with that of the subject.

Such a jroposal for the syntax of Shona adjectives clearly requires that we justify (1) and (3), especially the latter. ${ }^{2} 3$ Before we try to do so let us consider what such an analysis will buy us.

First of all, it will permit us (with a little extension) to generate all and only the correct agreement for predicate adjectives. The third part of the proposal has been specifically worded to cover the fact that first and second person pronouns select class 1 adjectives. I shall not discuss that extension further; it seems perfectly natural if the agreement in question is semantically based, since class 1 is the human class

22 This assumption may be wrong. Attributive adjectives are clearly derived from relative clauses in Shona -- whatever is the case in English. (See later in text.) But it is possible that the use of adjectives as sunerficial heads of noun phrases, as in footnote 19 above, arises not by deletion but by direct entry in deep structure. In any case, however, there are similarly restricted predicative nouns in knglish:

(i) *A nity $\left\{\begin{array}{l}\text { happened } \\ \text { was found } \\ \text { became }\end{array}\right\}$ yesterday.

(ii) That is a pity.

2. The justification of both (1) and (3) in fact forms the topic of section (4), Adjectives as a lexical class. It is easy to object to these nroposals in general terms on the grounds that they are "costly" -- but that is like complaining that linguistics is "difficult". Any alternative proposal must systematically explain at least as much as this one. 


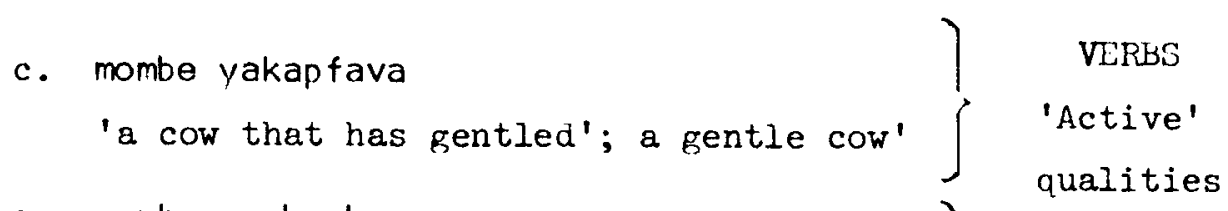

(ii) a. munhu anehasha

'a person who has anger; an angry person'

b. mukomana anamawara

'a boy with impulses; an impulsive rash boy'

c. mukadzi anenzara

'a woman with hunger; a hungry woman'

(iii) a. munhu wokusatenda

'a person of to-not-thank; an ungrateful person'

b. hosha yokuta

'a disease of to-die a deady disease'

c. mazwi okupedzisa

'words of to-finish; final words'

ABSTRACT NOUNS

'Independent'

qualities

POSSTSSIVE +

INFINITIVE

'Potential' or

'Indirect'

qualities

(iv) a. munhu mutete

'a person who is thin; a thin person'

b. muti murefu

'a tree that is tall; a tall tree'

c. rukova rupami

'a river that is broad; a broad river'

ADJECTIVES

'Inactive',

'Dependent'

qualities

In each case, semantically typical examples of the syntactic construction are given. Together they make up virtually all the notions represented in English by adjectives. As can be seen, the syntactic constructions divide roughly along semantic lines. These examples have not been chosen too unfairly but they probably represent the classification as a little more clear-cut than it actually is. 26 Nevertheless it seems quite clear

${ }^{26}$ For example some of the adjectives have related verbs. I am indebted to Earl Stevick for the example kureba 'to be long', probably morphologically related to the adjective refu 'Iong'. There are others like 
copula remains at this stage in the cycle, the high tone being lost from its subject concord. Loss of the copula may occur only on the last cycle, when there is no high tone to transfer to the prefix of the relativized adjective.) The attributive adjective ends up with the correct, low tone on its prefix.

Thirdly, such an analysis will permit us to modify Givón's spreading rule (37), as suggested above, to copy concord only onto the first constituent of VP.

Finally, and most important, this account will permit us to explain in semantic terms why nouns and adjectives take the same prefix series. For we can now permit the concord transformation(s) to enter not a copy of the prefix of the head noun, but the equivalent member of a related series of meaningless formatives. The adjective prefix on the other hand is the same as the noun prefix because it is not entered by concord transformation but is itself the noun prefix, a meaning-bearing element present in deep structure.

\section{Adjectives as a lexical class}

So far we have shown only that this proposal will work -- indeed will provide a more general account of a number of different aspects of the data than any other. Nothing has been said to justify the details of that proposal, in particular the idea that Shona adjectives are a special type of noun with a special selectional relation (of class identity) with their subjects.

Consider the following data showing some of the ways in which English adjectives would be translated into Shona:

(i) a. munhu anorurama

'a person who 'justs'; a just person'

VERBS

b. vanhu vanowadzana

'Active' 'people who befriend each other; friendly qualities
people'

copula; it seems correct and perfectly in harmony with the rest of the languase to interpret munhu mikuru 'the big person' as also possessing a deleted copula. 
It is the last class that interests us most. In contrast with all others, members of this class, represented by the Shona adjectives, typically refer to qualities which are both totally unrelated to activity, and involve no clearly separable emotion or quality which could serve to characterize them, as seems to be the case for set (ii). Among the concepts represented by Shona adjectives are (most of) the cardinal numbers: 'two', 'three' and so on as well as concepts like 'tall'. These, likewise, do not crucially involve either action or easily separable qualities, though they differ in other ways.

Having characterized the class of Shona adjectives in that way we are still unable to provide good independent theoretical reasons for analyzing them as a snecial class of nouns. For linguistic theory today lacks entirely a theory of lexical classes. There are some rather obvious things one can say about the syntactic characteristics of a (superficial) noun or verb. But it is clear that we know next to nothing about the universal semantic and syntactic properties of lexical classes or the inter-relationship between these. Nothing has been done even to define the semantic constraints which must be placed upon the notion "possible lexical class", let alone find out whether these can be derived from other aspects of grammatical theory.

A moment's reflection will serve to demonstrate that there are very definite syntactic constraints -- and that some of these are derivable immediately from the set of possible phrase structure grammars for natural language if lexical items are inserted into Chomsky's level of [1965] deep structure. The semantic constraints are less obvious but no less real. Some rather trivial negative examples should be persuasive.

We should not expect to find a language with four major lexical classes -- among which concepts represented in English by nouns, verbs, adjectives and adverbs were distributed at random, one class including, for example, words corresponding to 'jump', 'big', 'calmly' and 'beetle'. Obviously there must be some kind of semantic basis for every lexical class. But not every semantic notion can provide such a basis. We should be more than surprised to discover a language in which all the lexical items 
that Shona makes more suntactic distinctions than English in this area, and that the suntactic aistinctions possess semantic relevance.

It is very hard to talk precisely about the factors involved in this classification; we are far from having an empirically testable theory within which to analyze them. Nevertheless it may be worth trying to justify more adequately the claim that there is a real semantic classification involved. Starting with the examples of (55)(i), it is certainly possible to identify 'just', 'friendly' and 'gentle' as qualities which are recognized largely through characteristic, habitual itendencies toward certain) kinds of action; it is in this sense that they can be thought of as "astive" qualities. And such properties seen to be typically represented by verbs in Shona.

In contrast, there are independently recognizable emotions or feelings associated with the qualities named (under (ii)) by a relative clause formed on the associative -na 'have' followed by an abstract noun characterizing the emotion. It is these emotions (or phvsical pangs) rather than any actions which overtly at least, Shona uses to refer to the notions captured by the English adjectives 'angry', 'hungry' and imnulsive'.

The third class is harder to characterize. Syntactically it consists of a possessive with an infinitive. A verbal notion is involved, but there is no implication that the possessor noun head of the construction refers to something that actually carries out the activity in question. Often, in fact, the infinitive contains a negative, as is found in the form translating 'ungrateful'; in the other two examples, corresponding to 'deadly' and 'final', there is no question of the disease or the words dying or ending -- something else may, or may tend to.

kunamha 'to be wide' which are not related to an adjective. It is not yet clear how the grammar whould deal with such cases but in general it seems that the 'adjectival' use of such verbs does, as would be predicted by this analysis, involve a notion of activity or process. Thus kupamha which seems to mean primarily 'to be spread out', rather than simply 'wide' is closely related to verbs meaning 'to divide', 'to separate', etc. 'ihe other example, kureba, appears to be inanplicable to, for example, a piece of string. Hannan [1961] gives as an example of the use of this form, Rebesa nhambwe dzako 'Iengthen your stens' and it would seem that such usage is typical. 
Since we admittedly lack a theoretical framework in which to discuss the issues -- and can scarcely develop one here -- it is best to try and provide only a very general sketch of the semantic relationshio between nouns and Shona adjectives.

Basic, underived nouns like 'cow' seem most typically to define classes of entities linked by the fact that they characteristically possess various persisting properties in common. Derived nouns like 'swimmer' define subclasses which are characterized by more transient properties -- often actions. But we can leave those out of account for the present. For it is clear that such a noun is typically related to a verb, which defines a class solely by reference to one property (or a few linked properties) often having to do with an activity or process only temporarily associated with those entities.

Shona adjectives are like nouns in that they define sets of entities not on the basis of transient activity or change but on the basis of (relatively) persistent properties -- but they differ from most nouns in that the classes which they define are related only by a single more or less primitive property. All cows have much in common but all big things probably have nothing in common beyond the fact that they are big. Yet bigness, like 'cowness' -- and unlike the property of running -- tends to define a class with a fairly constant membership. If this is relevant, it may well thrn out that Shona adjectives can best be regarded as a special class of noun. Yet other factors both syntactic and semantic may cause us to isolate a different, broader class of distinct, non-nominal adjectives in English. The only way to tell is ultimately to work out the details of the interaction between interpretive functions assigned to the members of such classes.

Meanwhile, we can anticipate this result -- since it points the way to an explanation of otherwise unexplained facts -- and observe that since the Shona adjectives define classes which obviously cut right across the basic, stable semantic classification partially realized by the noun class system, and fail to have any effect on the basic classification of any entity to which they apply, it would be quite inappropriate for them to do more than recognize, as it were, the basic classificatory designation of that entity; 
referring to actions, processes, entities, or qualities associated with night as opposed to day or to find that animates as opposed to inanimates formed a single, syntactically and morphologically distinct class.

To characterize lexical classes positively in semantic terms is much more difficult. But even if we cannot yet constrain the notion "noun" semantically we can, on the basis of no more evidence than that just given assume that it is in principle possible to provide such constraints. And we must assume that linguistic theory must eventually yield an adequate semantic cheracterization of lexical classes.

It may be worth pointing out that recent work within generative semantics may well have obscured the importance of developing such a theory. For if lexical items are supposed to enter syntactic structures at relatively late stages in a derivation, 7 stages at which semantics has no direct relevance, there is no special reason to expect significant semantic relationshins to emerge from a study of lexical classes. Indeed, that such relationships exist constitutes something of a problem for generative semantics. It is frequently assumed or argued by generative semanticists, moreover, that nouns, verbs, adjectives, adverbs and quantifiers should all be derived from similar predicates at the only semantically relevant level allowed in that framework: underlying P-markers of the base. Hence even at that level there is no clear basis for the emergence of semantically and syntactically differentiated lexical classes at the various points of lexical insertion. llot that it is impossible to represent the fact that such classes do energe. But that their emergence is difficult to explain.

If on the other hand we assume that (I) there is a semantically relevant level at which lexical insertion takes place, and (2) each lexical class nlays a characteristic role in the semantic processes or relations at that level, then we have the basis for an explanation of the general semantic constraints on lexical classes and, more particularly relevant to our present concerns, an expianation of Shona adjectival concora. In so far as such an explanation is forthcoming it will provide prima facie justification for positinf, such a level.

2\%ee HcCawley [1968b]. 
For if nouns and "adjectives" turn out to be in effect a single major class in Shona we could actually simplify those rules and attribute to that fact the similarity in the application of the rules to both sub-classes of nouns. To account for the data in that way, however, would still be to describe what we could explain, and would crucially fail to represent the fact that the difference in prefix form depends, as we can now see clearly, on whether the prefix is entered from the lexicon with its stem, or is spread by transformation. Coupled with the objections listed earlier this suggests very strongly that a derivation by phonological rules from a single series of prefixes is wrong.

How then, are we to capture the relationships between the two series? The most likely solution seems to be in the following direction. The power of that part of the phonological component which is directly associated with the lexicon must be increased somewhat so that morpheme-structure type conditions (Stanley [1968]) are permitted to:

(a) recognize different "declensional" classes such as the noun classes; and

(b) apply after the rules combining the morphemes of a basic word; and

(c) hence to capture relationships holding between different basic forms of a morpheme in conformity with any special morphological conditions.

Thus we can suppose that a stem like -pfeni'29 'baboon' has TWO basic shapes -pfeni and -bveni. There is a structure condition:

(56) $\left[\begin{array}{l}\text { Class } 5 \\ \text { Prefix }\end{array}\right]+\left[\begin{array}{l}\downarrow-\text { continuant }] \\ {[+ \text { voice }]}\end{array}\right.$

This will ensure that only the second form is incorporated in a word with a class 5 prefix. We then define a convention permitting only the other

${ }^{29}$ I am assuming that by by, $R^{f}$, etc. are not clusters but affricates. There is no good reason to think otherwise. This assumption, however, is not important to my argument. 
hence the selectional agreement in terms of noun class between a predicate adjective and the head of the subject INP. Then, the fact that adjective prefixes are just like noun prefixes turns out to be a direct consequence of the semantic properties of adjectives: they are nouns that involve no essential classification.

That we are able to envisage an explanation at such a deep level of what would otherwise be a totally mysterious, superficial relationship between noun and adjective prefixes provides very strong grounds indeed for thinking that our analyses are basically correct and provides considerable impetus to efforts to develop a theory within which they can be adequately expressed. Notice that the relationship between noun and adjective prefixes is not an isolated fact about Shona. Although we have arawn our examples almost entirely from that language the word "Bantu" in the title is advisedly chosen. The details vary considerably but in very many Bantu languages there is a close relationship between nouns and a small closed class of adjectives. It remains to be seen whether other languages can provide equally strong support for similar hypotheses. 28

\section{Phonological relations in the lexicon}

The main result is now given, together with a clear program for future investigation. What remains is the nature of an epilogue. Let us return to consider briefly the implications of such an analysis for the phonology of Shona. I implied earlier that we should want to set up two related but distinct series of prefixes in Shona. It may not be clear how our present semantic and syntactic hypotheses strengthen the earlier phonological obiections to the series of rules presented in the first part of the paper.

28 We have not considered how far Ross's [1969] arguments that English adjectives are verbs on the deeper syntactic level might apply equally to Shona adjectives. It is likely that they do. But that should not be considered highly significant in view of the fact that nouns are likewise derived from verbs in generative semantics. The present naper suggests that Ross's data must be interpreted in some other way for Shona (whatever the case in English) since he would be unable to set up an appropriate relationship between the phonological and semantic facts in order to canture significant aspects of the relationship between shona nouns and adjectives. 
us to begin to distinguish formally between "live" and "dead" parts of the synchronic phonology. And, more generally, they enahle us to articulate in more detail our theory of linguistic structure.

It is extremely interesting and relevant to observe that in a great number of the Bantu languages there are "sound changes" of one sort or another associated with the initial consonants of classes 5, 9 and 10.31 The actual form of the relationships varies enormously from language to language. Yet the rules are almost always tied very closely to these or certain other morphological environments -- of which they often serve as the sole marker. There are scarcely any examples in the southern, central and eastern languages known to me of rules originally annlying to these morphological environments which have been generalized. ${ }^{32}$ such a situation is, of course, totally inexplicable in the standard theory but is just what is predicted by a modification along the lines sucgested in this paper. That fact in turn tends, of course, to support the non-phonological analysis pronosed earlier and hence the hypothesis that Shona adjectives form a special class of noun.

\section{Conclusion}

I have presented a number of conclusions here affecting widely different aspects of grammatical theory. None is, on its own, especially well motivated. I have not amassed 25 independent arguments in favor of

${ }^{31}$ For further details see Meinhof [1932] and other Bantu grammars cited here.

${ }^{32}$ Tswana appears to have a rather complex set of active phonological rules some of which apply to initial consonants in nouns of classes 5, 9 and 10 and verbs following either a first person object concord or a reflexive marker. Some of the same rules may well be involved in apparent phonological changes affecting stem final and other consonants when passive, causative, diminutive and locative suffixes are added to verbs and nouns. See Cole [1955] and Fudge [1967]. Especially persistent is a rule which may involve consonant changes before $/ \mathrm{y} /$. The data must, however, be reinterpreted in the light of claims made in the present paner, but if synchronic rules have really been generalized, the contrast between Tswana and Shona may be crucial in developing my nroposal -- in narticular, in discovering the factors necessary for a non-phonolopical restructuring of sound patterns in natural language. 
form to occur elsewhere. Similarly there must be three conditions controlling the form of initial consonants in class $9 / 10$ stems, conditions corresponding to the arrangement in (12), above.

As far as the prefixes go, it seems that there must be redundancy rules (roughly of the sort which Chomsky [1970] proposed largely for syntactic purposes) which capture the fact that most related pairs from the two series have precisely the same shape. The absence of the nasals from the concord series will be incorporated in those rules -- rather than the structure conditions -- since here we are dealing with two grammatically related series of formatives, and not two phonologically related forms of a single morpheme. ${ }^{30}$ Class 5,9 and 10 will have no phonologically realized prefixes in the noun series; hence they will not figure in the rules. Whatever such redundancy rules have to be permitted to do, they must not be allowed to make ordered, phonological changes in a sepment.

What is the advantage of such an account over the earlier one? To see that, we must take our extended structure conditions along with the Anticheating law. Together they amount to the claim that "sound changes" which serve solely to realize aspects of the syntax will be associated with particular morphemic environments and will not tend to generalize phonologically. They will not be ordered with respect to each other. And they wi]? be ordered prior to the other, "true" phonological rules. They permit

${ }^{30}$ Notice that the relationship between -bveni and -nfeni is a special, isolated, lexical, phonological relationshin between alternative forms of a single morpheme. On the other hand, the relationship between the noun prefix mu- and the concord prefix $u-$ (or $\varnothing$ and $r i-$ ) is $a$ (non-phonological) relationship between two distinct formatives. Two distinct kinds of redundancy rule are proposed in the text to handle these two kinds of relationships. The reader is referred to Lightner [1965: 54-55] for Russian examples (some involving a kind of ablaut, some not) which he seems to consider unsuited to a purely phonological treatment. It appears to me that Lightner's instinct was right, and that the forms which are not phonologically related cannot be used (as he used them) as evidence for the form of P-rules etc. Some of his examples appear to be related like -nfeni/-bveni; others like $\phi / \mathrm{ri}$. It would be interesting to see if this is so. ( $I$ am indebted to Linda Thomas for these examples.) 


\section{(c) incorporate other lexical redundancy rules linking related morphemes.}

Finally, the paper points to the need for a systematic study of the semantic and syntactic constraints on lexical classes.

\section{REFERFNCES}

Brame, M. 1970. Arabic Phonology: Implications for Phonological Theory and Historical Semitic. Unpublished doctoral dissertation, M.I.T.

Chomsky, N. 1964. "Current issues in linguistic theory", in Structure of Language. Edited by Fodor and J. Katz. Englewood Cliffs, N.J.: Prentice-Hall.

Chomsky, N. 1965. Aspects of the Theory of Syntax. Cambridge, Mass.: M.I.T. Press.

Chomsky, N. 1969. "Remarks on nominalization", in Readings in English Transformational Grammar. Edited by D. Jacobs and P. Rosenbaum. Waltham, Mass.: Ginn.

Chomsky, N. and M. Halle. 1968. The Sound Pattern of English. New York: Harper and Row.

Cole, D. 1955. An Introduction to Tswana Grammar. London: Longmans.

Fortune, G. 1955. An Analytical Grammar of Shona. London: Longmans.

Fudge, E. 1967. "The nature of phonological primes", Journal of Linguistics 3.1 .

Givón, T. 1969. Studies in Chibemba and Bantu Grammar. Unpublished doctoral dissertation, University of California, Los Angeles.

Gregerson, E. 1967. Prefix and Pronoun in Bantu. I.J.A.L., Memoir 21 , Supplement to I.J.A.L., 33.3.

llale, K. 1971. "On non-uniqueness in linguistic descriptions". Paper read at the University of Massachusetts, Amherst.

Hannan, M. 1961. Standard Shona Dictionary. London: Macmillan.

Heny, F. Forthcoming. "Focus, interrogatives and relative clauses in Bali, Mungaka and other languages". Unpublished, University of Massachusetts. (Revised version of a paper given at the 1971 conference on African languages, University of California, Los Angeles)

Jordan, A. 1967. "The adjective in the Nguni languages of Southern Africa with special reference to Xhosa", Journal of African Languages 6.2 . 
any one proposal. (And time alone is not responsible for that failure.) Instead, I have shown how various conclusions which emerge independently in a rather tenuous fashion combine to form a theoretical network which alone seems capable of supporting a very simple, deep explanation (itself still unfortunately loosely formulated) of an otherwise altogether mysterious irregularity in Bantu concord. It is this fabric as a whole, incorporating as it does the promise of an interesting explanation, which most strongly justifies each of the separate conclusions. For convenience I list here what seem to me to be the most significant of these results:

(1) Shona "adjectives" are in fact a special class of noun.

(2) The agreement of "adjective" prefixes with a head noun is handled by selection, not a concord spreading transformation. Only verbs, demonstratives, etc. have concord spread onto them.

(3) Lexical insertion (of nouns and "adjectives") in Shona takes place at a point where semantic considerations are relevant. (There is no narticular reason to distinguish this from Chomsky's deep structure.)

(4) Phonological theory must be extended to

(a) ban ordered P-rules which in effect use purely non-phonological contexts to delete ${ }^{33}$ segments or change features.

(b) permit structure conditions to apply beyond a single morpheme.

${ }^{33} \mathrm{I}$ intentionally permit phonological rules to add entire segments. There appear to be numerous cases of reduplication occurring in purely morphological environments as the sole surface representation of nominalization, intensification etc. In some cases reduplication probably has to follow true phonological rules. The mechanism involved forms an important subject for further study in the light of present proposals. Notice, however, that at least in the case of reduplication there is seldom any reason for thinking that phonological elements themselves nlay any crucial role in that process itself. In the simplest case, the rules just generate fresh copies of existing segments or, more properly, syllables. Any changes that are introduced may well result always from additional rules obeying our proposed constraint. 
FOCUS AND RELATIVIZATION: THE CASE OF KIHUNG'AN 1

\author{
Alexis Takizala \\ Department of Linguistics \\ University of California, San Diego
}

\title{
1. Introduction
}

In recent years two approaches to the analysis of stress-focus constructions in English have emerged. These two approaches coincide with the two approaches to deep structure in Transformational Linguistics. For example, consider the sentences:

(1) John bought a chair

(2) John bought a chair

(3) John bought a chair

While sentence (I) is neutral, (2) and (3) are semantically more complex, and may be paraphrased by (4) and (5), respectively:

(4) The thing that John bought is a chair

(5) The person who bought a chair is John

In other words, stress-focused sentences involve presupposed sentences which may be given in the form of relative clauses, as in (4), (5) above. For sentences (2) and (3), the corresponding presuppositions are, respectively:

(6) John bought something

(7) Someone bought a chair

Given its presupposition, the stress-focused sentence supplies -- in its predicate -- the identity of the unidentified constituent, i.e. 'chair' in (2), (4) and 'John' in (3), (5).

${ }^{1}$ Kihung'an (pronounced [kihùnàn]) is a Bantu language spoken in southwestern Congo (Kinshasa). I will use the tonal markings / ', ', and ' / to indicate $\mathrm{HIGH}$, LOW and MID tone, respectively. I am greatly indebted to S. Y. Kuroda for his kindness and patience in going over earlier drafts of this paper. I have also benefitted a great deal from comments from Talmy Givón. Neither of them may agree with the analysis presented below, for which -- as well as for inadvertent errors -- I am solely responsible. 
Kisseberth, C. 1970. "On the functional unity of phonolopical rules", Linguistic Inquiry 1.3 .

Kuroda, S. Y. 1967. Yawelmani Phonologr. Cambridge, Mass.: M.I.T. Press.

Lightner, T. 1965. Segmental Phonology of Modern Russian. Unpublished doctoral dissertation, M.I.T.

McCawley, J. 1968a. "The role of semantics in grammar", in Universals in Linguistic Theory. Edited by $\mathrm{E}$. Bach and R. Harms. New York: Holt, Rinehart and Winston.

McCawley, J. 1968b. "Lexical insertion in a transformational grammar without deep structure", in Papers from the Fourth Regional Meeting of the Linguistic Society. Edited by B. Darden, C. J. Bailey and A. Davidson. Chicago: Department of Linguistics, University of Chicago.

Meinhof, C. 1932. Introduction to the Phonology of Bantu Languages. (Transl., N. J. V. Warmelo). Berlin: Dietrich Reimer/Ernst Vosen.

Postal, P. 1966. "On so-called 'pronouns' in English", Georgetown Monograph Series No. 19, pp. 177-206.

Roberts, L. and M. Wolontis. 1972. "Conjunction and concord in Bantu". Paper read at the conference of African Linguistics, Bloomington, April 1972.

Ross, J. R. 1969. "Adjectives as noun phrases", in Modern Studies in English. Edited by D. Reibel and S. Schane. Finglewood Cliffs, N.J.: Prentice-Hall.

Stanley, R. 1968. "Redundancy rules in phonology", Language 43.1.

Vendler, Z. 1967. Linguistics in Philosophy. Ithaca, N.Y.: Cornell University Press.

Voeltz, E. 1970. "Toward the syntax of the ideophone in zulu", in Papers in African Linguistics. Edited by $\mathrm{Ch}-\mathrm{W}$. Kim and H. Stahlke. Edmonton/Chamnaign: Linguistic Research.

Voeltz, E. 1971. "Surface constraints and agreement resolution: some evidence from Xhosa", Studies in African Linguistics 2.1: 37-60.

Whiteley, W. 1966. A Study of Yao Sentences. Oxford: Clarendon. 
(11)
a. an ex-convict with a red shirt
b. With a red shirt
c. a red shirt
d. shirt

Chomsky then concludes that focus must be a property of surface structure, thus purporting to justify the existence of surface interpretation semantic rules.

Since the derivation of stress-focused constructions from cleft or pseudo-cleft sentences remains semantically attractive, it is of interest to see whether languages other than English offer more syntactic evidence to support it. Languages in which both semantic or syntactic parallelisms between focus constructions, cleft or pseudo-cleft and relative clauses are quite numerous. For recent discussion, see Robinson [1972] and Schachter [1971]. ${ }^{3}$ In this paper I will concern myself almost exclusively with Kihung'an, a language in which interesting syntactic features are shared by stress-focus constructions (here manifesting themselves as tone-focus), cleft/pseudo-clefts and relative clauses. Further, I will also show that several of the rules required for deriving focus constructions from pseudo-clefts in Kihung'an have independent justification in the grammar of this language. In addition, I will also show how this treatment may be generalized to WH-questions in Kihung'an, which share the presuppositional structure of cleft and pseudo-cleft.

One may of course argue that this analysis may apply only to Kinung'an and not to English, where comparable syntactic support for the 'relative clause and predicate' analysis does not exist. It seems to me unlikely, however, that given the universal nature of the semantic structure involved, languages should be analyzed differently on purely syntactic grounds. It is also very likely that a language may have had more syntactic evidence to support this semantic parallelism in the past and then lost it, and it is an open question whether a language of this kind has

${ }^{3}$ See also Awobuluyi [1972] for Yoruba, Callender [1971] for Old Egyptian and Langacker [1971] for French. Langacker also argues that WH-questions are structurally related to cleft sentences in French. 
The first approach to the analysis of focus construction corresponds to Generative Semantics and may be found in Postal [1971] or Lakoff [1965]. Both propose deriving stress-focused sentences from their corresponding cleft sentences, which exhibit the very same presuppositional structure. Taking this approach, (2) and (3) above will be derived from, respectively:

(8) It was a chair that John bought

(9) It was John who bought a chair

Since the underlying relation between cleft and pseudo-cleft constructions has been noted (see for example Akmajian [1970]), a variant of this approach may also derive both stress-focus and cleft constructions from pseudoclefts, such as (4) and (5) above. In English this approach has two things going for it. First, it accounts for the correct semantic interpretation in terms of presuppositions. Second, it accounts for the stress, since post-copular predicates in English are stressed under 'normal' intonation, while subject and object nominals are not.

A radically different approach, loosely corresponding to interpretative semantics, has been taken by Chomsky [1968]. He defines the focus as "a phrase containing the intonation center" and the presupposition as "an expression derived by replacing the focus with a variable" [1968: 205]. He offers two objections to the 'relative clause and predicate' approach of Postal and Lakoff. First, that it has no syntactic support but only a semantic justification involving presuppositions. Second, that many cases do not yield to 'relative clause and predicate' analysis without considerable artificiality. For example, for the sentence:

(10) It was an ex-convict with a red shirt that he was warned to look out for

Chomsky points out that either of the expressions in (11) below may be put in stress-focus: ${ }^{2}$

${ }^{2}$ Given Chomsky's definition, one would expect the entire phrase (i.e. 'ex-convict with red shirt') to be the focus in (10), regardless of what constituent bears the stress. Item (11), however, shows that the focus may vary with the 'intonation center' or, in other words, it is identified with it. 
Unlike English, however, Kihung'an provides enough evidence that contrastive sentences involve relative clauses and, therefore, that the syntactic similarity between them and their neutral counterparts is only superficial. Let us first examine the relative clause.

\subsection{Relative clauses in Kihung'an}

Given sentence (1la) above, the following represents an object relative clause derived from it:

$$
\begin{aligned}
& k i+k i \text { a-swiim-in Kipes zoon...6 } \\
& \text { chair pro -buy-past K. yesterday } \\
& \text { 'The chair that Kipese bought yesterday' }
\end{aligned}
$$

The object relative pronoun $k i$ agrees in gender and number with the head noun kit 'chair'.'

Two properties of relative clauses are of particular interest here. The first involves negation. In unembedded sentences the negative particle 10 is used, as in:

$$
\begin{aligned}
& \text { lo i-mween kit } \\
& \text { neg I-saw chair } \\
& \text { 'I didn't see the chair' }
\end{aligned}
$$

${ }^{6}$ As may be seen here, the subject of the embedded clause must be postposed in object relativization. For further discussion of this phenomenon, see Givón [1972b]. Givón, using my data, also argues that the relative pronoun in (14) must be bound to the verbal word, but I see no conclusive evidence why this has to be the case, and have therefore left it free. Unlike other elements attached to the verbal word, the object relative pronoun may be deleted under certain conditions. On the other hand, it may still turn out that Givón's analysis is correct.

7 This is in line with the characteristic grammatical agreement in Bantu, see for example Givón [1972a], Guthrie [1948, 1953], van den Eynde [1969]. The rules require that predicate verbs and adjectives agree with the gender-number of the subject noun (as expressed in its prefix, henceforth $\mathrm{PA}$ ), and that modifiers and pronouns agree with the gender-number of the head noun. In Kihung'an, for example:

$$
\begin{aligned}
& \text { bi }+b i-m i n \text { by-ool bi-beeng bi i-swi im-in zoon bi-bir-ir } \\
& \text { chairs PA-my PA-red pro I-buy-past yesterday PA-get-lost-past } \\
& \text { 'Wy two red chairs that I bought yesterday got lost' }
\end{aligned}
$$


thus changed in such a fundamental way, from a stage in which such deep semantic facts were represented in the Deep Structure, to a stage in which they are determined by surface interpretation rules. The structure of WH-questions in Kihung'an seems to be undergoing such a change right now.

One may also argue that the 'relative clause and predicate' analysis must be wrong, since it derives three surface constructions from one underlying representation. This type of an argument is best countered by asserting that when several surface constructions share some (or most) of their semantic structure, they do not necessarily share all of it. This is particularly true at the level of topic, which is the most likely level where stress-focus, cleft and pseudo-cleft differ from each other semantically (for further discussion see Shopen [1972]).

2. Tone-focus in Kihung'an

Sentences (11a), (12) and (13) below are comparable to the English sentences (1), (2) and (3) above:

(11a) Kipès ká-swîm-in kît zòòn ${ }^{4}$

Kipese -buy-past chair yesterday

'Kipese bought a chair yesterday'

(12) Kipès ká-swî́m-ín kît zóónó

Kipese -buy-past chair yesterday

'Kipese bought a chair yesterday'

$$
\begin{aligned}
& \text { Kipés a-swiim-ín kìt zóónó } \\
& \text { Kipese -buy-past chair yesterday } \\
& \text { 'Kipese bought a chair yesterday' }
\end{aligned}
$$

Sentence (12) is contrastive on the object, kit 'chair'; sentence (13) is contrastive on the subject, Kipese; sentence (1la) is neutral ${ }^{5}$.

${ }^{4}$ Except in certain environments, which need not be specified here, the final vowel is always deleted in Kihung'an. When it does appear, it is almost always identical with the preceding vowel, thus suggesting vowel harmony.

${ }^{5}$ Sentence ( $11 \mathrm{la}$ ) could also have a contrastive reading, e.g. 'Kipese bought a chair yesterday', but this is not the reading intended here. The a/ka prefixal alternation doesn't concern us here. Roughly speaking, it has to do with the subject being in focus in one case but not in the other. A systematic investigation of this will not be pursued here. 
In object relativization, on the other hand, the OP may not appear: ${ }^{9}$
*kit ki a-ki-swiim-in kipes zoon
chair pro PA-it-buy-past. Kipese yesterday

It is only natural that this restriction does not apply to subject relativization, where one may get either (22) or (23):

(22) muut wu a-ki-swi im-in kit zoon

person pro PA-it-buy-past chair yesterday

'The person who bought the chair yesterday

(23) muut wu a-ki-swiim-in zoon

person pro PA-it-buy-past yesterday

'The person who bought it yesterday'

2.2. Negation and OP in tone-focus constructions

While tone-focus constructions in Kihung'an superficially resemble neutral sentences in their word order, they follow the relative (rather than unembedded) pattern in negation:

(24) Kipès ká-khóón-ín kù-súúm kit zóónó

Kipese PA-fail-past to-buy chair yesterday

'Kipese did not buy a chair yesterday'

(i.e.: 'What Kipese did not buy yesterday is a chair')

And the use of the negative particle 10 here is as ungrammatical as it was in relative clauses:

*Kipès ló ka-swiim-ín kit zóónó

Similarly:

Kipés a-khóón-in kù-súúm kit zóónó

Kipese PA-fail-past to-buy chair yesterday

'Kipese didn't buy a chair yesterday'

(i.e.: 'The person who did not buy a chair yesterday was Kipese')

${ }^{9}$ This is unlike many other Bantu languages, such as Dzamba or Tswana, which require the presence of the object 'infix' pronoun in object relativization. The situation in Swahili is a bit more complex, with the object pronoun required in some patterns but not in others, where its presence or absence may be used to signal a semantic distinction. 
In relative clauses, on the other hand, the particle lo may not be used. Rather, the negative verb -khoon- 'fail' is used instead, as in: 8

(16) kit ki a-khoon-in Kipes ku-sullum

chair pro PA-fail-past K. to-buy

'the chair that Kipese didn't buy'

*kitki lo a-swiim-in kipes

(17) kit ki a-khoon-in ku-suum kipes kye (ki-e) ki-beeng

chair pro PA-fail-past to-buy K. PA-is PA-red

'The chair that Kipese failed to/didn't buy is red'

*kit ki lo a-swiim-in kipes kye ki-beeng

(18) Io i-mween kit ki a-khoon in kipes ku-sum

not I-saw chair pro PA-fail-past $K$. to-buy

'I didn't see the chair that Kipese failed to/didn't buy'

* lo i-mween kit ki lo a-swiim-in kipes

The second relevant property of relative clauses involves the 'infix' object pronoun. In unembedded sentences in Kihung'an the object pronoun (OP) may be used as a definitizer (as in (19) below) or as a pronoun (as in (20) below):

(19) Kipes ka-ki-swi im-in kit zoon

Kipese PA-it-by-past chair yesterday

'Kipese bought the chair yesterday'

(20) Kipes ka-ki-swi im-in zoon

Kipese PA-it-buy-past yesterday

'Kipese bought it yesterday'

${ }^{8}$ The arrows below indicate that the two elements involved may come in either order. Like several other Bantu languages, Kihung'an tolerates a considerable measure of freedom in word order (a notion which is yet to be properly characterized, and may indeed be inappropriate, given 'stylistic' considerations such as discourse structure and topic assignment). For example, (i) and (ii) below correspond to (Ila) and (12), respectively:

(i) kit Kipès ká-swîm-ín zòòn 'Kipese bought a chair yesterday' (ii) kít Kipès ká-swî́m-ín zóónó 'Kipese bought a chair yesterday' 
(32) (kiim) ki a-swiim-in kipes zoon (kwe/*kye) kit (thing) pro PA-buy-past Kipese yesterday (is) chair

'What Kipese bought yesterday is a/the chair'

(33) (muut) wu a-swiim-in kit zoon (kwe/*ke) Kipés

(person) pro PA-buy-past chair yesterday (is) Kipese

'The one who bought a/the chair yesterday is Kipese'

So far as presuppositional structure is concerned, cleft and pseudo-cleft sentences are identical with tone-focus sentences.

As far as negation is concerned, clefts and pseudo-clefts -- much like tone-focus sentences in Kihung'an -- take the negative -khoon-, characteristic of relative clauses, rather than the normal particle lo. Thus, for object focus:

(34) (kwe) kit kipes ka-khoon-in ku-suum zoono

(it's) chair Kipese PA-fail-past to-buy yesterday

'It's a/the chair that kipese didn't buy yesterday'

*(kwe) kit kipes lo ka-swiim-in zoono

(35) (kiim) ki a-khoon-in kipes ku-suum zoon (kwe) kit

(thing) pro PA-fail-past Kipese to-buy yesterday (is) chair

'What Kipese didn't buy yesterday is a/the chair'

* (kiim) ki lo a-swiim-in kipes zoon (kwe) kit

Similarly, for subject focus:

(36) (kwe) Kipés (wu) ka-khoon-in ku-suum kit zoono (it's) Kipese (pro) PA-fail-past to-buy chair yesterday

'It's Kipese who didn't buy a/the chair yesterday'

* (kwe) Kipés (wu) lo a-swiim-in kit zoono

(37) (muut) wu ka-khoon-in ku-suum kit zoon (kwe) kipés

(person) pro PA-fail-past to-buy chair yesterday (is) Kinese

'The one who didn't buy a/the chair yesterday is Kipese'

*(muut) wu lo a-swiim-in kit zoon (kwe) kipés 
But not:

*Kipés ló a-swiîm-ín kìt zóónó

Stress-focus constructions also follow the relative pattern in that they reject the OP in object relativization:

$$
\begin{aligned}
& \text { *Kipès ká-ki-swilm-in kit zóónó } \\
& \text { Kipese PA-it-buy-past chair yesterday }
\end{aligned}
$$

As expected from the discussion above, however, the OP is acceptable if the subject (rather than object) is in focus:

Kipés a-ki-swiim-in (kit) zóónó

Kipese PA-it-buy-past (chair) yesterday

'Kipese bought it yesterday

(i.e.: 'The person who bought it (the chair) yesterday was Kipese') As seen above, neutral sentences accept both the lo negative and the OP. As we shall see below, cleft and pseudo-cleft sentences share the relative pattern with tone-focus sentences in both respects.

3. Cleft and pseudo-cleft in Kihung'an

Much like tone-focus sentences, clefting in Kihung'an may be used to either focus on the object, as in:

(30) (kwe) kit kipes ka-swiim-in zoono

(it's) chair Kipese PA-buy-past yesterday

'It's a/the chair that Kipese bought yesterday'

or on the subject, as in:

(31) (kwe) Kipés a-swiim-in kit zoono

(it's) Kipese PA-buy-past chair yesterday

'It's Kipese who bought a/the chair yesterday'

Similarly with pseudo-cleft sentences: 10

10 Note the ungrammaticality of the copula kye (ki-e) and ke (ka-e). The copula in pseudo-clefts do not exhibit gramatical agreement with the subject (kiim 'thing' and mut 'person', respectively). The significance of this will be discussed later on. 
where the relative clause stands for the presupposition and the predicate, $k i+i$ 'chair', for the (object) noun in focus.

\section{The derivation of focusing constructions}

Given the underlying structure in (40) above, one must consider the derivation of tone-focus, clefts and pseudo-clefts from it. It turns out that most of the (transformational) operations necessary for this already have independent justification in Kihung'an. Those are illustrated below.

\subsection{Copula deletion}

The copula, in the present tense, is optionally deleted in Kihung'an as in many other Bantu languages. Thus, for example:

$$
\left\{\begin{array}{l}
k i+k y e \text { ki-beeng } \\
k i+k i-b e e n g
\end{array}\right\} \quad \text { 'The chair is red' }
$$

Similarly:

$$
\left\{\begin{array}{l}
\text { mwaan wu ke kidi } \\
\text { mwaan wu kidi }
\end{array}\right\} \quad \text { 'This child is an idiot' }
$$

In tone-focus, as seen earlier, no copula appears. In cleft and pseudocleft sentences it appears optionally.

\subsection{Relative pronoun deletion}

Object relative pronouns in Kihung'an may be optionally deleted, and if they are deleted the subject of the embedded clause is not postposed:

$$
\left\{\begin{array}{l}
k i+k i \text { a-swiim-in kipes zoon... } \\
k i+k i p e s \text { a-swiim-in zoon... }
\end{array}\right\}
$$

'The chair (that) Kipese bought yesterday'

The same is true with object cleft sentences:

$$
\left\{\begin{array}{l}
(k w e) \text { kit ki a-swi im-in kipes zoono } \\
(k w e) \text { kit kipes a-swiim-in zoono }
\end{array}\right\}
$$

'It's a/the chair (that) Kipese bought yesterday'

A similar deletion may be shown in subject-focus cleft sentences:

(45) $\left\{\begin{array}{l}(k w e) \text { kipés wu a-swiim-in kit zoono } \\ \text { (kwe) kipés a-swiim-in kit zoono }\end{array}\right\}$
'It's Kipese (who) bought.

a/the chair yesterday' 
The same parallelism with tone-focus and relative clause is observed with respect to the $O P$. Object-focus clefts and pseudo-clefts cannot take it, as is shown in:

(38) *(kwe) kit kipes ka-ki-swiim-in zoonoll

(it's) chair Kipese PA-it-buy-past yesterday

*(kwe) kit ki ka-ki-swiim-in kipes zoonoll

(it's) chair pro PA-it-buy-past Kipese yesterday

(39) *(kiim) ki a-ki-swiim-in kipes zoon (kwe) kit

(thing) pro PA-it-buy-past Kipese yesterday (is) chair

Given the syntactic similarities between relative clauses, on one hand, and focus, cleft and pseudo-cleft sentences on the other, one must conclude that syntactically too a relative clause is involved in focus constructions. This is in addition to the semantic arguments already mentioned. Taken together, the evidence strongly suggests deriving all three constructions from a similar underlying source which closely resembles the structure of a pseudo-cleft. Thus, for sentences (12), (30) and (32), the following underlying structure is suggested (this is without forgetting that at some discourse/stylistic level, perhaps involving topic, they may still differ):

(40)

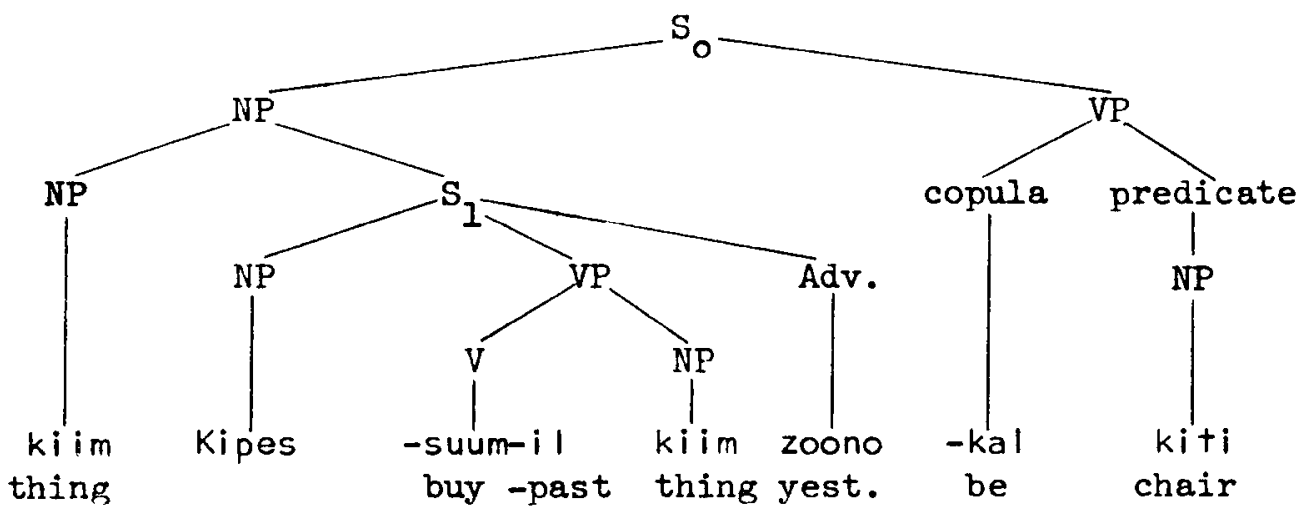

1 The object relative pronoun $k i$ is present only if the subject of the embedded sentence (i.e. subject of the object relative clause) is postposed. If the subject is not postposed, the object relative pronoun is deleted. For further discussion of this, see Givon [1972b]. 
Thus, sentence (50) may represent an intermediate between tone-focus and cleft. Notice also the possible variants, all with the same object focus:

(51) (kwe) kit kiim ki a-swiim-in kipes zoon

'It's a chair, the thing that Kipese bought yesterday'

(52) (kwe) kit ki a-swiim-in kipes zoon

'It's a chair, what Kipese bought yesterday'

One may thus consider (51) and (52) as earlier intermediates in the derivation of (50), and thus ultimately of the tone-focus sentence (49). As we shall see later on, a similar range of intermediates is also found in WH-questions. Although sentence (50) may resemble, in its syntactic order, a topicalized structure, it clearly could not be, since 'chair' is there in focus, and a noun cannot be topic and in focus at the same time, being that predicates are never in topic position.

From the discussion above it seems that most of the syntactic rules through which one may derive either cleft or tone-focus constructions in Kihung'an from the (pseudo-cleft like) underlying structure given in (40) exist in the language. Further, the existence of syntactic intermediates such as (50), (51) and (52) above strongly suggests that in essence this manner of derivation has not only syncrhonic validity but perhaps also some diachronic support. While many details of the required pruning and predicate-lowering conventions (for discussion see Ross [1967]) have yet to be elaborated, it seems to me that the following sequence can be tentatively proposed. Beginning with (40) above, one applies the relevant relativization rules, including subject-postposing, to obtain a pseudocleft with the head-noun intact, as in (53):

(53) kiim ki a-swiim-in kipes zoon kwe kit 'The thing that Kipese bought yesterday is a chair'

Optional copula deletion yields:

(54) kiim ki a-swiim-in kipes zoon kit 'The thing that Kinese bought yesterday (is) a chair' 
Tone-focus sentences of course show no relative pronoun. As we shall see later on, Wh-questions exhibit a similar optional deletion of a relative pronoun.

One may further argue that both copula deletion and relative-pronoun deletion are involved in the embedding of adjectives as modifiers in Kihung'an (and Bantu in general) ${ }^{12}$. In Kihung'an the optionality of these rules is attested in the existence of all three variants in (46) below:

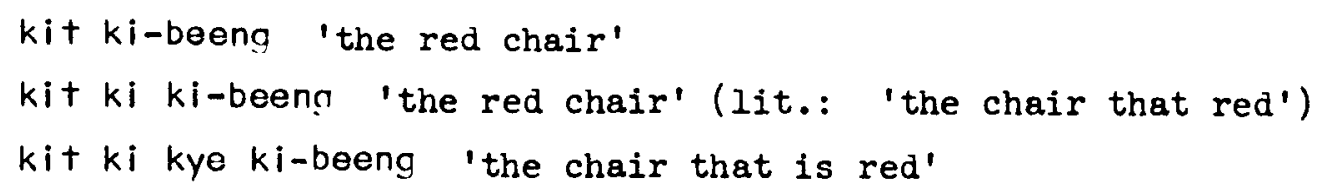

4.3. Head-NP deletion

In Bantu languages the subject of a sentence may be anaphorically deleted, pending a suitable discourse environment, after grammatical agreement has applied:

(47) Kipes ka-swiim-in kit zoon 'Kipese bought a chair yesterday' ka-swiim-in kit zoon '(He) bought a chair yesterday'

In this case, one may argue (see e.g. Givón [1972a, part 2]) that the agreement morpheme ( $k a$ ) serves as an anaphoric pronoun. A similar deletion also applies to object nouns, following ('infix') object pronominalization:

(48) Kipes ka-ki-swiim-in kit zoon 'Kipese bought the chair yesterday' Kipes ka-ki-swiim-in zoon 'Kipese bought it yesterday'

4.4. Optional movement and deletion in focusing

of considerable interest is the following 'stylistic' movement rule, by which the tone-focused object noun is preposed. Thus, given the normal tone-focus sentence (49), one also finds its paraphrase (50):

(49) Kipes ka-swiim-in kit zoon

'Kipese bought a chair yesterday'

(50) kit Kipese ka-swiim-in zoon

'(It's) a chair (that) Kipese bought yesterday'

${ }^{12}$ For details, see Takizala [ms]. 


\section{The complex-sentence and neg-raising argument}

Sentences with complex verb phrases turn out to present no further difficulty for the analysis suggested above. Thus, consider the following examples of tone-focus, cleft and pseudo-cleft sentences:

tone-focus:

(61) beet tu-mon-aak $\mathrm{ni}$ beet lo tu-biing

we PA-see-prog that we neg PA-win

'We think that we will not win'

\section{cleft:}

(62) kwe beet (ba) tu-mon-aak $n i$ beet lo tu-biing

it's we (who) PA-think-prog that we neg PA-win

'It's we who think that we will not win'

(63) beet baat ba $\left\{\begin{array}{l}\text { tu-mon-aak } n i \text { beet lo tu-biingl } 3 \\ \text { ba }\end{array}\right.$

we people who PA-think-prog that we neg PA-win

'It's we (who are) the people who think that we will not win'

(64) beet ba tu-mon-aak $n i$ beet lo tu-biing

we who PA-think-prog that we neg PA-win

$\left\{\begin{array}{l}\text { 'It's we who think that we will not win' } \\ \text { 'We are (the ones) who think that we will not win' }\end{array}\right\}$

pseudo-cleft:

(65) (baat) ba $\left\{\begin{array}{l}\text { tu-mon-aak ni beet lo tu-biing kwe beet } \\ \text { ba- }\end{array}\right.$

(people) who PA-think-prog that we neg win be we

'(The people) who think that we will not win are we'

13 The prefix-agreement variation ba-/tu- exemplifies how a language may be caught in the middle of gramatical re-analysis. In this case, it is caught in the middle between an overt relative-clause analysis (of cleft and pseudo-cleft) and a tone-focus analysis. Thus, for the pseudo-cleft sentence (65) 'The people who think that we will not win are we', we expect the agreement ba- to correspond with the head noun baat 'people'. But we already get the alternation with tu-, which agrees with beet 'we'. In the cleft sentence (63), where beet 'we' has been fronted but the head of the relative clause is still baat 'people', we again get the alternation. In the clefts (62) and (64), however, where the underlying 
Optional head-noun deletion yields:

ki a-swiim-in kipes zoon kit

'What Kipese bought yesterday is a chair'

Predicate-fronting rule may now yield a cleft-like construction:

(56) kit ki a-swiim-in kipes zoon

'It's a chair, what Kipese bought yesterday'

If this movement rule had applied without copula deletion, one may get the cleft:

(57) kwe kit ki a-swiim-in kipes zoon

'It's a chair, what Kipese bought yesterday'

If, in addition, relative-pronoun deletion had applied, one may get the cleft without subject postposing:

(58) kwe kit kipes a-swiim-in zoon

'It's a chair that Kipese bought yesterday'

For the derivation of tone-focus sentences, however, fewer rules are necessary. Beginning with (55), to which copula deletion and head-noun deletion have already applied, one also applies relative-pronoun deletion, which results in the movement of the subject noun back to its original place, to yield:

(59) Kipes ka-swiim-in zoon kit

Which is, in turn, a mere stylistic variant of the tone-focus construction:

(60) Kipes ka-swiim-in kit zoon

'Kipese bought a chair yesterday'

Thus, in terms of existing rules of the language, as well as in terms of the existence of surface forms resembling to quite an extent the putative intermediates in the derivation, deriving both cleft and tone-focus constructions in Kihung'an from pseudo-cleft like underlying structures does not appear to be very costly. 
(68) kwe beet (ba) tu-khoon-aak ku-mon ni beet tu-biing it's we (who) PA-fail-prog to-think that we PA-win 'It's we who don't think that we'll win'

*kwe beet (ba) 10 tu-mon-aak ni beet tu-biing

(69) beet baat ba $\left\{\begin{array}{l}\text { tu-khoon-aak ku-mon ni beet tu-biing } \\ \text { ba- }\end{array}\right.$

we people who PA-fail-prog to-think that we PA-win

'It's we (who are) the people who don't think that we'll win'

*beet baat ba $10\left\{\begin{array}{l}\text { tu-mon-aak ni beet tu-biing } \\ \text { ba- }\end{array}\right.$

(70) beet ba tu-khoon-aak ku-mon ni beet tu-biing we who PA-fail-prog to-think that we PA-win

'It's we who don't think that we'll win'

'We are (the ones) who don't think that we'll win'

*beet ba lo tu-mon-aak ni beet tu-biing

(71) (baat) ba $\left\{\begin{array}{l}\text { tu-khoon-aak ku-mon ni beet tu-biing kwe beet } \\ \text { ba- }\end{array}\right.$

(people) who PA-fail-prog to-think that we PA-win be we

'(The people) who don't think that we'll win are we'

*(baat) ba $10\left\{\begin{array}{l}\text { tu-khoon-aak ku-mon ni beet tu-biing kwe beet } \\ \text { ba- }\end{array}\right.$

Thus, if neg-raising is considered a valid (stylistic) rule of Kihung'an, then at the stage when this rule operates, the structure of focus sentences must involve a relative clause, since the raised NEG appears in the form appropriate to relative clauses.

\section{The anaphoric deletion argument}

I have mentioned above that under the appropriate discourse conditions, subject and object nouns in Kihung'an may be deleted, after agreement or pronominalization have applied. However, the same does not apply when the noun in question is in focus, either through tone-focus, cleft or pseudocleft. Thus, for subject nouns: 
Sentences (61) through (65) above may be all represented by the underlying structure in (66) below:

(66)

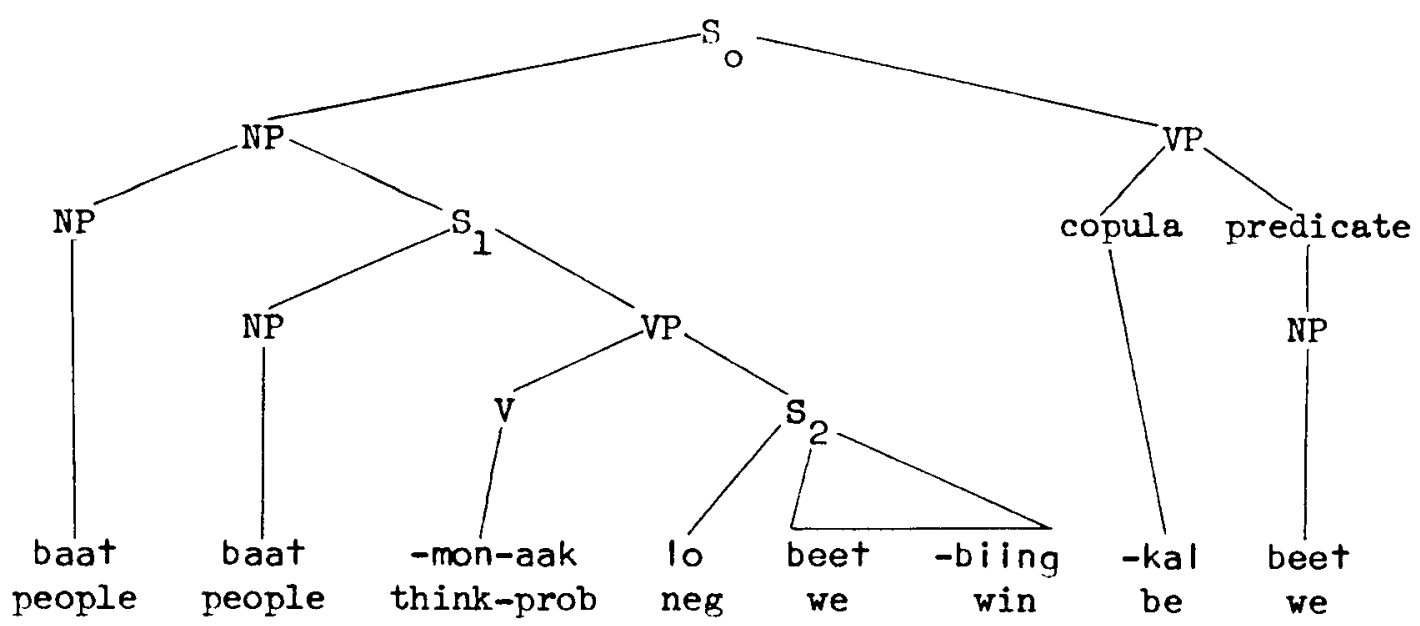

Now, the verb -mon- 'think' is a neg-raising verb. (The arguments in support of neg-raising in Kihung an are the same as those for English and will not be repeated here.) That is, the meaning of a sentence remains the same whether the negative is in the complement of 'think' or on 'think' itself. In Kihung'an, when the negative is in the complement of 'think', as in (61)-(65) above, one obtains the normal lo negative particle. However, if the negative is 'raised' to the higher clause, only -khoon'fail' may be used, regardless of whether a relative clause overtly appears on the surface. Thus, sentences $(67)-(71)$ below correspond to $(61)-(65)$ above, respectively.

(67) beet tu-khoon-aak ku-mon ni beet tu-biing

we PA-fail-prog to-think that we PA-win

'We don't think that we'Il win'

*beet lo tu-mon-aak ni beet tu-biing

baat 'people' has been deleted, we get obligatorily tu-, agreeing with the fronted beet 'we', and this represents already, in terms of the prefix agreement, the same situation as in the tone-focus sentence (61), where no superficial evidence of the relative pronoun (ba) has survived. The existence of intermediate forms of this type lends credence to the hypothesis of deriving focus constructions from (pseudo-) clefts, since it suggests that this process may have in fact occurred diachronically. 
(77) Kipes ka-swiim-in kit zoon 'Kipese bought a chair yesterday'
$=\Rightarrow$ kipes ka-ki-swiim-in kit zoon 'Kipese bought the chair yesterday'

$\Rightarrow$ kipes ka-ki-swiim-in zoon 'Kipese bought it yesterday'

but not for object focus sentences:

$$
\begin{array}{ll}
\text { Kipes ka-swiim-in kit zoon } & \Rightarrow \text { *kipes ka-ki-swiim-in kit zoon } \\
\text { 'Kipese bought a chair yesterday' } & \Rightarrow \neq \text { *Kipes ka-ki-swiim-in-zoon }
\end{array}
$$

Both restrictions, i.e. on both pronominalization and deletion, may now be explained quite independently of the restriction on object pronominalization in relative clauses. The 'infix' object pronoun in Kihung'an is used either as a definitizer or as anaphoric pronoun. Both processes are discourse phenomena, depending upon establishing the noun in question as topic in previous discourse. However, as I have just argued above, a noun in focus cannot be a topic noun. Now, if at the time when anaphoric object pronominalization and deletion applies the noun in focus is still in a predicate position, a natural explanation emerges for these restrictions: a predicate noun cannot be anaphorically deleted, since it contains the new information. Nor can it be replaced by a pronoun, since semantically it has not been mentioned in previous discourse, and syntactically the pronominalization process in question applies only to object nouns but not to predicates in Bantu. Thus, the restrictions on deletion and pronominalization of both subject and object nouns turn out to involve the very same explanation, one which is consonant with the 'relative clause and predicate' analysis of focus constructions. ${ }^{14}$

\section{WH-questions}

The semantic relation between $\mathrm{WH}$-questions, on one hand, and focusing sentences and relative clauses on the other, has been noted before (for some discussion of this subject in Bantu see Myers [1971] and Heny [1971]).

${ }^{14}$ For further discussion of object-infixation in Kihung'an, see appendix 1., below. 
276

$(72)$

$$
\begin{array}{ll}
\text { Kipes ka-swiim-in kit zoon } & =\Rightarrow \text { ka-swiim-in kit zoon } \\
\text { 'Kipese bought a chair yesterday' } & \text { '(He) bought a chair yesterday' }
\end{array}
$$

but not:

$$
\begin{aligned}
& \text { Kipés a-swiim-in kit zoon } \quad \Rightarrow \neq * a-s w i i m-i n k i t \text { zoon } \\
& \text { 'Kipese bought a chair yesterday' }
\end{aligned}
$$

nor:

(74) kwe Kịés (wu) a-swiim-in kit zoono $=\neq \Rightarrow$ *kwe (wu) a-swiim-in kit 'It's Kipese who bought a chair yesterday' zoono

nor:

(75) (muut) wu a-swiim-in kut zoon kwe kipés $=\neq \Rightarrow$ '(The man) who bought a chair yesterday is Kipese'

*(muut) wu a-swiim-in kit zoon kwe

Data of this kind are not readily explained under the Chomsky [1968] analysis. The 'relative clause and predicate' analysis, on the other hand, explains them quite naturally. Anaphoric deletion applies only to a noun previously mentioned in discourse. Or, in other words, to a topic noun. Nouns in focus, however, present the new information in the sentence, the one contained in the predicate. Thus, notice (as may also be seen from the pseudo-cleft (75) above) that predicate nouns in Bantu (as well as in any other language) may not be anaphorically deleted:

(76)

$$
\begin{aligned}
& \text { muut wu Kipés } \\
& \text { 'This man (is) Kipese' }
\end{aligned} \Rightarrow \text { *muut wu }
$$

At the stage where anaphoric deletion applies, then, the noun in focus must still be in predicate position -- and thus undeletable.

Let us now consider object nominals. It has already been mentioned before that (anaphoric) object pronominalization may not apply to focused constructions, just as it does not apply to relative clauses. Thus, for neutral sentences, one may get: 
Much like relative clauses and focus constructions, WH-questions do not allow object-pronoun infixation (or, for that matter, the deletion of the interrogative pronoun itself, which corresponds to the noun in focus):

*na Kipes ka-mu-mweene? *'Who did Kipese see him?'
*na wu ka-mu-mweene Kipes? $\quad\left\{\begin{array}{l}* \text { 'Who is it that Kipese saw him?' } \\ \text { 'Who is it that saw him Kipese?' }\end{array}\right\}$

The reason for this restriction must be identical to the one discussed in the preceding section. The schematic underlying structure for WH-questions may be thus represented by ( 86 ) below (in which the performative structure 'I request you' has been omitted), which corresponds to the underlying structure for focus constructions given in (40), above:

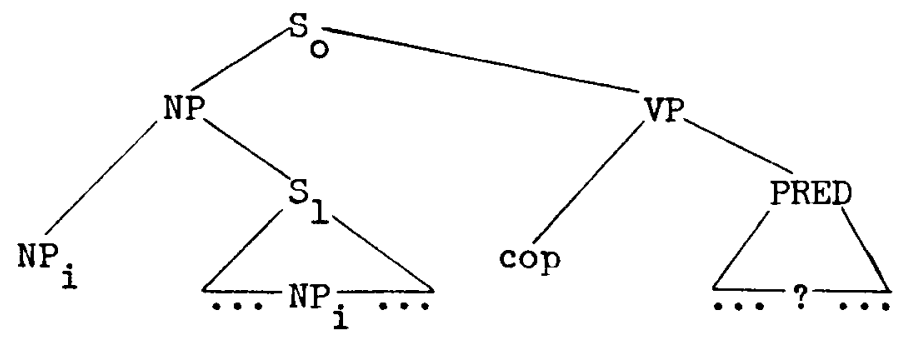

The difference between focus sentences and WH-questions may be then traced down to their different performative function. Given an identical presupposition (expressed in the relative clause modifying the subject noun of the construction), focus constructions supply ('state') the new information, while WH-questions request for it. Otherwise, the syntactic parallelism shown above tends to support the 'relative clause and predicate' analysis of focus constructions.

\subsection{Some possible difficulties}

An analysis proposed by Akmajian [1970] poses an apparent difficulty for the 'relative clause and predicate' approach to which, I have claimed above, the Kihung'an data lend considerable support. Akmajian has offered a rather similar analysis, but one involving a head-less relative clause. He rejects the full-relative-clause analysis because of difficulties raised by pseudo-cleft sentences such as ( 87 ) below, which are better paraphrased by sentences such as ( 88 ), in which a relative pronoun (locative pronoun) appears: 
Thus, it may be shown that a Wh-question involves the same presuppositional structure as stress-focus, cleft or pseudo-cleft, which may be likewise expressed by the presence of a relative clause. For example, compare sentences (79) (focus) and ( 80 ) (WH) below:

(79) Kipese bought chair = Presupposed: 'Someone bought a chair' Asserted: 'That person is Kipese'

(80) Who bought a chair? = Presupposed: 'Someone bought a chair' Querried: 'That person is who?'

Thus, while the performative involved is different ('declare' for focus, 'request' for $\mathrm{WH})$, the remainder of the semantic structure is the same.

Much like focus constructions, WH-questions in Kihung'an require negation with -khoon- - the one typical of relative clauses -- rather than with the normal (Io) neg-marker:

(81) khi Kipes ka-swiim-in? 'What did Kipese buy?'

khi kipes ka-khoon-in ku-suum? 'What didn't Kipese buy?'

*khi Kipes lo ka-swiim-in?

(82) na Kipes ka-mweene? 'Who did Kipese see?'

na Kipes ka-khoon-in ku-mon? 'Who didn't Kipese see?'

*na Kipes lo ka-mweene?

Further, one may show that these WH-questions further resemble relative clauses in that relative pronouns may optionally appear in them, much like they may appear in the corresponding cleft sentences. Thus, (83) below paraphrases (81), while one reading of the ambiguous (84) paraphrases (82):

(83) khi ki ka-swi im-in Kipes? 'What (is it) that Kipese bought?'

(84) na wu ka-mweene Kipes? $\left\{\begin{array}{l}\text { 'Who (is it) that Kipese saw?' } \\ \text { 'Who (is it) who saw Kipese?' }\end{array}\right\}$

The obligatory subject-postposing in (84) above creates the ambiguity ${ }^{15}$.

${ }^{15}$ And subject postposing, in turn, is motivated by the presence of the relative pronoun, in contrast with $(81)$ and $(82)$ where it is not present. For further discussion, see Givón [1972b]. 
may be handled by the 'relative clause and predicate' analysis' ${ }^{16}$. Multiplefocus sentences of the kind discussed by Chomsky [1968] may be found in kihung'an, as in:

(92) must wu a-fuun-aak Anglais phiim

'This man speaks English well' (not poorly)

(93) muut wu a-fuun-aak Anglais phiim

'This man speaks English well' (not French)

(94) muut wu a-fuun-aak Anglais phi im

'This man speaks English well' (not reads)

Their corresponding negatives must take -khoon- rather than lo, thus again suggesting that a relative clause is involved:

(95) muut wu a-khoon-aak ku-fuun Anglais phiim

'This man doesn't speak English well'

muut wu a-khoon-aak ku-fuun Anglais phi im

'This man doesn't speak English well'

muut wu a-khoon-aak ku-fuun Anglais phi im

'This man doesn't speak English well'

16 Take for example (i) below, taken from Chomsky [1968, ex. 52i]:

(i) No, he was warned to look for an automobile salesman

As Chomsky [1968] points out, it would indeed be quite artificial to derive it from:

(ii) *No, the thing that he was warned to look out for a salesman was an automobile

The artificiality of the paraphrases -- though not its acceptability -decreases, however, with:

(iii) ?No, the thing that he was warned to look out for a salesman of was an automobile

The inacceptability of (iii), however, arises from a violation of Ross's Complex NP Constraint, rather than any deep semantic reason. It may be easily paraphrased by:

(iv) Presupposed: He was warned to look for a salesman who sells

Asserted: What that salesman sells is automobiles

Thus, I think that Chomsky [1968] has raised difficulties which pertain to more superficial constraints and to lexicalization, but not to the validity of the semantic claims made by the 'relative clause and nredicate' analysis. 
(87) *The place where John beats his wife is in the garden

(88) Where John beats his wife is in the garden

This solution, it seems to me, suffers from a considerable drawback, in that it generalizes on the exceptional case while treating the general case as an exception:

(89) The $\left\{\begin{array}{l}\text { one } \\ \text { person }\end{array}\right\}$ who got killed was John

*Who got killed was John

The person to whom I gave the book was John

*(To) whom I gave the book was (to) John

In addition, note the instances, below, in which both variants are admissible:

(90) The thing that I saw was an armadillo

What I saw was an armadillo

How he did it was by working hard

The way he did it was by working hard

From this data it seems clear that the significance of these restrictions is at best superficial, and should better be expressed at the level of the lexicon, where specific restrictions on lexicalization, of precisely the same type, ought to be expressed. That these restrictions are superficial and highly lexical-specific is also apparent from the fact that while in the case of non-human direct objects (in (90) above) both the 'headed' and 'headless' relative clauses are accepted, the same is not true for human direct objects:

(91) The person (whom) I saw was John

*Whom I saw was John

8. Discussion

(a) The difficulty raised by Chomsky [1968] concerning the possibility of multiple-focusing in one sentence (see examples (10), (11) above) still remains. It seems to me, however, that much of the apparent difficulty 
analysis holds for Kihung'an and the languages surveyed by Schachter [1971], Hyers [1971] and Heny [1971], to mention only a few, but not for English. It seems to me, however, that adopting a highly language-specific solution such as Chomsky's [1968] for phenomena as seemingly universal -- certainly at the semantic level and to quite an extent at the syntactic level as well -- as focusing constructions turn out to be, does little to convey the underlying generalizations of language structure.

(d) The plausibility of the analysis presented here is enhanced, it seems to me, by the real possibility that the derivation of clefts, stress-focus sentences and WH-questions from pseudo-cleft like constructions has in fact taken place diachronically in Kihung'an (and very likely in other languages as well). The presence of several intermediate forms in Kihung'an, with or without the head of the relative clause, with or without the copula and with or without the relative pronoun, tends to lend credence to this diachronic hyothesis.

\section{REFERENCES}

Akmajian, A. 1970. "On deriving cleft sentences from pseudo-cleft", I,inguistic Inquiry 1.2: 149-168.

Awobuluyi, 0. 1972. "On the nature of relativization". Paper read at the Third Conference on African Linguistics, Bloomington, Indiana.

Bokamba, G. 1972. "Immediate dominance, topicalization and relativization". Paper read at the Third Conference on African Linguistics, Bloomington, Indiana.

Borkin, A. 1971. "Polarity items in questions", in Papers from the Seventh Regional Meeting, pp. 53-62. Chicago: Chicago Linguistic Society, University of Chicago.

Callender, J. B. 1971. "Notes on constructions with in", Studies in African Linguistics 2.1: 1-23.

Chomsky, I. 1968. "Deep structure, surface structure and semantic interpretation", in Semantics. Edited by Stenberg and Jakobovitz. Cambridge: Cambridge University Press.

Givón, T. 1971. "The magical number two, Bantu pronouns and the theory of pronominalization", Studies in African Linguistics 1.3: 279-300.

Givón, T. 1972a. Studies in ChiBemba and Bantu Gramar, Studies in African Linguistics, supplement $\# 3$. 
Finally, it seems that the semantic structure of these sentences may be characterized reasonably well by pseudo-cleft like constructions, as in e.g.:

(92') The way he speaks English is good

(93') The language he speaks well is English

(94') The thing he does well with English is sneak it

The underlying presuppositions and assertions involved are thus:

(92") P: He speaks English in a certain way

A: That way is good

(93") P: He speaks some language well

A: That language is English

( $\left.9 l^{\prime \prime}\right)$ P: He does something well with English

A: What he does is speak it well

While the accuracy of paraphrastic formulae of this kind is not complete, I think they clearly suggest that, at least in principle, Chomsky's [1968] objections are not extremely damaging to the analysis at which they are directed.

(b) I have shown that the data of Kihung'an strongly support the more abstract, 'relative clause and predicate' analysis of focus sentences rejected by Chomsky [1968]. Clear syntactic data link tone-focus, clefts, pseudo-clefts and relative clauses together. For data of this type Chomsky's analysis can give no natural explanation.

(c) The fact that similar syntactic support is also found for linking focusing constructions (and relative clauses) with WH-questions strengthens the analysis. This is so because WH-questions share much of the presuppositional-semantic structure of focusing constructions, in which the presupposed sentence is represented as a relative clause. Thus, the fact that the syntactic analysis proposed here meshes well with the semantic analysis in all three cases, should be considered as additional support for its viability. One nay of course wish to argue that this trpe of an 


\section{APPENDIX 1: Object Pronoun Infixation in Kihung'an}

Sentences (1), (2) below are related to the topicalized sentences (3), (4), respectively:

(1) ?kipes bu ka-yis-ir ayi kit Kipese asp. PA-come-past with chair

'Kipese came with a chair'

(2) Kipes bu ka-ki-swiim-in kiti

Kipese asp. PA-it-buy-past chair

'Kipese bought the chair'

(3) kit kipes bu ka-yis-ir akyo

chair Kipese asp. PA-come-past with-it

'The chair, Kipese came with it'

(4) kit kipes bu ka-ki-swiim-in

chair Kipese asp. PA-it-buy-past

'The chair, Kipese bought it'

While the topicalized sentence (4) is an infixed object pronoun, the topicalized sentence (3) as a preposition-bound object pronoun, and infixation in this case is ungrammatical, e.g.:

$$
\begin{aligned}
& \text { *kit kipes bu ka-ki-yis-ir ayi } \\
& \text { chair Kinese asp. PA-it-come-past with }
\end{aligned}
$$

Now, notice that the restriction on the appearance of object pronouns in relative clauses applies only to infixed object pronouns, as in (6) below, but not on preposition-bound object pronouns:

$$
\begin{aligned}
& k i+k i \text { a-swiim-in Kipes zoon } \\
& \text { chair pro PA-buy-past Kipese yesterday } \\
& \text { 'The chair that Kipese bought yesterday' } \\
& \text { *ki+ ki a-ki-swiim-in kipes zoon } \\
& \text { chair that PA-it-buy-past Kipese yesterday }
\end{aligned}
$$

In contrast, an object pronoun must appear if the relativized object is prepositional, as in: 
Givón, T. 1972b. "Pronoun attraction and subject postposing in Bantu", in Papers from the Eighth Regional Meeting, supplement. Chicago: Chicago Linguistic Society, University of Chicago

Guthrie, M. 1948. The Classification of the Bantu Languages. London: Oxford University Press.

Guthrie, M. 1953. The Bantu Languages of Western Equatorial Africa. London: Oxford University Press.

Heny, F. 1971. "Focus and interrogative in Bali". Paper read to the Second Conference on African Linguistics, University of California, Los Angeles.

Lakoff, G. 1965. On the nature of Syntactic Irregularity, NSF, Harvard Computational Laboratory.

Langacker, R. W. 1971. "French interrogatives revisited". Manuscript.

Myers, A. 1971. "Emphatics and questions in Kikuyu", in Proceedings of the Second Conference on African Linguistics, Studies in African Linguistics, supplement \#2, pp. 11-18.

Postal, P. 1971. Cross-over Phenomena. New York: Holt, Rinehart and Winston.

Robinson, J. O. 1972. "Focus, presupposition and WH-questions in Igbo". Paper read at the Third Conference on African Linguistics, Bloomington, Indiana.

Ross, J. R. 1967. "A proposed rule of tree-pruning", in Modern Studies in English. Edited by Reiber and Schane. Englewood Cliffs, N. J.: Prentice-Hall.

Schachter, P. 1971. "Focus and relativization", to appear in Language.

Shopen, T. 1972. "Deep structure and semantic structure", in Papers from the Eighth Regional Meeting. Chicago: Chicago Linguistic Society, University of Chicago

Takizala, A. 1972. "Random notes on Kihung'an". Manuscript. van den Eynde, K. 1969. Eléments de Grammaire Yaka. Kinshasa: Université Lovanium. 
(2) ákwà màsị rị Úcè cloth please Uce 'The cloth pleased Uce'
$\Rightarrow \quad$ à'kwá 'másịrị Úcè

cloth please Uce

'The cloth that pleased Uce'

In focus construction, the same tonal change appears in object-focus as seen in the relative clause in (1) above:

(3) 乌́ bị ákwà kà ú'cé ṇyèrè nwó'ké

it is cloth Uce gave man

'It's cloth that Uce gave the man'

In contrast, no tonal change appears in subject-focus constructions. as seen from (4) below (compared with (2)):

(4)

$$
\begin{aligned}
& \text { Ó bụ ákwà màsịri Úcè } \\
& \text { it is cloth please Uce } \\
& \text { 'It's cloth that pleased Uce' }
\end{aligned}
$$

To begin with, it is significant that in the object-focus (3) the relative tone does appear. Part of its absence in (4), further, may be readily explained. Notice first that the relative tone of the subject relative clause in (2) appears in two places: on the head noun ('cloth') and on the verb itself ('please'). In the object relative ( 1 ), on the other hand, the relative tone appears on the underlying subject of the embedded clause. Now, notice that 'cloth' in (4) does not, under the 'relative clause and predicate' analysis, arise from the relative clause (whose underlying form is 'Something pleases Uce'). Rather, it is the transported predicate noun brought into focus. Our analysis would in fact predict this behavior. In contrast, the subject 'Uce' in (3) does arise from inside the underlying relative clause ('Uce gave something to the man'). It is thus not an accident that it does indeed preserve the characteristic relative tone. The only fact which remains to be explained is the non-relative tone on the verb in (4). This may necessitate positinf some kind of analogical leveling, of the type discussed earlier above in connection with WH-questions in Kihung'an. But the Igbo data are not necessarily as damaging to our analysis as one may have assumed at first glance. 
(7) Kipes ka-di-ir ayi mbeel $\Rightarrow$ mbeel yi a-di-ir ayo Kines Kipese PA-eat-past with knife knife pro PA-eat-nast with-it Kinese 'Kipese ate with a knife' 'The knife that Kipese ate with'

(8) Kipes ka-yis-ir ayi mwaan $\Rightarrow \Rightarrow$ maan wu a-vis-ir ando kipes Kipese PA-come-past with child child pro PA-come-past with-him 'Kipese came with a child' Kipese

'The child that Kipese came with'

It thus seems that the restriction on anaphoric object pronouns in relativization in Kihung'an applies only to the infix pronouns, but not to other, prep-bound pronouns. The appearance of anaphoric object pronouns in relativization is widely attested in Bantu. Swahili allows the infix OP in relativization. Both Dzamba and Tswana require them obligatorily. The 'double pronominalization' shown in prep-object relativization in Kihung'an is also attested in Bantu (see for discussion Givón [1971, $1972 \mathrm{~b}]$. What this suggests is that the restriction on object pronominalization in Kihung'an relativization is a superficial restriction, specifically applying to the infix op but not to others. This is important because, as argued in section 6 . above, the restrictions on the appearance of object pronouns in focusing constructions (also in WH-questions, see section 7 ., above) are independently motivated by the semantics of the underlying construction involved. This restriction is therefore not related to relativization, as $I$ have erroneously suggested above.

APPENDIX 2: Is Igbo an exception to the 'relative clause and predicate' analysis?

Robinson [1972] has argued that in Igbo (Nigeria) one should not postulate an underlying relative clause for focus sentences. There are no surface relative pronouns in Igbo, and a relative clause is characterized by a tonal change, as shown in:

(1) Úcè gyèrè ņwó'ké ákwà $=\Rightarrow$ ákwà Úc'é pyèrè ņwó'ké Uce gave man cloth cloth Uce gave man

'Uce gave the man cloth' 'The cloth that Uce gave the man' 


\title{
A NOTE ON SUBJECT POSIPOSING ${ }^{1}$
}

\author{
Talmy Givón \\ Department of Linguistics \\ University of California, Los Angeles
}

\section{Preface}

In Bokamba [1971], Meeussen [1971] and Takizala [1972] an interesting movement rule which applies to object relative clauses in several Bantu languages of the Congo is described. The rule involves the postposing of the subject of the embedded sentence, thus moving it from the normal preverbal position to a post-verb nosition. For an example, consider the following Dzamba data, taken from Bokamba [1971]:

(1) Zaki a-bundaki imo-kondo

'Jack caught the alligator'

(2) oPetelo a-nyamozi imo-kondo i-mu-bundaki Zaki

Peter sold the-alligator rel-it-caught Jack

'Peter sold the alligator that Jack caught'

The languages involved are $\mathrm{S}-\mathrm{V}-\mathrm{O}$ languages. In this paper I hope to show that there exists a natural explanation for the subject postposing rule, motivated by the universal principle of pronoun (or subordinator) attraction in relativization. Informally given, this principle is the one by which relative pronouns tend to appear directly adjacent to the head noun modified by the relative clause. In $\mathrm{S}-\mathrm{V}-\mathrm{O}$ languages, in which the order NOUNMODIFIER is most common in the noun phrase, subject relativization involves no pronoun movement rule, while object relativization would require a rule of movement or copying over the verb (the opposite direction of the subject postposing rule) in order to abide by the pronoun attraction principle.

IFor the Dzamba data I am indebted to George Bokamba, for the Swahili data to Salma Mbaye, for the Kihung'an to Alexis Takizala. The Bemba data are from my own field notes. I have benefited from discussing a preliminary draft of this paper with A. E. Meeussen, the late W. Whiteley, E. Voeltz and $G$. Bokamba. An earlier version of this paper appeared in Paners from the Eighth Regional Meeting, (supplement), Chicago Linguistic Society, University of Chicago. 
(6) kit ki-a-swiim-in kipes zoon

chair that-ag-buy-past Kipese yesterday

'The chair that Kipese bought yesterday'

As I hope to show, of these two morphological features, only the one pertaining to the bound morphemic status of the relative pronoun (or relative subordinator) is relevant to the subject postposing rule. The data cited from Kihung'an, above, already suggest this. The case of Swahili serves as added support.

There are three morphemic patterns for relative pronouns in Swahili. In one of those, which is historically the more recent one, the relative pronoun is not bound to the verb, but rather is carried by the supporting morpheme (formerly the verb 'say') amba-, as in:

(7) mtoto a-me-ki-ona kitabu

child ag-nerf-it-see book

'The child has seen the book'

(8) kitabu amba-cho mtoto a-me-ki-ona

book say-that child ag-perf-it-see

'The book that the child has seen'

Thus, in this pattern, the rule of subject postposing is not obligatory; though it is still an option, as in (9) below, which paraphrases (8):

(9) kitabu amba-cho a-me-ki-ona mtoto book say-that ag-perf-see child

'The book that the child has seen'

In the next Swahili pattern, confined to three independent tenses (-1i- 'past', -na- 'present' and -ta- 'future'), the relative pronoun is bound to the verbal word, in a prefixal position following the tense morpheme. In this pattern the rule of subject postposing is obligatory:

(10) mtoto $a-1 i-k i-o n a k i+a b u$

child ag-past-it-see book

'The child saw the book' 
I also hope to show how the verbal morphology of the language, and in particular the bound vs. free morphemic status of the relative pronoun (or relative subordinator), plays a controlling role in determining the application of the pronoun attraction principle. Finally, I will attempt to show that the pronoun attraction principle helps explain otherwise baffling data concerning the position of the relative pronoun in some Bantu languages, and that other data cited by Meeussen [1971] fit very well with suggestions I have made (Givón [1971]) concerning diachronic developments in Bantu syntax.

\section{Subject postposing and verb morphology}

In Dzamba, as well as in the Lomongo-type languages cited by Meeussen [1971], two other morphological features also appear, in addition to the rule of subject postposing:

a. No subject-agreement morpheme appears in the object relative clause;

b. The object relative pronoun is bound as prefix to the verbal word. These two added traits do not appear in all Bantu languages. In Bemba, for example, neither appears:

(3) umuana a-a-mweene icitabo

child ag-past-see book

'The child saw the book'

(4) icitabo icyo umuana a-a-mweene book that child ag-past-see

'The book that the child saw'

In other Bantu languages, such as Kihung'an, subject agreement does occur in object relative clauses, but the object relative pronoun is still a bound prefix to the verbal word -- and the subject postposing rule is obligatory:

(5) Kipes a-swiim-in kit zoon

Kipese ag-buy-past chair yesterday

'Kipese bought a/the chair yesterday' 
stress-focus, cleft, pseudo-cleft and WH-questions in Kihung'an all involve the deep presence of a relative clause. Now, in cleft constructions in Kihung'an no overt relative pronoun appears -- and no subject postposing occurs :

kwe kit kipes ka-swiim-in zoono

it's chair Kipese ag-buy-past yesterday

'It's $a /$ the chair (that) Kipese bought yesterday'

In pseudo-cleft constructions, however, an overt object relative pronoun does appear -- and is bound to the verb. And subject postposing is obligatory:

(17) (kiim) ki-a-swiim-in kipes zoon kwe kit

(thing) that-ag-buy-past Kipese yesterday is chair

'(the thing) what Kipese bought yesterday is a/the chair'

In Wh-questions in Kihung'an the underlying object relative pronoun may optionally appear. When it does not appear, no subject postposing occurs, but when it does appear, subject postposing occurs:

na Kipes ka-mweene?

whom Kipese ag-saw

'Whom did Kipese see?'

na wu-u-mweene Kipes?

whom that-ag-saw Kipese

'Who (is it) that Kipese saw?'

'Thus, whenever the subject noun would have intervened between the relative pronoun and the head noun, it is postposed. When no relative pronoun appears, the subject of the embedded clause retains its original (pre-verb) position.

\section{Subject postposing and subject agreement}

As seen above, the lack of subject agreement in object relative clauses is not an obligatory feature coupled to subject postposing. It appears in Dzamba (and other Iomongo-type Bantu languages), but is absent in both Swahili and Kihung'an -- when subject postnosing is still present. This 
(21) kitabu a-1i-cho-ki-ona mtoto

book ag-nast-that-it-see child

'The book that the child saw'

(12) *kitabu mtoto a-li-cho-ki-ona

Finally, Swahili also has a more archaic (see discussion later on) relativization pattern, now confined to the -a- ('present', 'habitual') tense only, where the relative pronoun is a bound suffix to the verbal word. And in this pattern too, subject postposing is obligatory:

(13) mtoto a-a-ki-ona kitabu child ag-pres-it-see book 'The child sees a book'

(14) kitabu a-ki-ona-cho mtoto book ag-it-see-that child 'The book that the child sees'

(15) *kitabu mtoto a-ki-ona-cho

Given the data above, it seems that the following generalization can be made: whenever the relative pronoun is free -- and thus can be positioned directly adjacent to the head noun -- the rule of subject postposing does not apnly obligatorily. However, when the (object) relative pronoun is bound to the verb, as in the case of Dzamba, Kihung'an and the last two patterns of Swahili, subject postposing applies obligatorily. What is clearly involved, it seems, is the principle of pronoun attraction. In an S-V-O language, if the object relative pronoun is bound to the verb, the subject noun of the embedded sentence is sure to intervene between the pronoun and the head noun. The subject postposing rule rectifies this situation, thus rescuing the pronoun attraction principle

The relation between the relative pronoun and the rule of subject postnosing may be further illustrated by the following data from Kinung'an. As seen in (5), (6) above, subject postposing is obligatory in object relativization in this language, where the relative pronoun is bound to the verbal word. Takizala [1972j has shown much evidence to suggest that 
(22) imo-nkanda i-ta-mu-tomaki opetelo

the-letter that-neg-it-wrote Peter

'The letter that Peter did not write'

In (21) above two agreement morphemes -- although pertaining to the same noun -- appear before the verb. Obtaining two agreement morphemes prefixed one next to the other before a Bantu verb is not uncommon, see e.g. some of the Swahili and Kihung'an examples above. Swahili also allows three agreeing morphemes before the verb, as in (11) above. However, in that case the subject agreement falls to the left of the tense marker, while the object relative pronoun and the anaphoric object pronoun fall to its right. It may well be that two-in-a-row is a morphemic maximum for Dzamba or perhaps most Bantu languages. This type of constraint is not unreasonable, and may have firm grounding in the perceptual problems that may arise in attempting to find the coreferents of three agreement morphemes strung next to each other before the verb.

Bokamba [1971] has suggested an alternative formal account for the loss of subject agreement in Dzamba object relativization. Briefly, this solution involves an explicit ordering convention, by which the rule of subject postposing be ordered before the copying rule of subject-vert agreement. This would presumably require that the subject-verb agreement rule be formulated in terms of 'noun phrase left of the verb', so as to prevent copying from the right of the verb. There are several reasons why I think this type of a solution is not altogether adequate.

a. The copying rule by which the 'infix' object pronoun in Bantu is obtained involves copying from the right of the verb to a prefixal position. In Givón [1972] I have brought a considerable amount of evidence to suggest that the conying nrocesses involved in both apreement and pronominalization in the grammar occur at the very same noint in the grammar. The solution suggested above would split the two, and will further require some mechanism by which to discriminate between an NP to the right of the verb which could not give rise to copied features (the postposed subject) and an NP to the right of the verb which could (the underlying object). This is clearly an undesirable consenuence of the formalism. 
trait is nevertheless of some interest. Bokamba [1971 and also in private communication] has suggested that a natural explanation for the subject postposing rule of Dzamba should be sought in a different direction, namely a restriction on two NP's preceding the verb in S-V-O languages. This configuration, according to Bokamba, would have resulted in a confusion with respect to subject agreement. In this way both subject postposing and the lack, of subject agreement in Dzamba are presumably explained. This explanation is inadequate in several respects. To begin with, we have seen that in Swahili and Kihung'an subject postposing exists but the subject agreement morpheme is retained. The two features are clearly unrelated. Further, English is a clear counter-example to Bokamba's alternative constraint, since two nouns may annear before the verb in object relativization:

(20) The man my sister married...

The house Jack built...

etc.

The alternative constraint is thus less universal than the pronoun attraction (adjacency) principle. It is still of interest to discover what motivates the loss of the subject agreement morpheme in object relativization in Dzamba, and I suspect the reason may hinge on some languagespecific morphemic constraints. Note, first, that in Dzamba object relativization two obligatory prefixal morphemes appear -- both agreeing in gender-number with the deleted object noun (or the equi head noun). One is a prefix-initial vowel (here $i$ - for class 3 ) which acts as a relative subordinating morpheme. The other is the anaphoric ('infix') object pronoun. Their separateness may be illustrated by using negative relative clauses, where the subordinator falls to the left of the negative morpheme, while the anaphoric pronoun to the right:

(21) imo-nkanda i-mu-tomaki opetelo the-letter that-it-wrote Peter 'The letter that Peter wrote' 
to this universal may be found in Givbn [1971a], though for the purpose of this discussion the explanation is not relevant.) Now, notice that, given the principle of pronoun attraction, one would expect to find relative pronouns (or relative subordinators) in $S-O-V / R E L-N$ languages at a verb-suffix position -- since only then would they be adjacent to the head noun:

(23)

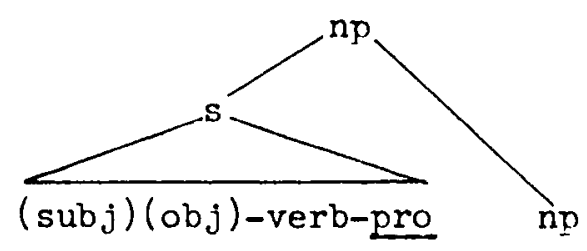

In other words, in $\mathrm{S}-\mathrm{O}-\mathrm{V} / \mathrm{REL}-\mathrm{N}$ languages one would expect relative pronouns (or subordinators) to move to the right over the verb, while in $\mathrm{S}-\mathrm{V}-\mathrm{O} / \mathrm{N}-\mathrm{REL}$ languages one expects object relative pronouns to move to the left over the verb -- all in order to abide by the same universal principle, pronoun attractions.

5. Some concluding remarks on pronoun attraction

There are some indications that the pronoun attraction rule applies only to relative pronouns that have merged with a relative subordinating particle, or where a separate subordinating particle does not exist. Thus, the 'which', 'what', 'who', 'whom', 'where', 'when' relative pronouns in English arose as a fusion between a subordinator and an anaphoric pronoun, and in older stages of English a situation roughly paraphrased by (24) below prevailed, where the subordinator was attracted to the head noun -but the (anaphoric) pronoun was not:

(24) the man $\frac{\text { that }}{\text { sub }}$ saw him

(25) the man that $\frac{\text { he }}{\text { sub }} \frac{\text { paw me }}{\text { pro }}$

The attraction principle in this case applied only to the subordinator, since the pronoun was still an anaphoric pronoun.

As a similar case one may cite Hebrew, in which the relative subordinator must be adjacent to the head noun, unlike the anaphoric ('resumptive') pronoun which remains in its original syntactic position: 
b. On more general grounds, I think it has become somewhat questionable (see e.c. Koutsoudas [1971], among others) whether syntactic rules are in fact strictly ordered extrinsically. It now seems that in many if not most cases, erstwhile extrinsically ordered rules turn out to be intrinsically ordered or not at all ordered (above and beyond the convention of cyclic application from the bottom up).

c. Finally, I have elsewhere attempted to show (Givón [1972]) that subjectverb agreement rules are cyclic in the sense that they annly within the comain of the unembedded sentence without reference to its embedded position or to entities outside its boundaries. A solution of the type suggested by Rokamba clashes directly with this claim, since it would apply only to the apreement of subjects of sentences embedded as object relative clauses. It thus appears that this solution is undesirable. Rather, it is formally easy to let the agreement rule apply cyclically as it may, since it is (cf. Givón [1972]) a feature-copving rule to bepin with. The constraint in Dzamba may be then viewed as a morphomic constraint at the level of the second lexicon, where the copied gender-number features of the subject will simply not receive any overt spelling.

4. Pronoun attraction and diachronic change in Bantu syntax

In Givón [1971] it was suggested that of the three relativization patterns of Swahili, the one involving verb-suffix relative pronoun is the oldest, and is also the one which gave rise to the other two. Meeussen [1971] has presented tonological evidence which surgests that the relative pronouns in Bantu were at some earlier historical stage verb suffixes. In this section I would like to show that, given the universal principle of pronoun attraction, this seemingly older state of affairs with respect to Bantu relative pronouns was not only natural but also predictable. And, further, that the earlier verb-suffix position of the Bantu relative pronoun constitutes added support for my contention (see Givón [1971]) that at some earlier stage of their history, Bantu languages were $5-0-V$ languages (rather than the current S-V-O).

Greenberf [1966] has noted that $\mathrm{S}-\mathrm{O}-\mathrm{V}$ lanpuages usually show the syntactic order MODIFIER-NOUN in their noun phrase. (A natural explanation 
antecedent close to its referring pronoun, presumably for some ease in maintaining reference relation. It seems, however, that the attraction principle pertains primarily to subordinating particles, and only incidentally to relative pronouns, when they themselves serve as subordinators. One may perhaps conclude that the attraction principle must have something to do with the perceptual clues by which the boundary between a head noun (in point of fact, head NP) and its modifyinf clause is signalled.

\section{REFERENCES}

Bokamba, G. 1971. "Specificity and definiteness in Dzamba", Studies in African Linguistics 2.3: 217-238.

Givon, T. 1971. "On the verbal origin of the Bantu verb suffixes", Studies in African Linguistics 2.2: 145-16\%.

Givon, T. 1971a. "Historical syntax and synchronic morphology: an archaeologist's field trip", in Papers from the Seventh Regional Meeting. Chicago: Chicago Linguistic Snciety, University of Chicago.

Givon, T. 1972. Studies in ChiBemba and Bantu rremar, revised and expanded, studies in $\Lambda$ frican Linguistic, cipplement \#3.

Greenberg, J. 1966. "Some universals of grammar with particular reference to the order of meaningful elerients", in Universals of Language. Edited by J. Greenberg. Cambridoe: M.I.T.Press.

Hudson, G. 1972. "Why Amharic is an SOV langlape", Studies in African Linguistics 3.1: 127-165.

Koutsoudas, A. 1971. "The strict-order fallacy", Indiana Linguistic Club (mimeo).

Meeussen, A. E. 1971. "Bantu relative clauses", Studies in African Linguistics, supplement $\# 2$, po. 3-10.

Takizala, A. 1972. "Focus and relativization: the case of Kihung'an", Studies ir. African Linguistics 3.2 . 
(26) haish she-liiryam raata oto etmol

man that-Mary saw him yesterday

'The man who Mary saw yesterday'

One may also cite Bambara, a language which often does not embed a relative clause but rather leaves it conjoined behind the matrix sentence. In this case, an anaphoric pronoun appears in the 'embedded' (conjoined) sentence, but a subordinating particle ( $\mathrm{min}$ ) appears adjacent to the 'head' noun in the matrix sentence: ${ }^{2}$

(27) $n$ ye ce min ye, o ye mbumu san

I past man that see, he past knife buy

'I saw the man who bought the knife'

Finally, in Amharic, currently an S-O-V/REL-N language, it has long been a puzzle why the relative subordinator yä- does not remain at the beginning of the relative clause but rather, if a verb exists in the clause, it migrates to the verb (for detailed discussion, see Hudson [1972]). Amharic does not have a relative pronoun per se, though 'resumptive' anaphoric pronouns normally occur in relativization. Those are verb-suffixes, arising from an earlier stage when Amharic probably exhibited the Semitic V-S-O syntactic order (for some discussion, see Givón [1971a]). Now, given the universal principle of relative pronoun/subordinator attraction, the position of the Amharic relative subordinator is not only natural but also predicted, since it gets attracted to the position closest to the head noun but still consistent with its morphemic nature as a prefix:

(28) gaäbäre t+nänt+na yä-säbbärä-士 wämbär

farmer yesterday that-broke-it chair

'The chair that a farmer broke yesterday'

Some reasonably natural explanation must surely underlie a principle as seemingly universal as that of pronoun/subordinator attraction. If it were relevant only to relative pronouns, one might be tempted to suggest that the underlying principle has something to do with keeping the

\footnotetext{
${ }^{2}$ For the Bambara data I am indebted to Karen Courtenay.
} 
antecedent close to its referring pronoun, rresumably for some ease in maintaining reference relation. It seems, bowever, that the attraction principle pertains primarily to subordinating narticles, and only incidentally to relative pronouns, when they themselves serve as subordinators. One may perhaps conclude that the attraction rrinciple must have something to do with the perceptual clues by which the boundary between a head noun (in point of fact, head NP) and its modifying ciause is signalled.

\section{REFERENCES}

Bokamba, G. 1971. "Specificity and definiteness in Dzamba", Studies in African Linguistics 2.3: 217-238.

Givon, T. 1971. "On the verbal origin of the Bantu verb suffixes", Studies in African Linguistics 2.2: $145-16 \%$.

Givon, T. 1971a. "Historicel svntax and synchronic morphology: an archaeologist's field trip", in Papers from the Seventh Regional Meeting. Chicago: Chicago Linguistic Society, University of Chicago.

Givon, T. 1972. Studies in ChiBemba and Bantu regmar, revised and expanded, Studies in $\Lambda$ frican Linguistic, , mplement \#3.

Greenberg, J. 1966. "Some universals of grammar with particular reference to the order of meaningful elemencs", in Universals of Language. Edited by J. Greenberg. Cambridge: M.I.T.Press.

Hudson, G. 1972. "Why Amharic is an SOV language", Studies in African Linguistics 3.1: 127-165.

Koutsoudas, A. 1971. "The strict-order fallacy", Indiana Linguistic Club (mimeo).

Meeussen, A. E. 1971. "Bantu relative clauses", Studies in African Linguistics, supplement \#2, pn. 3-10.

Takizala, A. 1972. "Focus and relativization: the case of Kihung'an", Studies ir ifrican Linguistics 3.2 . 